\title{
Observation of $\mathrm{CH}_{4}$ and other Non- $\mathrm{CO}_{2}$ Green House Gas Emissions from California
}

Prepared For:

California Energy Commission

Public Interest Energy Research Program

Prepared By:

Lawrence Berkeley National Laboratory

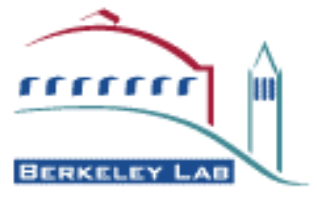

January 2009

CEC-XXX 


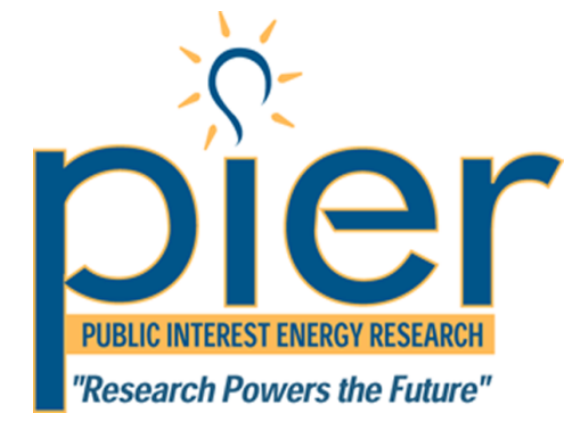

Prepared By:

Lawrence Berkeley National Laboratory

Marc L. Fischer

Chuanfeng Zhao

William J. Riley

Arlyn C. Andrews (NOAA-ESRL)

Berkeley, CA, 94720

Commission Contract No.

Commission Work Authorization No.:

Prepared For:

Public Interest Energy Research (PIER)

California Energy Commission

Contract Manager

Program Area Lead

Energy-Related Environmental Research

\author{
Office Manager \\ Energy Systems Research
}

Martha Krebs, Ph.D.

PIER Director

Thom Kelly, Ph.D.

Deputy Director

ENERGY RESEARCH \& DEVELOPMENT DIVISION

Melissa Jones

Executive Director

\section{DISCLAIMER}

This report was prepared as the result of work sponsored by the California Energy Commission. It does not necessarily represent the views of the Energy Commission, its employees or the State of California. The Energy Commission, the State of California, its employees, contractors and subcontractors make no warrant, express or implied, and assume no legal liability for the information in this report; nor does any party represent that the uses of this information will not infringe upon privately owned rights. This report has not been approved or disapproved by the California Energy Commission nor has the California Energy Commission passed upon the accuracy or adequacy of the information in this report. 


\section{Acknowledgements}

This report was written by Dr. Marc L. Fischer (Principal Investigator, LBNL), Dr. Chuanfeng Zhao (LBNL), Dr. William J. Riley (LBNL), and Dr. Arlyn Andrews (NOAA-ESRL). The work was performed in close collaboration with Adam Hirsch, and Laura Bianco, and Pieter Tans at NOAA's Earth System Research Laboratory, Janusz Eluszkiewicz and Thomas Nehrkorn at Atmospheric and Environmental Research Inc., and Clinton MacDonald at Sonoma Technology Inc. The authors thank Dave Field, Dave Bush, Edward Wahl, and particularly Jon Kofler for assistance with installation and maintenance of the instrumentation at WGC, Edward Dlugokencky for advice and assistance in verifying the Picarro instrument performance at NOAA, John Lin, Christoph Gerbig, and Steve Wofsy for generously sharing the STILT code, Chris Potter and William Salas for sharing their models of $\mathrm{CH}_{4}$ emission for use as a priori estimates, Larry Hunsaker and Webster Tassat for providing the CARB estimates of landfill $\mathrm{CH}_{4}$ emissions, Ken Massarie for providing the global $\mathrm{CH}_{4}$ background data, and Susan James for assistance running WRF on the LBNL-ASD computer cluster. The authors gratefully acknowledge NOAA Air Resources Laboratory (ARL) for the use of the HPSPLIT model underlying STILT, and NCEP for the provision of the NARR meteorology. The authors also thank Sebastien Biraud, Jean Bogner, Nancy Brown Eric Crosson, Guido Franco, Ling Jin, YingKuang Hsu, Eileen McCauley, Tony VanCuren, Margaret Torn, James Wilzack, and Wlodek Zahorowski for valuable discussions.

This work was supported by the U.S. Department of Energy under Contract No. DE-AC02-05CH11231.

Please cite this report as follows:

Fischer, M. L., C. Zhao, W. J. Riley and A.C. Andrews. 2009. Observation of $\mathrm{CH}_{4}$ and other NonCO Green House Gas Emissions from California. California Energy Commission, PIER EnergyRelated Environmental Research. CEC-XXX. 


\section{Preface}

The California Energy Commission's Public Interest Energy Research (PIER) Program supports public interest energy research and development that will help improve the quality of life in California by bringing environmentally safe, affordable, and reliable energy services and products to the marketplace.

The PIER Program conducts public interest research, development, and demonstration (RD\&D) projects to benefit California.

The PIER Program strives to conduct the most promising public interest energy research by partnering with RD\&D entities, including individuals, businesses, utilities, and public or private research institutions.

- PIER funding efforts are focused on the following RD\&D program areas:

- Buildings End Use Energy Efficiency

- Energy Innovations Small Grants

- Energy Related Environmental Research

- Energy Systems Integration

- Environmentally Preferred Advanced Generation

- Industrial/Agricultural/Water End Use Energy Efficiency

- Renewable Energy Technologies

- Transportation

Observation of $\mathrm{CH} 4$ and other Non-CO2 Green House Gas Emissions from California is the final report for the Natural Gas Observations from California project contract number 500-06-006 conducted by the Lawrence Berkeley National Laboratory. The information from this project contributes to PIER's Energy Related Environmental Research Program.

For more information about the PIER Program, please visit the Energy Commission's website at www.energy.ca.gov/research/ or contact the Energy Commission at 916-654-4878. 


\section{Abstract}

In 2006, California passed the landmark assembly bill AB-32 to reduce California's emissions of greenhouse gases (GHGs) that contribute to global climate change. AB-32 commits California to reduce total GHG emissions to 1990 levels by 2020, a reduction of 25 percent from current levels. To verify that GHG emission reductions are actually taking place, it will be necessary to measure emissions. We describe atmospheric inverse model estimates of GHG emissions obtained from the California Greenhouse Gas Emissions Measurement (CALGEM) project. In collaboration with NOAA, we are measuring the dominant long-lived GHGs at two tall-towers in central California. Here, we present estimates of $\mathrm{CH}_{4}$ emissions obtained by statistical comparison of measured and predicted atmospheric mixing ratios. The predicted mixing ratios are calculated using spatially resolved a priori $\mathrm{CH}_{4}$ emissions and surface footprints, that provide a proportional relationship between the surface emissions and the mixing ratio signal at tower locations. The footprints are computed using the Weather Research and Forecast (WRF) coupled to the Stochastic Time-Inverted Lagrangian Transport (STILT) model. Integral to the inverse estimates, we perform a quantitative analysis of errors in atmospheric transport and other factors to provide quantitative uncertainties in estimated emissions. Regressions of modeled and measured mixing ratios suggest that total $\mathrm{CH}_{4}$ emissions are within $25 \%$ of the inventory estimates. A Bayesian source sector analysis obtains posterior scaling factors for $\mathrm{CH}_{4}$ emissions, indicating that emissions from several of the sources (e.g., landfills, natural gas use, petroleum production, crops, and wetlands) are roughly consistent with inventory estimates, but livestock emissions are significantly higher than the inventory. A Bayesian "region" analysis is used to identify spatial variations in $\mathrm{CH}_{4}$ emissions from 13 sub-regions within California. Although, only regions near the tower are significantly constrained by the tower measurements, $\mathrm{CH}_{4}$ emissions from the south Central Valley appear to be underestimated in a manner consistent with the under-prediction of livestock emissions. Finally, we describe a pseudo-experiment using predicted $\mathrm{CH}_{4}$ signals to explore the uncertainty reductions that might be obtained if additional measurements were made by a future network of tall-tower stations spread over California. These results show that it should be possible to provide highaccuracy estimates of surface $\mathrm{CH}_{4}$ emissions for multiple regions as a means to verify future emissions reductions.

Keywords: non- $\mathrm{CO}_{2}$, methane, nitrous oxide, greenhouse gas, emissions, atmospheric, transport, footprint, inverse model, Bayesian 


\section{Table of Contents}

Preface

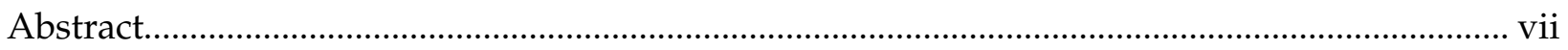

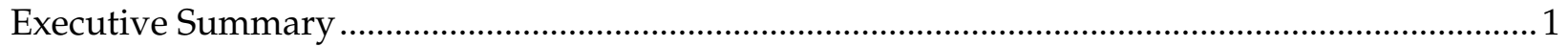

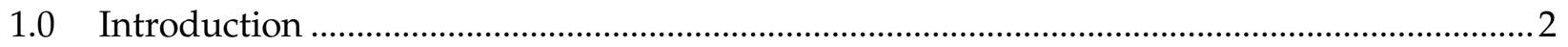

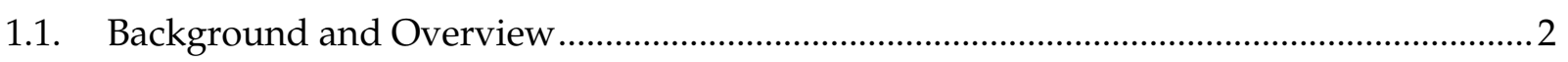

1.1.1. $\quad \mathrm{CH}_{4}$ and other non- $\mathrm{CO}_{2}$ Greenhouse Gases............................................................ 2

1.1.2. Atmospheric Inverse Methods …...................................................................................... 3

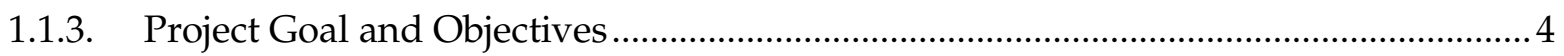

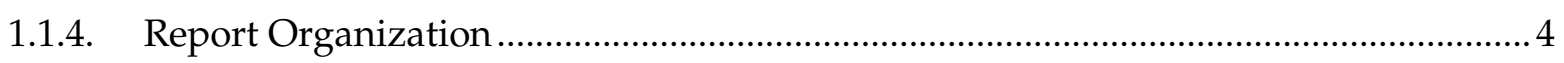

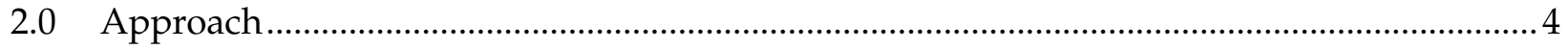

2.1. Identification of Measurement Stations ..............................................................................

2.1.1. Inventory Estimates of $\mathrm{CH}_{4}, \mathrm{~N}_{2} \mathrm{O}$ and ${ }^{222} \mathrm{Rn}$ Emissions ............................................ 4

2.1.2. Predicted maps of time varying $\mathrm{CH}_{4}$, and ${ }^{222} \mathrm{Rn}$ mixing ratios................................... 5

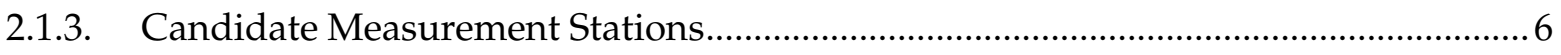

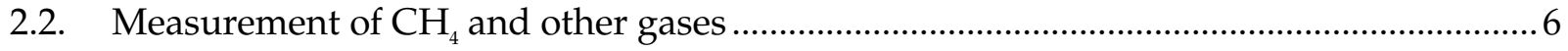

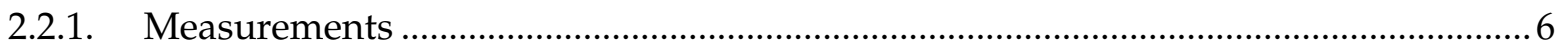

2.3. Preliminary Estimation of Regional $\mathrm{CH}_{4}$ and $\mathrm{N}_{2} \mathrm{O}$ Emissions ......................................... 8

2.3.1. Radon Mixing Model Emission Estimates.................................................................... 8

2.3.2. Lagrangian Model Prediction of GHG Mixing Ratios ................................................ 8

2.3.3. Linear Regression Analysis of Predicted and Measured $\mathrm{CH}_{4}$ Signals......................12

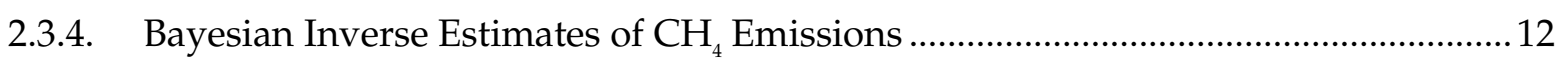

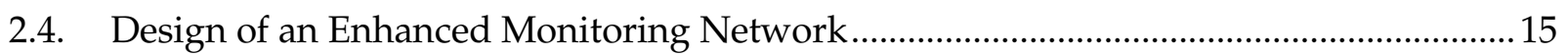

2.4.1. Benefit of Additional Measurement Sites.................................................................. 15

2.4.2. Use of Radiocarbon Methane $\left({ }^{14} \mathrm{CH}_{4}\right)$ to Identify Fossil $\mathrm{CH}_{4}$ Emissions................... 15

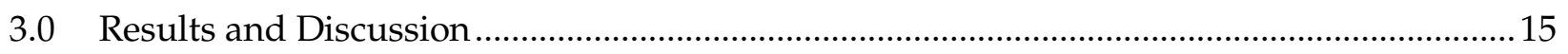

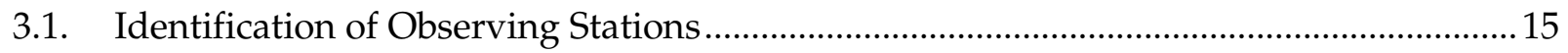

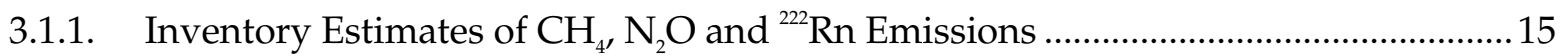

3.1.2. Predicted maps of time varying $\mathrm{CH}_{4}$ Mixing Ratios ................................................ 19

3.1.3. Locations of Potential Measurement Stations .............................................................20

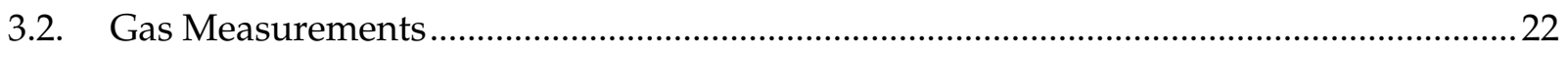


3.2.1. Mixing Ratios Measured at Towers......................................................................... 22

3.2.2. Background GHG mixing ratio time series ................................................................... 26

3.2.3. Preliminary Measurement of Soil Radon Fluxes .......................................................27

3.3. Preliminary Estimation of Regional $\mathrm{CH}_{4}$ and $\mathrm{N}_{2} \mathrm{O}$ Emissions .....................................27

3.3.1. Radon Mixing Model Emission Estimates................................................................2

3.3.2. Lagrangian Model of GHG Mixing Ratios .................................................................. 28

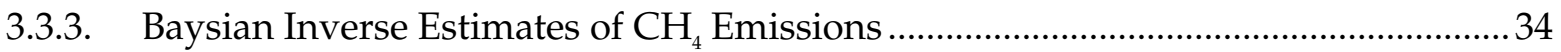

3.4. Design of a Future Observation Network ..................................................................... 38

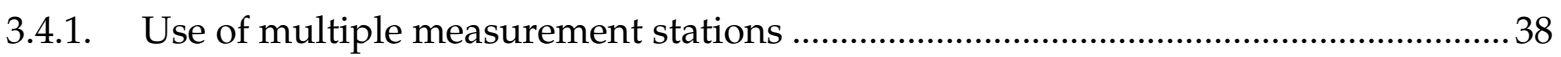

3.4.2. Use of Radiocarbon Methane $\left({ }^{14} \mathrm{CH}_{4}\right)$ to Identify Fossil $\mathrm{CH}_{4}$ Emissions................... 40

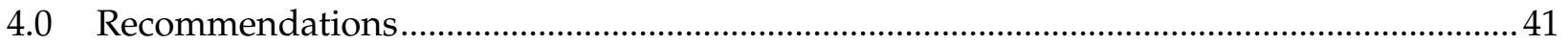

4.1. Refinement of Atmospheric Transport Model ............................................................... 41

4.2. Long-term Measurements for Trend Detection ............................................................ 42

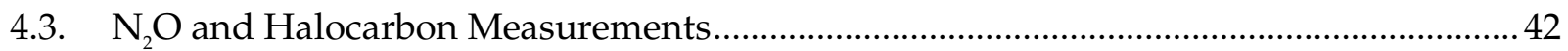

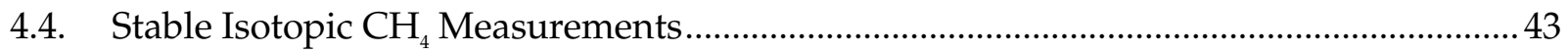

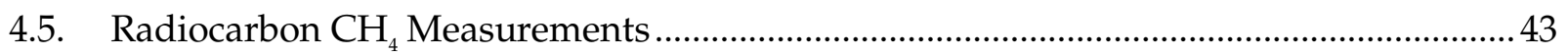

4.6. Statewide Measurement Network and Other Platforms ................................................ 43

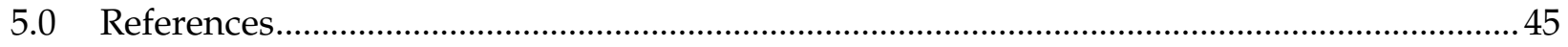

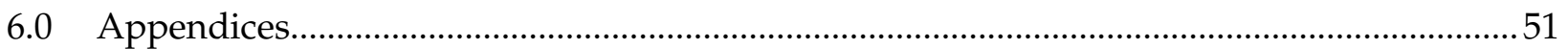

6.1. Sensitivity Test for the a priori $\mathrm{CH}_{4}$ Emission Uncertainty .............................................51

6.2. The Effects of Multiple Stations for Source Sector Analysis. ..........................................52 


\section{Executive Summary}

\section{Introduction}

Atmospheric methane plays an essential role in Earth's climate. $\mathrm{CH}_{4}$ currently accounts for about $1 / 2$ of the change in non- $\mathrm{CO}_{2}$ radiative GHG forcing from pre-industrial times to the present (Hofman et al., 2006). Consequently, reduction in anthropogenic emissions of $\mathrm{CH}_{4}$ and other non- $\mathrm{CO}_{2}$ GHGs may be an important component of an initial strategy for avoiding the most severe impacts of global warming (Hansen et al., 1998; Hansen, 2004; Shindell et al., 2005). In California, $\mathrm{CH}_{4}$ contributes approximately $6 \%$ of total $\mathrm{CO}_{2}$ equivalent $\mathrm{GHG}$ emissions (CARB, 2007). Now that California has passed Assembly Bill 32, careful accounting of current $\mathrm{CH}_{4}$ emissions and of their future reductions is essential. Current inventory and model-based estimates of $\mathrm{CH}_{4}$ emissions are uncertain because many of the factors controlling emissions are poorly quantified. Atmospheric measurements and inverse modeling may provide an independent method to quantify local to regional $\mathrm{CH}_{4}$ emissions from California.

\section{Purpose}

The purpose of the following research is to provide California with the information necessary to plan a network for quantitative estimation of regional emissions of non- $\mathrm{CO}_{2} \mathrm{GHGs}$.

\section{Project Goals and Objectives}

The goals of this project are to 1) design and implement a baseline program to monitor atmospheric concentrations of CH4 and other GHGs in California, and (2) develop the basic information needed for the future deployment of more advanced and complete monitoring system. To accomplish these goals, the authors conducted research with the following objectives:

- Identification of observing stations for atmospheric concentration measurements of non$\mathrm{CO}_{2}$ GHGs in California.

- Implementation of trace gas concentration measurements at a subset of the identified tower stations, and quality control of the measured data.

- Preliminary analysis to determine the desirability deploying a more spatially complete monitoring system.

Key Results of the project are that:

- Estimated $\mathrm{CH}_{4}$ emissions from inventories exhibit high spatial variability due to the patchy distribution of urban and rural sources.

- Atmospheric $\mathrm{CH}_{4}$ mixing ratio signals are predicted to be readily measurable with standard instrumentation at many locations in California.

- Measurements of $\mathrm{CH}_{4}, \mathrm{~N}_{2} \mathrm{O}$, and other $\mathrm{GHG}$ gases, initiated at two tower sites Central California, regularly exceed values expected for marine background air, demonstrating that emissions from within California are measurable. 
- Atmospheric inverse model estimates of $\mathrm{CH}_{4}$ surface fluxes suggest that $\mathrm{CH}_{4}$ emissions from livestock in the Central Valley may be higher than the a priori emission inventory, but consistent with results of recent research on livestock $\mathrm{CH}_{4}$ emissions.

- A pseudo-data modeling experiment shows that while the two initial towers are able to quantify $\mathrm{CH}_{4}$ emissions from a portion of Central California, additional measurement sites in other regions of California are required to accurately quantify California's total $\mathrm{CH}_{4}$ emissions.

\section{Project Recommendations}

The recommendations resulting from the research conducted in this project are to:

Estimate and reduce errors in the transport model used to estimate GHG emissions from tower observations. This work should include model-measurement comparisons of wind velocities and mixed layer heights using data from profilers and other trace gases (e.g., $222 \mathrm{Rn}$ ).

Develop and maintain the capability for the long-term GHG measurements necessary to detect variations and the trends in spatial patterns, seasonal and inter-annual cycles of GHG mixing ratios, and underlying emissions.

Evaluate the potential value of more intensive $\mathrm{N}_{2} \mathrm{O}$ and initial halocarbon measurements at tower sites in California to quantify regional emissions of these species using both ${ }^{222} \mathrm{Rn}$ mixing model and atmospheric inverse model methods.

Investigate whether some combination of stable and radiocarbon isotopic measurements of $\mathrm{CH}_{4}$ would provide effective separation of the multiple sources of $\mathrm{CH}_{4}$ emitted from California.

Initiate GHG measurements at additional strategic locations in California to establish a statewide GHG measurement network as well as beginning work to synthesize GHG measurements from aircraft and satellite platforms.

\section{Anticipated Benefits for California}

This work benefits California utility ratepayers by identifying the non- $\mathrm{CO}_{2} \mathrm{GHG}$ emissions from California that contribute to global warming. These results set the stage for verifying progress on controlling GHG emissions. This project addresses state and national needs for reliable quantification of terrestrial sources and sinks of carbon cycle gases. Ultimately, California ratepayers will benefit from more-informed greenhouse gas policies developed by California decision makers.

\subsection{Introduction}

\subsection{Background and Overview}

\subsection{1. $\mathrm{CH}_{4}$ and other non- $\mathrm{CO}_{2}$ Greenhouse Gases}

Changes in atmospheric methane play an essential role in Earth's climate. $\mathrm{CH}_{4}$ is now associated with a direct radiative forcing of $\sim 0.48$ (IPCC, 2007) and an indirect radiative forcing of $\sim 0.13$ (Lelieveld et al. 1998), which accounts for about $1 / 2$ of the non- $\mathrm{CO}_{2}$ radiative 
forcing (0.98 W m-2 in 2004) (Hofman et al., 2006) and about $1 / 4$ of the total radiative forcing (2.64 W m-2 from IPCC 2007) from all greenhouse gases (GHGs) in term of changes from preindustrial times to the present. It has been argued that reducing anthropogenic emissions of methane may be an important component of an initial strategy for avoiding the most severe impacts of global warming (Hansen et al., 1998; Hansen, 2004; Shindell et al., 2005). In particular, reduction of anthropogenic methane emissions may be possible (e.g., improving $\mathrm{CH}_{4}$ recovery from landfills and waste treatment, reducing industrial emissions, and improving agricultural practices) (Harriss, 1994). In view of methane's role in the climate system, increased attention has been brought recently to assessing $\mathrm{CH}_{4}$ sources (Houweling et al., 2006, Gimson and Uliasz 2003, Miller et al. 2007, Kort et al. 2008)

In California, total 2004 GHG emissions were approximately $480 \mathrm{MMT} \mathrm{CO}_{2}$ equivalent, with $\mathrm{CH}_{4}$ contributing approximately $6 \%$ (CARB, 2007). Now that California has passed Assembly Bill 32, which requires that greenhouse gases emissions be reduced to 1990 levels by 2020, careful accounting of current $\mathrm{CH}_{4}$ emissions and of their future reductions is essential. Unfortunately, current inventory and model-based estimates of $\mathrm{CH}_{4}$ emissions are uncertain because many of the factors controlling emissions are poorly quantified. Atmospheric measurements and inverse modeling may provide an independent method to quantify local to regional $\mathrm{CH}_{4}$ emissions from California.

\subsubsection{Atmospheric Inverse Methods}

Atmospheric inverse methods to estimate the surface $\mathrm{CH}_{4}$ fluxes from in-situ and remotely sensed $\mathrm{CH}_{4}$ mixing ratio measurements and modeled wind fields have been widely applied at both global and regional scales (Hein et al., 1997; Houweling et al., 1999; Vermeulen et al., 1999; Bergamaschi et al., 2000; Dentener et al., 2003; Gimson and Uliasz, 2003; Manning et al., 2003; Mikaloff Fletcher et al., 2004a, b; Bergamaschi et al., 2005; Chen and Prinn, 2006, Bergamaschi et al., 2007; Kort et al., 2008). In general, the components of atmospheric inverse emission estimates are $\mathrm{CH}_{4}$ mixing ratio measurements, an atmospheric transport model (including chemistry for global simulations), in some cases a priori estimates for $\mathrm{CH}_{4}$ emissions and sinks or their correlation structure, and a statistical technique to minimize differences between measured and predicted $\mathrm{CH}_{4}$ mixing ratios. To estimate $\mathrm{CH}_{4}$ emissions and their associated uncertainties, errors from each of these components should be accounted for and formally propagated through the inversion process. In this study, the authors employ an approach originally developed to estimate regional $\mathrm{CO}_{2}$ emissions (Gerbig et al., $2003 \mathrm{a}, \mathrm{b}$ ) that combines calculation of surface footprints (Lin et al., 2004) with procedures to estimate transport model uncertainty (Lin et al., 2005; Lin and Gerbig, 2005) using the Stochastic Time-Inverted Lagrangian Transport (STILT) model. Of particular relevance to our work, Kort et al. (2008) recently used observations of $\mathrm{CH}_{4}$ and $\mathrm{N}_{2} \mathrm{O}$ from an airborne platform in combination with STILT to infer $\mathrm{CH}_{4}$ and $\mathrm{N}_{2} \mathrm{O}$ emissions from the continental interior of North America in MayJune 2003. Our study also uses STILT, but applies it to a smaller model domain at finer spatial and temporal resolutions, taking advantage of unique computational benefits offered by the Lagrangian approach. 


\subsubsection{Project Goal and Objectives}

The goals of this project are to (1) design and implement a baseline program to monitor atmospheric concentrations of $\mathrm{CH}_{4}$ and other GHGs in California, and (2) develop the basic information needed for the future deployment of more advanced and complete monitoring system. To accomplish the project goals, the authors conducted a project with the following objectives:

Identify observing stations for atmospheric concentration measurements of non- $\mathrm{CO}_{2} \mathrm{GHG}_{\mathrm{H}}$ in California.

Implement trace gas concentration measurements at a subset of the identified tower stations and perform quality control and data archiving for measured data.

Perform a preliminary analysis with the data to determine the desirability of the deployment of a more sophisticated and spatially complete monitoring system.

\subsubsection{Report Organization}

This report is broken into the following three sections. Section 2 describes the project approaches taken to identifying measurement stations (Section 2.1), measurement of $\mathrm{CH}_{4}$ and other GHGs (Section 2.2); preliminary estimates of $\mathrm{CH}_{4}$ emissions from Central California (Section 2.3); and design of an enhanced monitoring network to estimate total $\mathrm{CH}_{4}$ emissions from California (Section 2.4). Section 3 then describes the results, of the each of the efforts described in section 2 above. Finally, section 4 presents conclusions and recommendations for further research.

\subsection{Approach}

\subsection{Identification of Measurement Stations}

\subsubsection{Inventory Estimates of $\mathrm{CH}_{4}, \mathrm{~N}_{2} \mathrm{O}$ and ${ }^{222} \mathrm{Rn}$ Emissions}

The authors used two methods to estimate $\mathrm{CH}_{4}$ emissions. As a base-case, they used the North American maps of total anthropogenic $\mathrm{CH}_{4}$ from the EDGAR 3.2 model with $1 \times 1$ degree spatial resolution (Olivier et al. 2005). To provide finer spatial resolution inside California, they also estimated California $\mathrm{CH}_{4}$ emissions separately for six sources sectors: landfills (LF), livestock (LS), natural gas production and use (NG), petroleum refining (PL), crop agriculture $(\mathrm{CP})$, and wetlands (WL). $\mathrm{CH}_{4}$ emissions from landfills were estimated by the California Air Resources board using IPCC methods (IPCC, 2006) driven by landfill specific waste application statistics from the CA Waste Management Board (e.g., Carr, 2004) and site-specific estimates of $\mathrm{CH}_{4}$ recovery. $\mathrm{CH}_{4}$ from livestock was estimated using USDA county level animal stocking densities (Census 2002) and animal specific emission factors for dairy and beef cattle separately (Franco, 2002). $\mathrm{CH}_{4}$ from natural gas production and use and from petroleum refining activities were estimated as the difference of total minus reactive hydrocarbon emissions estimated from the CARB emission criteria pollutant emission inventory for those source sectors (http://www.arb.ca.gov/app/emsinv/fcemssumcat2006.php). $\mathrm{CH}_{4}$ emissions from crop agriculture were assumed to follow emissions from the DNDC model for an average climate year with high irrigation as described by Salas et al. (2006). $\mathrm{CH}_{4}$ emissions from wetlands in 
California were assumed to follow the NASA-CASA estimates from Potter et al. (2006). Although some of these sources are expected to vary on a seasonal basis, they do not incorporate temporal variation in current study, which may cause the a priori emissions to be slightly overestimated or underestimated.

For nitrous oxide $\left(\mathrm{N}_{2} \mathrm{O}\right)$, soil fluxes from crop agriculture were assumed to follow emissions from the DNDC model for an average climate year with high irrigation as described by Salas et al. (2006). Other sources were not considered in this preliminary estimate, though total $\mathrm{N}_{2} \mathrm{O}$ emissions from internal combustion engines are estimated to be about $2 / 3$ those from agriculture in California (Bemis, 2006), but presumably with a spatial distribution heavily weighted to urban regions with high motor vehicle use.

Radon $\left({ }^{222} \mathrm{Rn}\right)$, soil fluxes were estimated using a model generously provided by Segvary (private communication). The model, which used a constant linear proportionality between soil radon flux and surface gamma ray activity, was calibrated using soil radon flux measurements at three sites in northern Europe (Szegvary et al., 2007). Maps of soil radon flux for California were generated using the same coefficient applied to surface ${ }^{238} \mathrm{U}$ concentrations estimated from aircraft gamma ray surveys (Duval et al., 1989). Given than the estimated radon fluxes are significantly lower than the value of 1 atom $\mathrm{cm}^{-2} \mathrm{~s}^{-1}$ commonly assumed in previous work (e.g., Biraud et al., 2000), there remains some question as to whether this scaling is appropriate and suggests that some measurements of soil radon flux should be performed.

\subsubsection{Predicted maps of time varying $\mathrm{CH}_{4}$, and ${ }^{222} \mathrm{Rn}$ mixing ratios}

The authors used a previously developed, tested, and applied coupled atmosphere and landsurface model to estimate atmospheric $\mathrm{CH}_{4}, \mathrm{CO}_{2}$, and $\mathrm{N}_{2} \mathrm{O}$ concentrations. This modeling framework couples MM5, LSM1, and emission fields so that interactions between the landsurface and atmosphere are fully interactive. MM5 (Grell et al., 1995) is a nonhydrostatic, terrain-following sigma-coordinate mesoscale meteorological model used in weather forecasting and in studies of atmospheric dynamics, surface and atmosphere coupling, and pollutant dispersion. The model has been applied in many studies in a variety of terrains, including areas of complex topography and heterogeneous land-cover (for a partial list: http://www.mmm.ucar.edu/mm5/Publications/mm5-papers.html). The following physics packages were used for the simulations shown here: Grell convection scheme, simple ice microphysics, MRF planetary boundary layer (PBL) scheme, and the CCM2 radiation package. The MRF PBL scheme (Hong and Pan, 1996) is a high-resolution PBL transport model that includes both local and non-local vertical transport. The inert tracer model follows the current MM5 transport calculations for water vapor. They tested the numerical solution of the tracer transport predictions and successfully compared predicted and measured $\mathrm{CO}_{2}$ mixing ratios at the Trinidad Head station (located on the northern California coast) (Riley et al., 2005), against data from the FIFE campaign (Cooley et al.), and against 14C measurements in California (Riley et al. 2008).

LSM1 (Bonan, 1996) is a "big-leaf" (e.g., Dickinson et al. (1986), Sellers et al. (1996)) land-surface model that simulates $\mathrm{CO}_{2}, \mathrm{H}_{2} \mathrm{O}$, and energy fluxes between ecosystems and the atmosphere. Modules are included that simulate aboveground fluxes of radiation, momentum, sensible heat, 
and latent heat; belowground energy and water fluxes, and coupled $\mathrm{CO}_{2}$ and $\mathrm{H}_{2} \mathrm{O}$ exchange between soil, plants, and the atmosphere. Twenty-eight land surface types, comprising varying fractional covers of thirteen plant types, are simulated in the model. Soil hydraulic characteristics are determined from soil texture. LSM1 has been tested in a range of ecosystems at the site level (e.g., Bonan et al., 1997; Bonan et al., 1995; and Riley et al., 2003). Cooley et al. (2005) described the integration of LSM1 with MM5 and demonstrated that the model accurately predicted surface latent, sensible, and ground heat fluxes; near-surface air temperatures; and soil moisture and temperature by comparing model simulations with data collected during the FIFE campaign (Betts and Ball, 1998).

The authors used the standard initialization procedure for MM5v3.5, which applies first-guess and boundary condition fields interpolated from the NOAA National Center for Environmental Prediction (NCEP) reanalysis data (Kalnay et al., 1996; Kistler et al., 2001) to the outer computational grid. The model was run with a single domain with horizontal resolution of 36 $\mathrm{km}$ and 18 vertical sigma layers between the surface and $5000 \mathrm{~Pa}$; the time step used was $108 \mathrm{~s}$, and output was generated every two hours. A second, high-resolution nest centered on the Walnut Grove Tower was also run at $6 \mathrm{~km}$ horizontal resolution and 33 vertical sigma layers. They simulated four months that spanned the annual cycle between October 2007 and July 2008.

\subsubsection{Candidate Measurement Stations}

Candidate measurement stations were identified from the combination of inspection of the predicted $\mathrm{CH}_{4}$ mixing ratio maps and consideration of available communications towers included in the US Federal Communication Commission listings (FCC). After identifying a larger set of towers, the authors contacted individual tower operators and found two towers for initial GHG measurements (see below). A larger list containing the two initial measurement sites and five additional towers was also constructed to investigate the potential for a more complete measurement network.

\subsection{Measurement of $\mathrm{CH}_{4}$ and other gases}

\subsubsection{Measurements}

\section{Mixing Ratio Measurements at Towers}

The authors initiated GHG measurements at a tower near Walnut Grove, CA $\left(121.491^{\circ} \mathrm{W}\right.$, $38.265^{\circ} \mathrm{N}$, henceforth WGC), and a tower on Mount Sutro $\left(122.4517^{\circ} \mathrm{W}, 37.7553^{\circ} \mathrm{N}\right)$ above San Francisco beginning in September 2007. Flask samples were collected at both WGC (at 91m) and STR (at 232m) twice daily (1000 and 2200 GMT), shipped to NOAA-ESRL, and analyzed for $\mathrm{CO} 2, \mathrm{CH}_{4}, \mathrm{~N}_{2} \mathrm{O}$ and supporting tracer species $\left(\mathrm{CO}, \mathrm{SF}_{6}, \mathrm{H}_{2}\right)$.

At Walnut Grove (WGC), continuous measurements include $\mathrm{CO}_{2}, \mathrm{CH}_{4}$, and $\mathrm{CO}$ at 30, 91 and $483 \mathrm{~m}$ above ground level (site is at sea level), and ${ }^{222} \mathrm{Rn}$ at $91 \mathrm{~m}$. The in-situ measurements of $\mathrm{CH}_{4}, \mathrm{CO}_{2}$, and $\mathrm{CO}$, were made using a sampling and analysis system combining pumps, air driers, and three gas analyzers. Briefly, air samples are drawn continuously from the different heights on the tower, are partially dried by a condensing system that lowers water vapor to a 5 ${ }^{\circ} \mathrm{C}$ dew point, are sequentially applied on a 5 minute interval to a temperature stabilized membrane drier (Purmapure Inc.) which dries air to a $-33^{\circ} \mathrm{C}$ dew point, and then are supplied 
to the gas analyzers. The first 4.5 minutes of each measurement interval are used to allow equilibration of the gas concentrations and instrument response, while the last 30 seconds is used as the measurement interval. In particular, $\mathrm{CH}_{4}$ is measured using a cavity ring-down spectrometer (Picarro EnviroSense 3000i) with an accuracy and precision of approximately 0.3 ppbv.

To quantify and correct instrument drifts in the in-situ measurements, the offset is measured and corrected every $1 / 2$ hour using a reference gas, while the gain (and linearity) is checked and corrected every 12 hours using 4 NOAA gas primary standards. To provide additional quality assurance, the in-situ $\mathrm{CH}_{4}$ measurements were compared $\mathrm{CH}_{4}$ measurements obtained from twice-daily flask samples collected from a separate dedicated sample line at the same height on the tower as the in-situ measurement. This redundancy allows the detection of even small sampling errors.

Measurements of ${ }^{222} \mathrm{Rn}$ mixing ratios in ambient air were made using a dual-filter continuous ${ }^{222} \mathrm{Rn}$ analyzer (Zahorowski et al., 2004), sampling air from an inlet at $91 \mathrm{~m}$ on the WGC tower. The ${ }^{222} \mathrm{Rn}$ instrument was calibrated monthly using a calibration standard with a known activity. The calibration coefficient was constant to within $8 \%$ RMS over the 12 calibration events collected over the year-long data set. ${ }^{222} \mathrm{Rn}$ concentrations $\left(\mathrm{Bq} \mathrm{m}^{-3}\right)$ were also converted to mixing ratios (atoms $\mathrm{mol}^{-1}$ air) using pressure, temperature, and relative humidity measured inside the radon detector.

\section{Soil Radon Flux Measurements}

Soil radon fluxes to the atmosphere were made using an automated soil gas flux chamber designed for soil $\mathrm{CO}_{2}$ fluxes (Licor LI-8100) combined with a portable alpha spectrometer to (Durridge Company, Rad-7). In this closed-loop measurement, air was circulated from the soil into the LI-8100, through a desiccant tube (Dririte) to remove water, and then through the Rad-7 before returning to the soil chamber. The ${ }^{222} \mathrm{Rn}$ flux, $\mathrm{F}_{\mathrm{Rn}}$, was determined from the time rate of change of $R n$ concentration, $d R n / d t$ as $F_{R n}=V / A d R n / d t$, where $A$ is the surface area of the soil chamber, and $\mathrm{V}$ is the volume of the measurement system. The calibration of the system volume was verified to within $10 \%$ using a source (Pylon Inc.) with known ${ }^{222} \mathrm{Rn}$ emission. The automated measurements of $\mathrm{dRn} / \mathrm{dt}$ each lasted 2 hours and were repeated every 6 hours over periods of about 10 days.

\section{Meteorological Measurements}

To quantify uncertainties in modeled atmospheric transport, hourly boundary layer heights and vertical profiles of winds were obtained from a radar wind profiler (RWP) operated by the Sacramento Metropolitan Air Quality Management District. The profiler is located $\left(38.3025^{\circ} \mathrm{N}\right.$, $121.4214^{\circ} \mathrm{W}$ ) within $8 \mathrm{~km}$ of the tower used for the $\mathrm{CH}_{4}$ measurements, which given the level terrain of the delta region, is sufficiently close to provide an accurate assessment of winds and PBL heights at the tower. The RWP wind data have a vertical resolution of about $100 \mathrm{~m}$ at heights from $\sim 120 \mathrm{~m}$ up to $\sim 3500 \mathrm{~m}$ agl. Boundary layer heights were estimated from subhourly RWP vertical velocity and returned signal strength (signal-to-noise ratio) data using 
objective algorithms and qualitative analysis following techniques found in Wyngaard and LeMone (1980), Bianco and Wilczak (2002), and Bianco et al. (2008). The RWP can detect boundary layer heights from about $120 \mathrm{~m}$ to $4,000 \mathrm{~m}$ with an estimated accuracy of $\pm 200 \mathrm{~m}$ (Dye et al., 1995). For the work presented in this paper, the boundary layer heights were either the top of the marine boundary layer or convective boundary layer during the day and the marine boundary layer at night. Shallow nocturnal boundary layers were rarely observed due to a persistent onshore marine flow that occurs in the summertime in the central Sacramento Valley. The RWP wind and boundary layer height data were quality controlled prior to comparison with the model predictions.

\subsection{Preliminary Estimation of Regional $\mathrm{CH}_{4}$ and $\mathrm{N}_{2} \mathrm{O}$ Emissions}

The goal of this task is to perform a proof-of-concept estimation of regional $\mathrm{CH} 4$ emissions and other GHG gases using initial GHG and 222Rn measurements, and the inverse and mixing model approaches described above. The inverse and mixed model approaches are techniques designed to estimate the geographical location from which the air mass being measure at a given time originates.

Estimate $\mathrm{CH} 4$ emissions derived from initial measurements

- Investigate the reduction in uncertainty of $\mathrm{CH} 4$ sources that can be obtained using data from additional measurement stations and/or 222Rn measurements. $-\mathrm{CZ}$ - you need to do some runs combining data and simulations from both WGC and STR for Oct-Dec2007. (Not here, this part is approach part, the simulations or estimates should be put in the results part)

- Investigate the use of $14 \mathrm{CH} 4$ as a tracer of natural gas and other fossil fuel $\mathrm{CH} 4$ emissionsWJR-can they use the output from the tracer runs to inform this?

\subsubsection{Radon Mixing Model Emission Estimates}

Following previous work, the authors estimate $\mathrm{CH}_{4}$ and $\mathrm{N}_{2} \mathrm{O}$ emissions using the radon mixing model approach (Levin et al., 1999, Biraud et al., 2000). Here, the surface flux of an unknown species, Fx, is assumed to be spatially similar to the surface flux of ${ }^{222} \mathrm{Rn}$ and undergo the same atmospheric transport to the measurement site. Under these assumptions, the variations in mixing ratios are expected to be linearly related such that the flux can be determined as $\mathrm{Fx}=$ FRn $\mathrm{dX} / \mathrm{dRn}$, where $\mathrm{X}$ is $\mathrm{CH}_{4}$ or $\mathrm{N}_{2} \mathrm{O}$ mixing ratio respectively. In the following work, the authors compare the measured mixing ratios of $\mathrm{CH}_{4}$ and $\mathrm{N}_{2} \mathrm{O}$ to the measurements of $\mathrm{Rn}$ to determine best estimates for the footprint averaged surface fluxes of $\mathrm{CH}_{4}$ and $\mathrm{N}_{2} \mathrm{O}$.

\subsubsection{Lagrangian Model Prediction of GHG Mixing Ratios Calculation of Footprints and Mixing Ratio Signals}

Lagrangian particle transport was calculated using the STILT model, run in the time-reversed (receptor-oriented) mode. STILT is a Lagrangian Particle Dispersion Model (LPDM) that has been specifically developed and applied to regional simulations and inverse flux estimates for $\mathrm{CO}_{2}$, other greenhouse gases, and CO. Its detailed description is provided elsewhere (Lin et al., 2003, 2004a; Gerbig et al., 2003a; Matross et al., 2006; Kort et al., 2008; Miller et al., 2008) and, 
consequently, only the most pertinent features will be summarized here. As in all LPDMs, transport in STILT includes both advective and turbulent components, with turbulence being responsible for the dispersion of particles. In this application, given input meteorological data, the STILT model transports ensembles of 100 particles (air parcels) backwards in time 5 days for a receptor point (WGC site here). The authors calculate the response of the target gas concentration at the receptor point to surface sources ("footprint"), in units of $\mathrm{ppb} /\left(\mathrm{nmol} \mathrm{m}^{-2} \mathrm{~s}^{-}\right.$ ${ }^{1}$ ). The footprint, which represents the adjoint of the transport field, is calculated by counting the number of particles in a surface-influenced region (defined as $1 / 2$ of the estimated PBL height in the STILT model, for example see Gerbig et al., 2003a; Kort et al., 2008) and the time spent in the region (for details, see Lin et al., 2003). When multiplied by the a priori field of surface flux, the footprint gives the associated contribution to the mixing ratio measured at the receptor, hence the footprints can be used to estimate parameters of the source functions and their respective uncertainties.

The authors use a customized version of the Weather Research and Forecast (WRF) model (Skamarock et al. 2005) to drive STILT. This combined model will henceforth be referred to as WRF-STILT. Specifically, the WRF model version 2.2 has been modified to output timeaveraged (hourly in this study) values of the mass-coupled velocities, which significantly improve mass conservation in STILT (compared with the instantaneous advective velocities), as well as convective mass fluxes that are used directly in the STILT calculations. The main physical options are set as following: (a) Radiation: RRTM scheme (Mlawer et al., 1997) for the longwave and Goddard scheme (Chow and Suarez, 1994) for the shortwave; (b) Planetary Boundary Layer: Yonsei University (YSU) scheme coupled with the NOAH land surface model and the MM5 similarity theory based surface layer scheme. (c) Microphysics: Purdue Lin scheme (Lin et al., 1983; Chen and Sun, 2002) (d) Convection: Grell-Devenyi ensemble mass flux scheme (Grell and Devenyi, 2002). The initial and boundary meteorology conditions for WRF are provided by the North American Regional Reanalysis (NARR, Mesinger et al., 2006). A oneway nesting WRF running with 3 nest levels is used for the meteorology simulations around the WGC tower location, which is shown in Figure 1 (Domain 1: $-149.16^{\circ}<$ lon $<-102.21^{\circ}, 17.82^{\circ}<$ lat $<50.53^{\circ}$ on a $40 \mathrm{~km}$ grid; Domain 2: $-123.53^{\circ}<$ lon $<-120.66^{\circ}, 36.76^{\circ}<$ lat $<38.94^{\circ}$ on a $8 \mathrm{~km}$ grid; Domain 3: $-121.71^{\circ}<$ lon $<-121.23^{\circ}, 38.09^{\circ}<$ lat $<38.45^{\circ}$ on a $1.6 \mathrm{~km}$ grid). The vertical resolution is taken from the input meteorology from NARR with 30 layers. Each day was simulated separately using 30-hour run (including 6 hours from the previous day for spin-up) with hourly output. Growth in transport model errors were minimized by nudging the forecast fields to the gridded NARR analysis fields every 3 hours. 


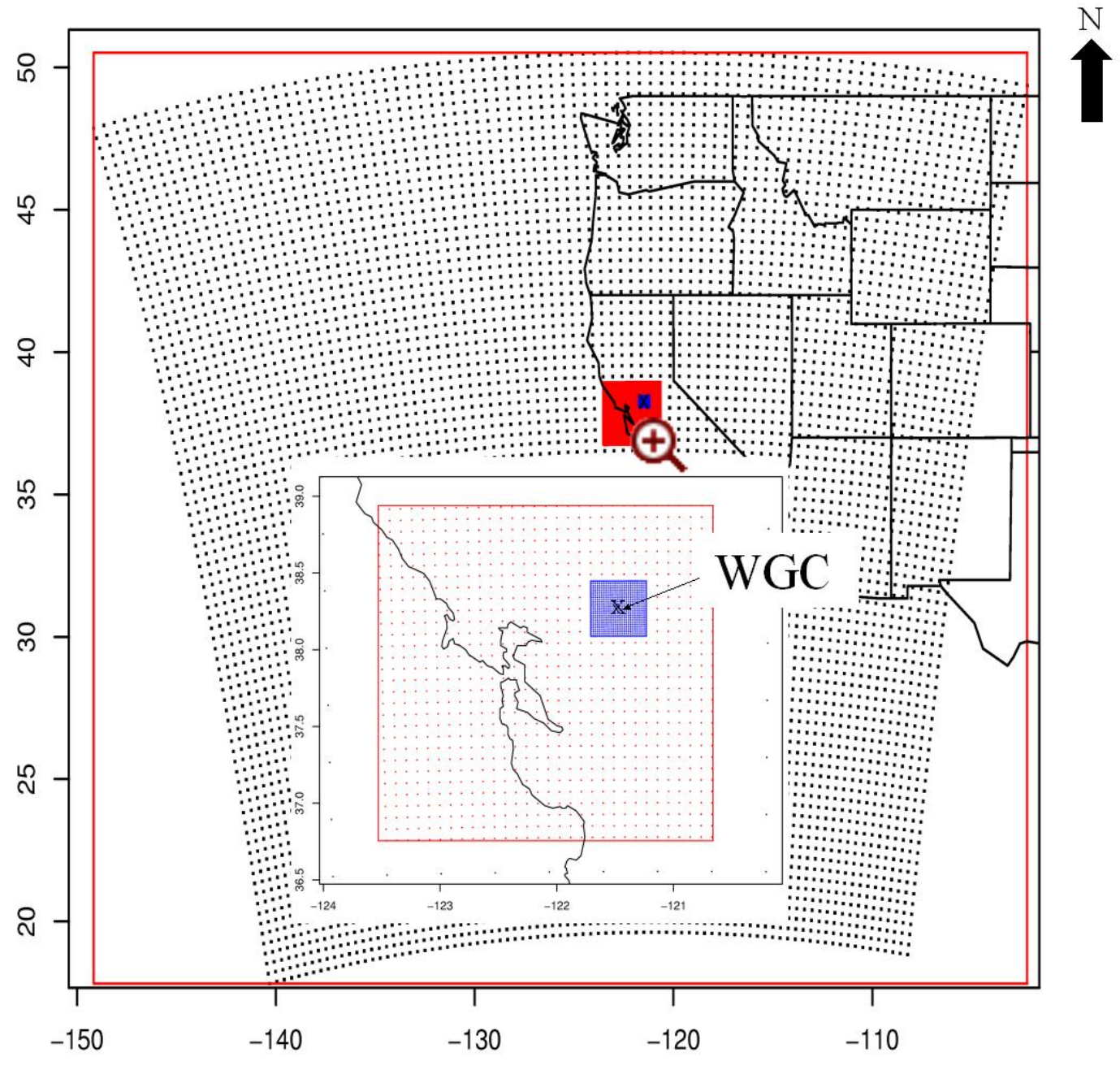

Figure 1. Map grids showing the three model domains used in the meteorological predictions, and WGC tower location " $X$ " $(-121.49,38.26)$ of the measurements.

Particle trajectories were calculated using STILT driven by the WRF winds. One hundred particles are released every 3 hours (from UTC hour 00) at the tower locations and transported backward in time 5 days to insure a majority of the particles reach positions representative of the marine boundary layer. Footprints are then calculated from the particle trajectories as in Lin et al. (2004).

Predicted local $\mathrm{CH}_{4}$ signals $C_{l}\left(\underline{X}_{r}, t_{r}\right)$ (index ' 1 ' denote local and ' $\mathrm{r}$ ' denote receptor) from land surface emissions are calculated using the product of the footprint maps and the a priori emission maps, as 


$$
C_{l}\left(\underline{X}_{r}, t_{r}\right)=\sum_{i, j, m} f\left(\underline{X}_{r}, t_{r} \mid x_{i}, y_{j}, t_{m}\right) \cdot F\left(x_{i}, y_{j}, t_{m}\right)
$$

where $\underline{X}_{r}$ and $t_{r}$ are receptor (tower) location and time, $f\left(\underline{X}_{r}, t_{r} \mid \underline{X}, t_{m}\right)$ is the footprint and $F\left(x_{i}, y_{j}, t_{m}\right)$ is the surface emission map at location $\left(x_{i}, y_{j}\right)$ and time $t_{m}$. The total $\mathrm{CH}_{4}$ mixing ratio at the receptor can be expressed as

$$
C\left(\underline{X}_{r}, t_{r}\right)=C_{l}\left(\underline{X}_{r}, t_{r}\right)+C_{B G}\left(\underline{X}_{r}, t_{r}\right)
$$

where $C_{B G}\left(\underline{X}_{r}, t_{r}\right)$ is the upstream $\mathrm{CH}_{4}$ background condition.

In order to compare the simulated local $\mathrm{CH}_{4}$ mixing ratios to the tower measurements, the upstream $\mathrm{CH}_{4}$ background mixing ratios should be subtracted from the total measurements. For this study, the authors calculated the upstream $\mathrm{CH}_{4}$ mixing ratio using the final latitude of each particle as a lookup into the longitudinal average marine boundary layer $\mathrm{CH}_{4}$ mixing ratios for October-December, 2007 (NOAA Globalview $\mathrm{CH}_{4}$ ). The authors note, on average, persistent longitudinal gradients in $\mathrm{CH}_{4}$ at background sites up to $\sim 10 \mathrm{ppb}$. Particularly, annual means at sites of SHM and CBA in the Pacific are typically about 10 ppb greater that site of MHT in the Atlantic. Therefore, our adoption of background $\mathrm{CH}_{4}$ mixing ratios might be somewhat underestimated, which causes the 'measured' local contributed $\mathrm{CH}_{4}$ mixing ratios a little higher than true values. For measurements at WGC site, the authors also use the daily minimum $\mathrm{CH}_{4}$ mixing ratio measured at $483 \mathrm{~m}$ to evaluate the the error in $\mathrm{CH}_{4}$ background. The reason that the daily minimum $\mathrm{CH}_{4}$ mixing ratio at $483 \mathrm{~m}$ often reflects that of background air is because the 483m sample height decouples from the surface at night (when $91 \mathrm{~m}<\mathrm{Zi}<483 \mathrm{~m}$ ).

\section{Analysis of Transport Model Errors}

As a first approximation to evaluate the transport errors in the WRF-STILT predictions of surface influence footprints, the authors compared the modeled estimates of WRF winds and WRF-STILT boundary layer heights $(Z i)$ with corresponding profiler measurements of wind velocity and $\mathrm{Zi}$. at Sacramento site.

Errors in modeled winds are estimated by comparing WRF predictions with profiler or tower measurements of the $\mathrm{u}$ and $\mathrm{v}$ wind components. First, the authors compare the winds of $\mathrm{u}$ and $\mathrm{v}$ between measurements and WRF-STILT simulations, and figure out their residual errors $\sigma_{u}$ and $\sigma_{v}$ (RMS). Then, for simplicity, the authors assumed errors in $\mathrm{u}$ and $\mathrm{v}$ are independent, and hence that the RMS horizontal wind error can be calculated as $\sigma_{V}=\sqrt{\sigma_{u}^{2}+\sigma_{v}^{2}}$.

The evaluation of errors in boundary layer height was performed when profiler measurements of $\mathrm{Zi}$ were available. The authors used a best fitting geometric regression method to find the linear relationship between WRF-STILT and radar profiler PBL heights. Considering the relatively bigger uncertainties in Zi for both WRF-STILT and radar profiler at night period, only the linear relationship determined by well-mixed daytime reliable PBLs (e.g. WRF-STILT Zi bigger than the minimum of $215 \mathrm{~m}$ ) are used to correct the PBLs in WRF-STILT. After the correction of WRF-STILT PBL, the authors re-compared the PBLs between WRF-STILT and radar profiler to figure out the RMS residual error. The scaled $\mathrm{Zi}$ and new RMS residual error 
will be used to estimate the footprints and the transport error due to PBL uncertainties in the following work.

\subsubsection{Linear Regression Analysis of Predicted and Measured $\mathrm{CH}_{4}$ Signals}

As a first order comparison of measured and predicted $\mathrm{CH}_{4}$ signals, the authors plot total predicted signal versus background-subtracted measured $\mathrm{CH}_{4}$ and compute a best-fit linear model. In this case, the authors use a Chi-squared (fitexy, Press et al. 1992) mean linear regression model, which assumed the same relative errors in $\mathrm{x}$ and $\mathrm{y}$ components. While this does not provide information on individual source sectors or spatial regions, a comparison of total signals provides and shows the degree to which the combination of the prior emission inventories and transport model captures the measured signal.

\subsubsection{Bayesian Inverse Estimates of $\mathrm{CH}_{4}$ Emissions}

A posteriori $\mathrm{CH}_{4}$ emissions were estimated by optimizing scaling factors for the a priori $\mathrm{CH}_{4}$ emissions that provide the best fit between measured and predicted $\mathrm{CH}_{4}$ mixing ratios. This was done by scaling emissions from different sectors or sub-regions separately and incorporates individual estimates for the uncertainties in different a priori emissions.

Combining Eq. (1) and (2), the difference between measured and predicted background $\mathrm{CH}_{4}$ relates to the surface emission flux as

$$
\underline{C}-\underline{C_{B G}}=\underline{f} \underline{F}
$$

where $\underline{\underline{f}}$ is footprints, $\underline{F}$ is surface $\mathrm{CH}_{4}$ emission, $\underline{C}$ and $\underline{C_{B G}}$ is $\mathrm{CH}_{4}$ mixing ratios from tower measurements and background calculations, respectively. Assuming mixing ratio measurements from local sources as $y=\underline{C}-\underline{C_{B G}}$. Following Gerbig et al. (2003a), the authors introduce a model parameter or a state vector of scaling factors, $\lambda$, for the surface flux, $\underline{F}(\underline{\lambda})$. The inversion adjusts the model parameters $\lambda$ such that the modeled changes in $\mathrm{CH}_{4}$ concentrations are optimally consistent (in standard least square sense) with the observed values. In the study of surface $\mathrm{CH}_{4}$ emissions from different sources ("source analysis" hereafter), $\underline{\lambda}$ represents the scaling factor for different sources; in the study of surface $\mathrm{CH}_{4}$ emissions from different regions ("region analysis" hereafter), $\underline{\lambda}$ represents the scaling factor for different areas. For both the "source analysis" and "region analysis" study, $\underline{F}(\underline{\lambda})$ is linearly dependent on $\underline{\lambda}$ :

$$
\underline{F}(\underline{\lambda})=\underline{\phi} \underline{\underline{\lambda}}
$$

where $\underline{\underline{\phi}}$ is the a priori emissions for different sources or regions in this study.

Using the same method as Lin et al. (2004), the analytical solutions to Eqs (3) and (4) are

$$
\begin{aligned}
& \underline{\hat{\lambda}}=\left(\underline{\underline{K}}^{T} \underline{\underline{S}}_{\varepsilon}^{-1} \underline{\underline{K}}\right)^{-1}\left(\underline{\underline{K^{T}}} \underline{S}_{\varepsilon}^{-1} \underline{y}+\underline{S}_{\text {prior }}^{-1} \underline{\lambda \text { prior }}\right) \\
& \underline{\underline{\hat{S}_{\lambda}}}=\left(\underline{\underline{K}} \underline{\underline{S}} \underline{\underline{K}} \underline{\underline{K}}+\underline{\underline{S}}{ }_{\text {prior }}^{-1}\right)^{-1}
\end{aligned}
$$


where $\underline{\underline{K}}=\underline{\underline{\phi}}, \underline{\underline{S}}_{\varepsilon}$ is measurement error covariance matrix $\underline{\lambda}$ prior and $\underline{\hat{\lambda}}$ are the a priori and $a$ posteriori vectors, and $\underline{\underline{S}}_{\text {prior }}$ and $\underline{\underline{S}}_{\lambda}$ are the a priori and a posteriori error matrices for $\underline{\lambda}$. Corresponding to our initial estimate of $30 \%$ uncertainty in the $\mathrm{CH}_{4}$ emission maps, the initial value of $\underline{S}_{\text {prior }}$ is 0.09 . Note that the measurements and a priori emission error matrices are diagonal, equivalent to assuming that the prior errors are uncorrelated. .

\section{Measurement-Model Error Matrix}

In the Bayesian analysis, the authors put the errors in both measurements and model simulations together as an equivalent "measurement" error. The equivalent "measurement" error covariance matrix $S_{\varepsilon}$ is formed as the sum of different components

$$
\underline{\underline{S}}_{\varepsilon}=\underline{\underline{S}}_{\text {part }}+\underline{\underline{S}}_{\text {aggr }}+\underline{\underline{S}}_{\text {Trans } W N D}+\underline{\underline{S}}_{\text {TransPBL }}+\underline{\underline{S}}_{b k g d}+\underline{\underline{S}}_{\text {emis }}+\underline{\underline{S}}_{\text {eddy }}+\underline{\underline{S}}_{\text {ocean }}
$$

Here, as in Lin et al. (2004), the contribution of instrumentation error in the $\mathrm{CH}_{4}$ measurements is assumed to be random, uncorrelated, and negligible in magnitude relative to the other sources of error, and hence not considered further in the inverse model estimates. The authors consider each of the terms in Eq. (6) below.

The particle number error $\left(S_{\text {part }}\right)$ is due to the finite number of released particles at the receptor location. It can be estimated by comparing the simulated signals from the STILT running with release of 1000 particles and those from the STILT running with release of 100 particles. The standard error between them will be used as the particle number error. For all of the following error analyses, the authors used 1000 particles in order to minimize the effect of particle number error.

The "aggregation error" $\left(S_{\text {aggr }}\right.$ ) arises from aggregating heterogeneous fluxes within a grid cell into a single average flux (Kaminski et al., 2001). Gerbig et al. (2003b) demonstrated that a rough estimate of the aggregation error can be derived from the observed "representation error", which is derived from the difference between a point observation and a value averaged over a specific grid size (Gerbig et al., 2003a). Without multiple observation stations over a specific grid, the authors try to estimate the aggregation error based on the a priori $\mathrm{CH}_{4}$ emissions. Although the authors do not have high-resolution emission maps for all of the $\mathrm{CH}_{4}$ sources, the authors estimate aggregation error using landfill emissions, which are fully resolved. Here, the aggregation error is estimated by comparing the un-aggregated landfill signal from to the landfill signal estimated after averaging emissions over each county (the maximum aggregation used for the other sources).

The transport error $\left(\underline{\underline{S}}_{\text {Trans }}=\underline{\underline{S}}_{\text {Trans } W N D}+\underline{\underline{S}}_{\text {Trans } P B L}\right)$ denotes the errors in modeling transport, which can be caused by the uncertainties in wind speeds and directions, and the uncertainties in PBL heights. Following Lin and Gerbig (2005), the transport error due to winds $\underline{\underline{S}}_{\text {Trans } W N D}$ is calculated as the RMS difference between signals predicted from simulations with and without input of an additional stochastic component of wind error $\sigma_{V}$ in STILT. 
Uncertainty due to errors in modeled PBL heights $\underline{S}_{\text {Trans } P B L}$ is estimated by propagating the residual error $\mathrm{Zi}$ into the predicted $\mathrm{CH}_{4}$ signals. Here, the authors use the estimate of residual error in $\mathrm{Zi}$ determined from the comparison between predicted WRF-STILT PBL height and PBL height measured with the wind profiler. The sensitivity of $\mathrm{CH}_{4}$ signal to $\mathrm{Zi}$ is expressed as a first order perturbation in $C$ as

$$
\gamma=\frac{d C}{d Z i}
$$

where $\gamma$ is estimated by calculating STILT footprints and then variations in $C$ for small perturbations in $\mathrm{Zi}$. The error due to error in $\mathrm{Zi}$ can then be estimated as

$$
S_{\text {transPBL }}=\frac{\Delta C}{<C>}=\frac{\gamma \bullet \Delta Z i}{<C>}
$$

where $\Delta Z i$ is the residual error in WRF-STILT $Z i$, and $\left\langle C>\right.$ is the mean total $\mathrm{CH}_{4}$ signal. Using Eqs. (7) and (8), the estimated transport error due to PBL uncertainties can be calculated. Assuming the transport errors due to winds and PBL height are independent, the total transport error is obtained by $\underline{\underline{S}}_{\text {Trans }}=\underline{\underline{S}}_{\text {Trans } W N D}+\underline{\underline{S}}_{\text {Trans } P B L}$.

The background error $\left(\underline{\underline{S}}_{b k g d}\right)$ is due to the uncertainty in estimating the background contribution to the $\mathrm{CH}_{4}$ measurements at the tower location. For this study, the authors estimate the upstream background $\mathrm{CH}_{4}$ mixing ratio using the final latitude of each particle as a lookup into the latitudinally averaged marine boundary layer (MBL) $\mathrm{CH}_{4}$ for OctoberDecember, 2007 (NOAA Globalview $\mathrm{CH}_{4}$ ). Only time points (>95\% of the total) for which more than $80 \%$ of the particles reached longitudes 1.5 degrees from the coast were included in the study. The authors expect that the NOAA MBL average will be a reasonable approximation for the $\mathrm{CH}_{4}$ background because it is heavily weighted to the Pacific and the typical $\mathrm{CH}_{4}$ gradients between Pacific and Atlantic are less than $10 \mathrm{ppb}$. For WGC site, the authors evaluate the error in $\mathrm{CH}_{4}$ background using the daily minimum $\mathrm{CH}_{4}$ mixing ratio measured at $483 \mathrm{~m}$.

$S_{\text {emis }}$ indicates the emission error due to possible missing emission sources. The authors assume that there are no other emission sources and thus no emission error $\left(S_{\text {emis }}=0\right)$ in this study. The eddy flux error $\left(S_{e d d y}\right)$ specifies the fluctuations in column integrated $\mathrm{CH}_{4}$ due to contributions from turbulent eddies. Gerbig et al. (2003a) observed it is $\sim 0.2 \mathrm{ppmv}$ for $\mathrm{CO}_{2}$. For $\mathrm{CH}_{4}$ studied here, a value of $1 \%$ is assumed. The error due to omitting ocean emissions $\left(\underline{\underline{S}}_{\text {ocean }}\right)$ is assumed to be negligible. To evaluate this assumption, the authors calculated the expected $\mathrm{CH}_{4}$ signal from the Coal Point field near Santa Barbara, the largest known coastal natural gas field near California (Mau et al., 2007), and found the signals to be less than $1 \mathrm{ppb}$.

In order to combine the above errors from different sources, the authors need to know their correlations, which are unfortunately unknown. Assuming the errors from different sources are 
independent, the above errors are combined in quadrature to yield a total expected modelprediction mismatch error using Eq. (6).

\subsection{Design of an Enhanced Monitoring Network}

After completing the initial analysis of $\mathrm{CH}_{4}$ emissions, the authors considered the potential benefit of adding measurement sites to form a tower network, and the use of radiocarbon methane measurements for separating fossil and biogenic $\mathrm{CH}_{4}$ sources.

\subsubsection{Benefit of Additional Measurement Sites}

To evaluate the benefit of adding additional measurement stations, the authors conducted a synthetic data experiment to retrieve $\mathrm{CA} \mathrm{CH}_{4}$ emissions using seven measurement stations distributed across California. For each station, footprints and simulated tower $\mathrm{CH}_{4}$ mixing ratios are calculated as in section 2.3.2. Synthetic "data" was generated by adding random noise (mean=0, std $=10 \mathrm{ppb}$ ) to the simulated $\mathrm{CH}_{4}$ signals. Different combinations of synthetic data from one or more of the seven stations are then used in joint inversions for regional emissions as in Section 2.3.4. The reduction in uncertainty for the scaling factors for regional emissions is used to judge the effectiveness of adding additional measurement stations.

\subsubsection{Use of Radiocarbon Methane $\left({ }^{14} \mathrm{CH}_{4}\right)$ to Identify Fossil $\mathrm{CH}_{4}$ Emissions}

Atmospheric measurements of radiocarbon $\left({ }^{14} \mathrm{C}\right)$ in $\mathrm{CO}_{2}$ have been used to estimate fossil fuel $\mathrm{CO}_{2}$ emissions (Turnbull et al., 2006; Levin et al., 1995; Hsueh et al., 2007; Riley et al., 2008). In the current study the authors tested an analogous approach using radiocarbon in atmospheric methane $\left({ }^{14} \mathrm{CH}_{4}\right)$. Because $14 \mathrm{C}$ has a relatively short half live $(\sim 5730 \mathrm{y})$ compared to the ancient plant material from which fossil fuels are derived, carbon in fossil fuels is effectively free of ${ }^{14} \mathrm{C}$ (i.e., $\Delta{ }^{14} \mathrm{C}=-1000 \%$ o). Current atmospheric ${ }^{14} \mathrm{CH}_{4}$ content is the result of previous atmospheric nuclear weapon testing, nuclear power sources, and terrestrial and aquatic exchanges (Lassey et al. 2007). To make a first estimate of the impact of fossil fuel $\mathrm{CH}_{4}$ emissions on atmospheric $\Delta^{14} \mathrm{C}$ of $\mathrm{CH}_{4}$, the authors used preliminary estimates of the ${ }^{14} \mathrm{C}$ content of each $\mathrm{CH}_{4}$ source that the authors considered in California: anthropogenic natural gas and petroleum (-1000\%o), landfills $(100 \%)$, livestock $(100 \%)$, wetlands $\left(100 \%\right.$ ), and boundary $\left(60 \%\right.$ o). The uncertainty in the ${ }^{14} \mathrm{C}$ content of these sources is large; increasing confidence in the use of ${ }^{14} \mathrm{C}$ in $\mathrm{CH}_{4}$ necessitates better characterization of these values.

\subsection{Results and Discussion}

\subsection{Identification of Observing Stations}

\subsubsection{Inventory Estimates of $\mathrm{CH}_{4}, \mathrm{~N}_{2} \mathrm{O}$ and ${ }^{222} \mathrm{Rn}$ Emissions}

Maps of the a priori $\mathrm{CH}_{4}$ emissions are shown in Fig. 2a-f for these six California-specific source sectors. For comparison, Fig. 2g shows total EDGAR 3.2 emissions for the Western US, while Fig. $2 \mathrm{~h}$ shows the sum of the $\mathrm{CA}$-specific $\mathrm{CH}_{4}$ emissions. Last, Fig. 2i shows a set of California sub-regions that roughly correspond to air basins that are nearby or distant from the measurement locations and will be used in following analysis. In the following work, the authors follow previous work on uncertainty analysis (USEPA, 2004; Farrel, 2005) and assign a $30 \%$ uncertainty across the different sources as the a priori uncertainty on emissions estimates 
used below. The authors consider the uncertainties in US total $\mathrm{CH}_{4}$ emissions only a rough estimate to the uncertainties for sub-regions of California (and over the time period of this study) because the $30 \%$ estimate was derived for more aggregated emissions over annual cycles and the entire continental US.

Table 1 summarizes the $\mathrm{CH}_{4}$ emissions from different California-specific sources in the 13 subregions. $\mathrm{CH}_{4}$ emissions are scaled to equivalent $\mathrm{CO}_{2}$ forcing using a global warming potential

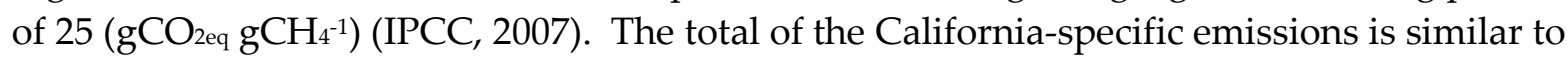
total $\mathrm{CH}_{4}$ emissions ( $31 \mathrm{MMT} \mathrm{CO}_{2 \text { eq }}$ ) reported by the California Air Resource Board (CARB, 2007), but is approximately half the total emissions from California pixels in the Edgar 3.2 inventory. Inspection of the Edgar 3.2 emissions shows that the largest sources are from natural gas (22.5 MMT $\mathrm{CO}_{2 \mathrm{eq}}$ ) and landfills (19.3 $\mathrm{MMT} \mathrm{CO}_{2 \mathrm{eq}}$ ), suggesting very different assumptions about emissions from these sources.

\begin{tabular}{|l|l|l|l|l|l|l|l|l|}
\hline $\mathrm{CH}_{4}$ & $\mathrm{CP}$ & $\mathrm{LF}$ & $\mathrm{LS}$ & $\mathrm{NG}$ & $\mathrm{PL}$ & WL & CA.spec & Edgar3.2 \\
\hline MMT CO2еq) & & & & & & & & \\
\hline Region 01 & 0.04 & 0.02 & 0.04 & 0.00 & 0.02 & 0.06 & 0.18 & 0.92 \\
\hline Region 02 & 0.01 & 0.04 & 0.15 & 0.00 & 0.10 & 0.02 & 0.29 & 1.09 \\
\hline Region 03 & 0.01 & 0.05 & 0.20 & 0.01 & 0.20 & 0.02 & 0.45 & 1.74 \\
\hline Region 04 & 0.04 & 0.10 & 0.18 & 0.00 & 0.17 & 0.05 & 0.48 & 1.56 \\
\hline Region 05 & 0.05 & 0.02 & 0.39 & 0.00 & 0.11 & 0.07 & 0.57 & 1.76 \\
\hline Region 06 & 0.02 & 0.40 & 0.51 & 0.36 & 0.62 & 0.04 & 1.81 & 4.30 \\
\hline Region 07 & 0.01 & 0.74 & 0.31 & 0.67 & 1.50 & 0.02 & 3.25 & 5.95 \\
\hline Region 08 & 0.01 & 0.27 & 2.06 & 0.01 & 0.32 & 0.02 & 2.32 & 3.73 \\
\hline Region 09 & 0.02 & 0.26 & 0.24 & 0.13 & 0.37 & 0.02 & 0.96 & 3.48 \\
\hline Region 10 & 0.11 & 3.75 & 1.68 & 0.88 & 3.62 & 0.17 & 10.21 & 25.14 \\
\hline Region 11 & 0.02 & 0.13 & 0.19 & 0.01 & 0.10 & 0.02 & 0.47 & 1.09 \\
\hline Region 12 & 0.06 & 0.31 & 3.65 & 0.31 & 0.73 & 0.10 & 5.16 & 7.95 \\
\hline Region 13 & 0.01 & 0.06 & 0.06 & 0.19 & 0.19 & 0.02 & 0.53 & 1.07 \\
\hline Whole CA & 0.42 & 6.15 & 9.66 & 2.57 & 8.03 & 0.63 & 27.46 & 59.78 \\
\hline
\end{tabular}

Table 1. Inventory estimates of a priori $\mathrm{CH} 4$ emissions from 6 different sources including crop agriculture (CP), landfills (LF), livestock (LS), natural gas (NG), 
petroleum (PL), wetlands (WL) and 13 California sub-regions identified in Error! Reference source not found.Fig. 2 i.

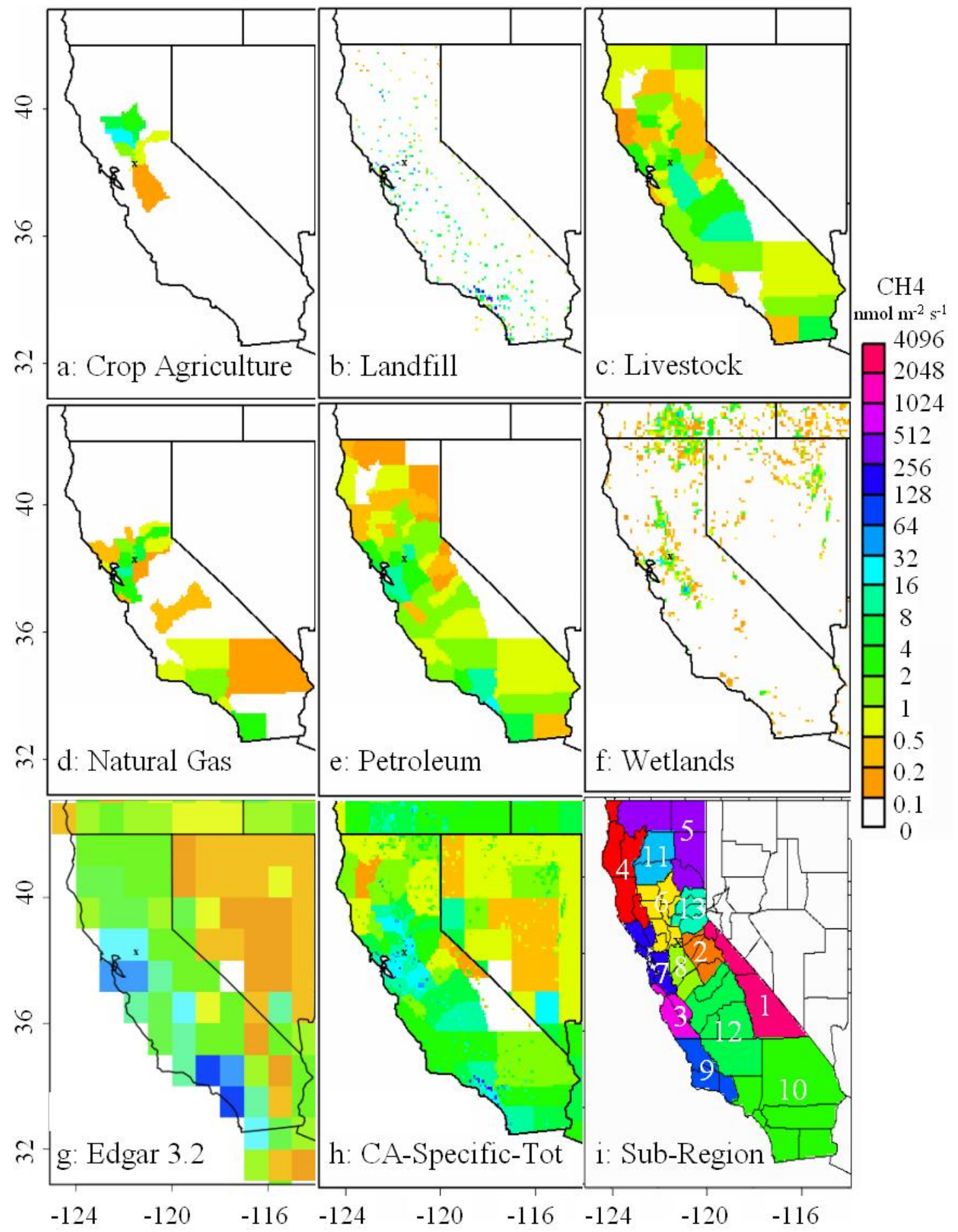

Figure 2. The a prioriemission maps and regions in California. a-f) are the CAspecific surface $\mathrm{CH}_{4}$ emissions from different sources; $\mathrm{g}$ ) is the sum of 
anthropogenic surface $\mathrm{CH}_{4}$ emissions from Edgar 3.2; h) is the sum of maps b-g) specific to California; and $\mathrm{i}$ ) is an illustration of the 13 California sub-regions considered in the spatial analysis.

The authors also examined $\mathrm{N}_{2} \mathrm{O}$ emissions from crop agriculture estimated by Salas et al. (2006) and from Edgar3.2 for the year 2000. As shown in the first three panels of Fig. 3, the emissions vary significantly with season, largely due to the combination of timing in fertilizer application and irrigation. Other significant sources of $\mathrm{N}_{2} \mathrm{O}$ in California include wastewater treatment and fuel combustion sources. Hence, total anthropogenic $\mathrm{N}_{2} \mathrm{O}$ emissions are likely to be temporally smoother (see lower right panel) because other $\mathrm{N}_{2} \mathrm{O}$ sources are likely to be more constant across seasons.
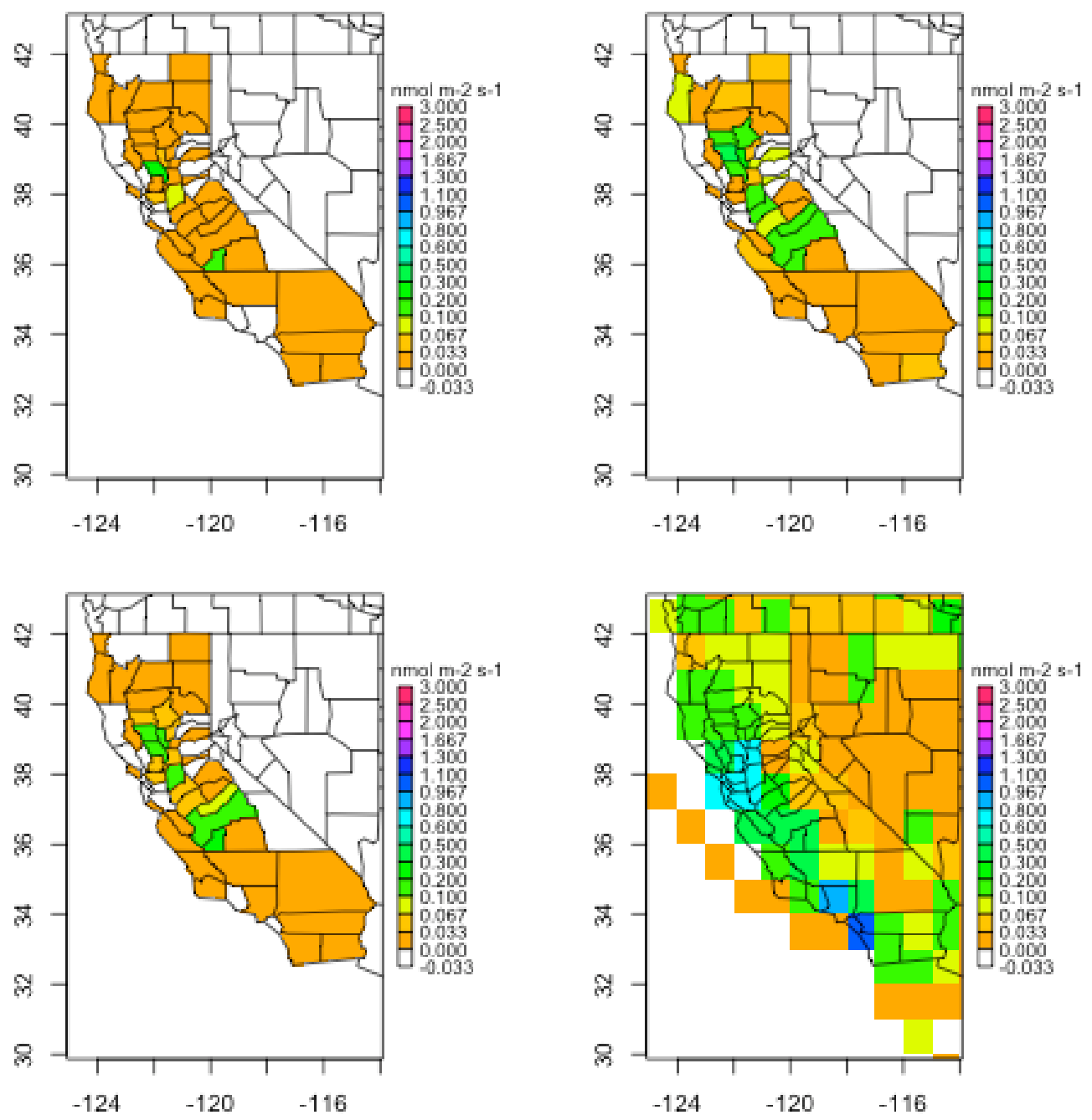

Figure 3. The a priori $\mathrm{N}_{2} \mathrm{O}$ emissions simulated for a dry year (1997) with low irrigation in July, (upper left), October (upper right), and annual mean (lower left) from Salas et al. (2006), while annual mean anthropogenic $\mathrm{N}_{2} \mathrm{O}$ emissions from Edgar3.2 are shown in lower right. 


\subsubsection{Predicted maps of time varying $\mathrm{CH}_{4}$ Mixing Ratios}

\section{MM5 Results}

The authors compared radon-corrected $\mathrm{CH}_{4}$ predictions to $\mathrm{CH}_{4}$ measurements at the Walnut Grove Tower using the MM5-LSM model predictions. As shown in Fig. 4, the model predictions followed many of the dynamics observed during October and February, with values falling within the \pm 1 SD of the measurements for much of these periods. During July, however, the model substantially under predicted the observations.
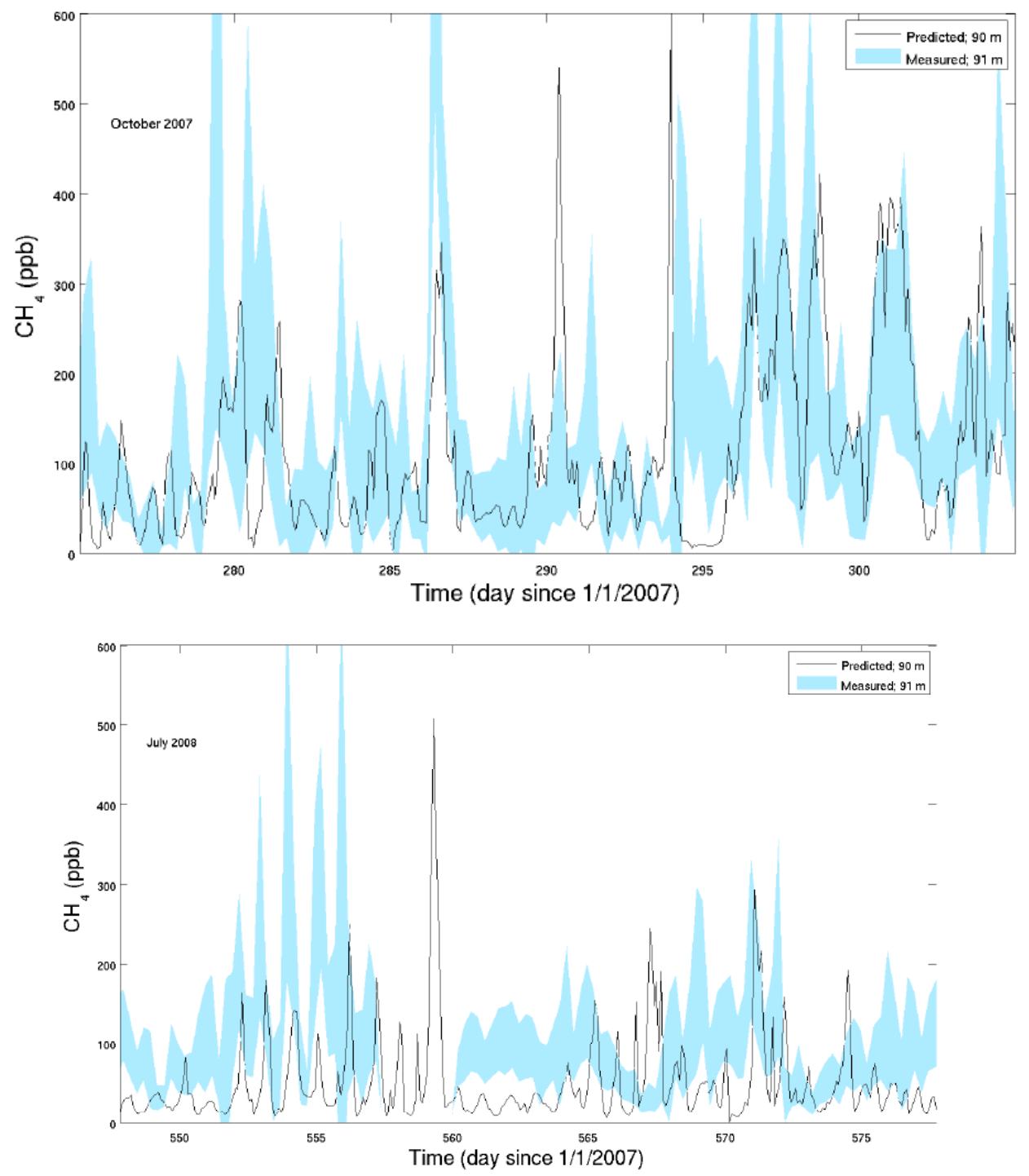

Figure 4. Comparison between predicted and observed $\mathrm{CH}_{4}$ concentrations at the Walnut Grove Tower for October, 2007 (top), and July, 2008 (bottom). Because the measurements are highly variable, a 6-hour running averaged has been applied. The range shown for the measurements represents the \pm 1 SD range of the measurements at $91 \mathrm{~m}$. 
Predicted well-mixed afternoon (1400 local time) $\mathrm{CH}_{4}$ mixing ratio at $91 \mathrm{~m}$ varied substantially over the state and over time. Fig 5. shows predicted monthly-average midday $\mathrm{CH}_{4}$ mixing ratios for October, 2007, and July, 2008, calculated using the Edgar $\mathrm{CH}_{4}$ emission inventory. The largest predicted $\mathrm{CH}_{4}$ mixing ratios were found for the Los Angeles, where the Edgar inventory has very strong emissions, while the Central Valley also shows elevated mixing ratios that should be readily measured with current instrumentation. The authors also predicted $\mathrm{N}_{2} \mathrm{O}$ mixing ratios, which were elevated by several 1-10 ppb due to emissions from agricultural regions of the Central Valley.
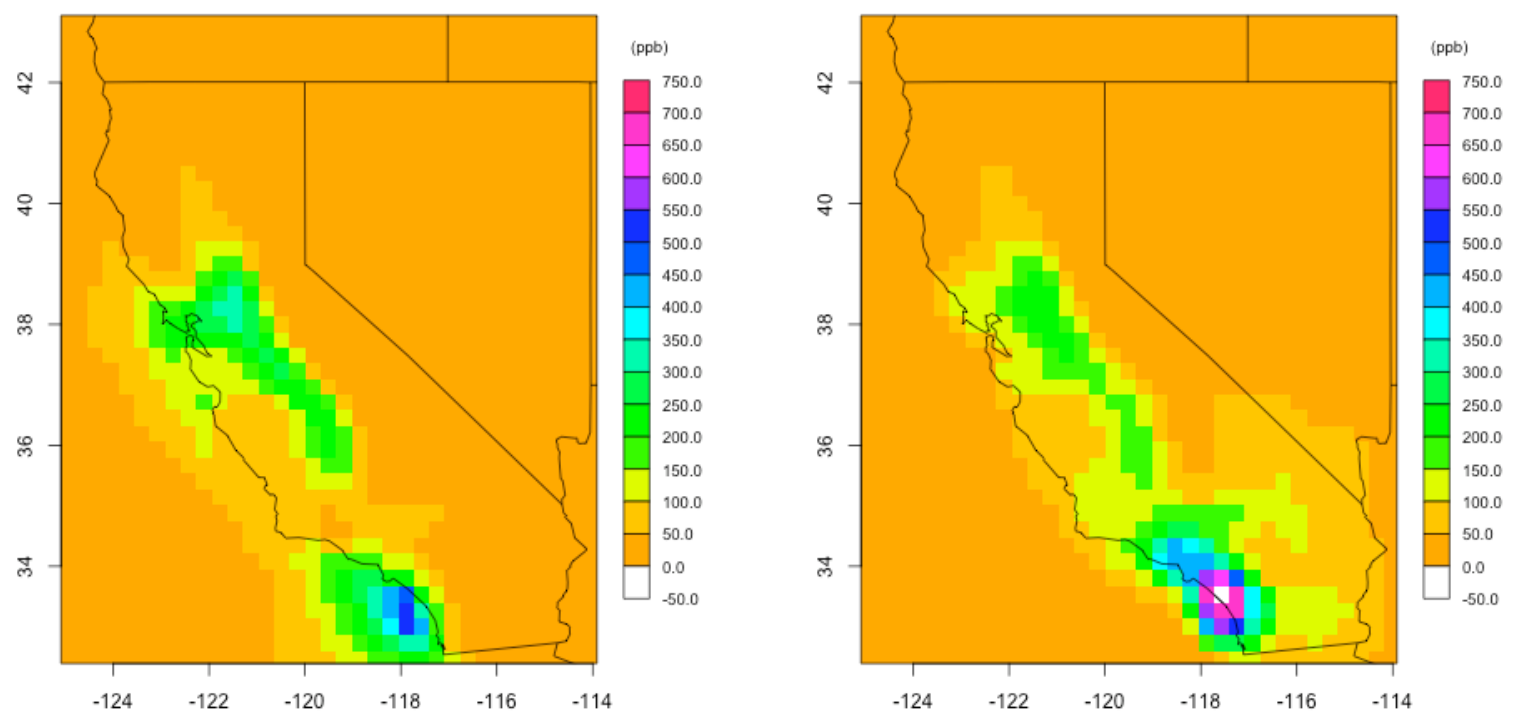

Figure 5. Predicted monthly-average midday $\mathrm{CH}_{4}$ mixing ratios at $91 \mathrm{~m}$ for October, 2007 and July, 2008.

\subsubsection{Locations of Potential Measurement Stations}

The authors identified a set of potential tower measurement stations from FCC lists using the predicted $\mathrm{CH}_{4}$ mixing ratios as a guide to where the different measurements could identify different sources: background air entering California, urban emissions, and rural emissions. The general locations of these sites correspond to a subset of the sites identified previously for $\mathrm{CO}_{2}$ measurements (Fischer et al., 2005). The seven potential measurement sites, spanning a range of emissions sources and air basins, are shown in Fig. 6 and listed in Table 2. 


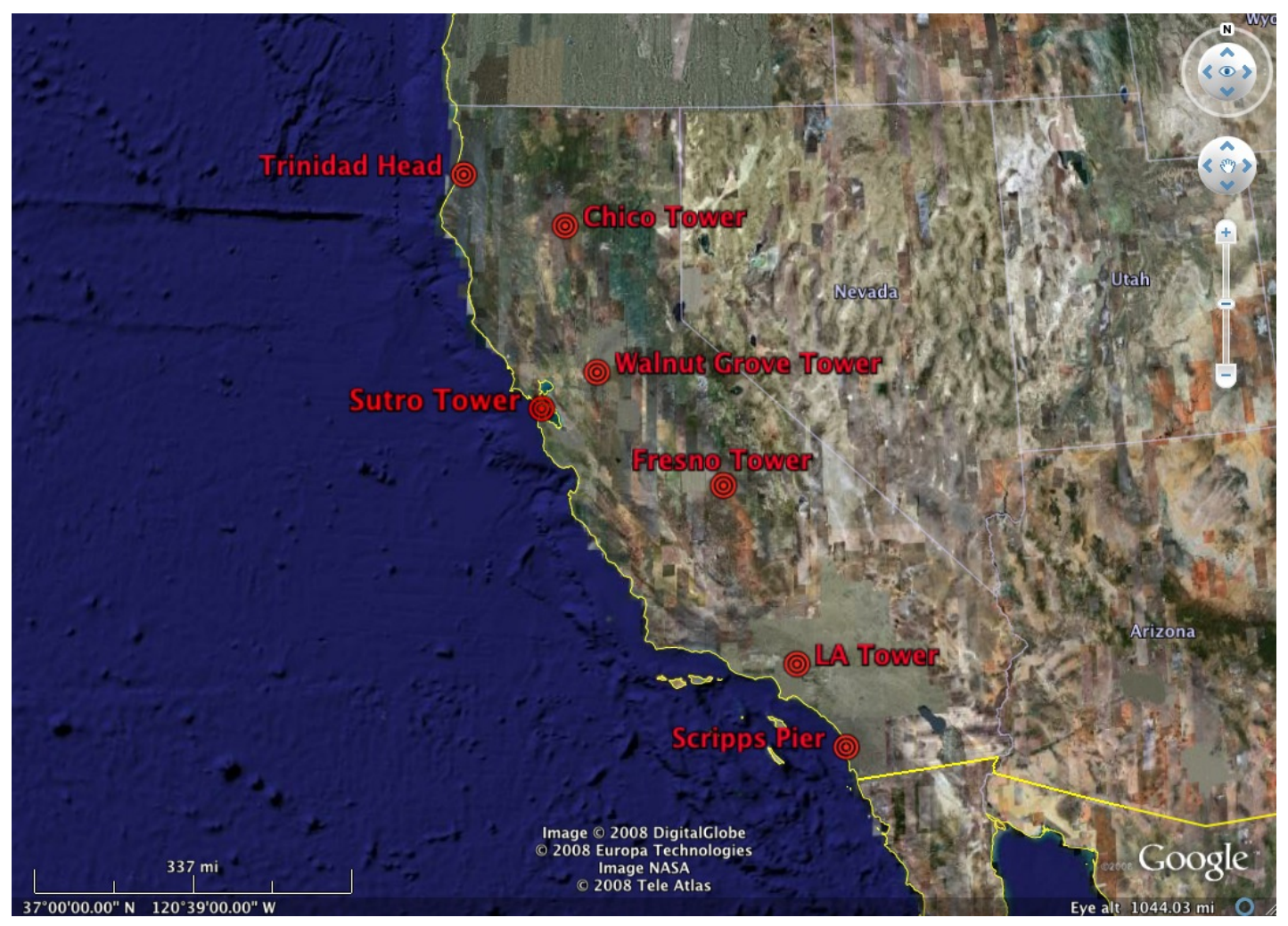

Figure 6. List of potential measurement sites for observation of $\mathrm{CH}_{4}$ and other GHG mixing ratios from background air, and urban and rural sources in California. 


\begin{tabular}{|l|l|l|l|l|}
\hline Station & Name & $\begin{array}{l}\text { Latitude } \\
\text { (degree) }\end{array}$ & $\begin{array}{l}\text { Longitude } \\
\text { (degree) }\end{array}$ & $\begin{array}{l}\text { Measurement } \\
\text { height (m agl) }\end{array}$ \\
\hline 1 & $\begin{array}{l}\text { LA Tower } \\
\text { (near Mt Wilson) }\end{array}$ & 34.223 & -118.0625 & 296 \\
\hline 3 & $\begin{array}{l}\text { South Coastal Tower } \\
\text { (near Scripps Pier) }\end{array}$ & 32.867 & -117.257 & 10 \\
\hline 4 & Sutro Tower (STR) & 37.755 & -122.453 & 232 \\
\hline 5 & $\begin{array}{l}\text { North Coastal Tower } \\
\text { (near Trinidad Head) }\end{array}$ & 41.050 & -124.15 & 10 \\
\hline 6 & $\begin{array}{l}\text { South Valley Tower } \\
\text { (near Fresno, CA) }\end{array}$ & 36.700 & -119.300 & 259 \\
\hline 7 & $\begin{array}{l}\text { Walnut Grove Tower } \\
\text { (WGC) }\end{array}$ & 38.2650 & -121.4911 & 91 \\
\hline & $\begin{array}{l}\text { North Valley Tower } \\
\text { (near Tuscan Buttes) }\end{array}$ & 40.262 & -122.093 & 304 \\
\hline
\end{tabular}

Table 2. List of seven potential measurement sites spanning a range of dominant emissions sources across California. Two of these towers (Sutro Tower and Walnut Grove Tower) were instrumented for GHG measurements.

\subsection{Gas Measurements}

\subsubsection{Mixing Ratios Measured at Towers}

Flask measurements of $\mathrm{CH}_{4}, \mathrm{CO}_{2}, \mathrm{~N}_{2} \mathrm{O}, \mathrm{CO}, \mathrm{SF}_{6}$, and $\mathrm{H}_{2}$, are shown for the Walnut Grove (WGC, at $91 \mathrm{~m}$ ) and Sutro (STR, at $232 \mathrm{~m}$ ) towers in Error! Reference source not found.Fig. 7 and Fig. 8 respectively. Measurements, from October 2007 through September 2008 period, at both WGC and STR exhibit long term trends reflecting global buildup (IPCC(2007)of some of the gases (e.g., SF6), while other gases (e.g., $\mathrm{CO}_{2}$ ) exhibit seasonal variations in background mixing ratios. With the exception of some high mixing ratios measured during in winter and spring, the measurements at STR largely reflect background air, while those at WGC exhibit considerably more variability due to local to regional terrestrial sources. Gaps in the data sets are due to periods (e.g., STR in July, 2008) when sampling systems malfunctioned or leaks were detected. 
QuickTime $^{\mathrm{TM}}$ and a

decompressor
are needed to see this picture.

Figure 7. Mixing ratios of $\mathrm{CO}_{2}, \mathrm{CH}_{4}, \mathrm{~N}_{2} \mathrm{O}, \mathrm{CO}, \mathrm{SF}_{6}$, and $\mathrm{H}_{2}$ measured at $91 \mathrm{~m}$ agl on the Walnut Grove (WGC) Tower. 


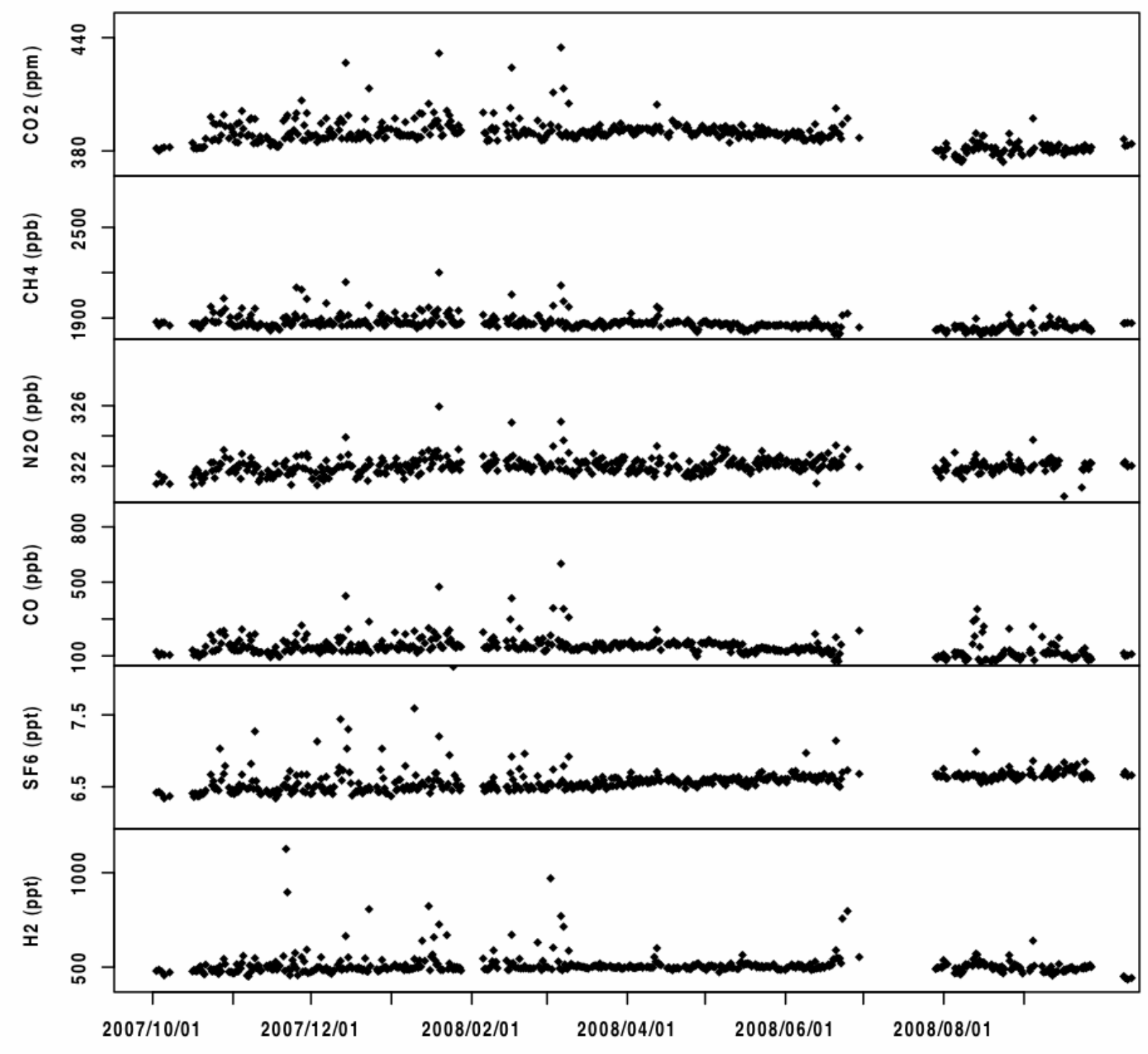

Figure 8. Mixing ratios of $\mathrm{CO}_{2}, \mathrm{CH}_{4}, \mathrm{~N}_{2} \mathrm{O}, \mathrm{CO}, \mathrm{SF}_{6}$, and $\mathrm{H}_{2}$ measured at $232 \mathrm{~m}$ agl on Sutro Tower.

In-situ measurements of $\mathrm{CH}_{4}, \mathrm{CO}_{2}, \mathrm{CO}$, and ${ }^{222} \mathrm{Rn}$ are shown for all sampling heights on the WGC tower. As shown in Fig. 9, the measurements show both diurnal, synoptic, and seasonal variations reflecting the combined effects of boundary layer heights, air flow patterns, and varying emissions. Generally the 30 and $91 \mathrm{~m}$ measurements reflect local to regional emissions and are tightly coupled through the planetary boundary layer, while the $483 \mathrm{~m}$ measurements more reflect a combination of tropospheric or marine boundary layer air with comparatively small influence from regional emissions except during the summer or warm afternoons in winter or the boundary layer grows higher than $483 \mathrm{~m}$. To evaluate errors in the sampling and analysis, the authors computed the difference between the in-situ and flask analyses for daytime and nighttime flask samples separately. For both of these periods, the differences 
exhibit negligible bias and variance consistent with the larger of instrument precision and the atmospheric variability determined from the variance of in-situ measurements in 30 minute windows centered on the flask samples.

Walnut Grove, 20071001-20081001

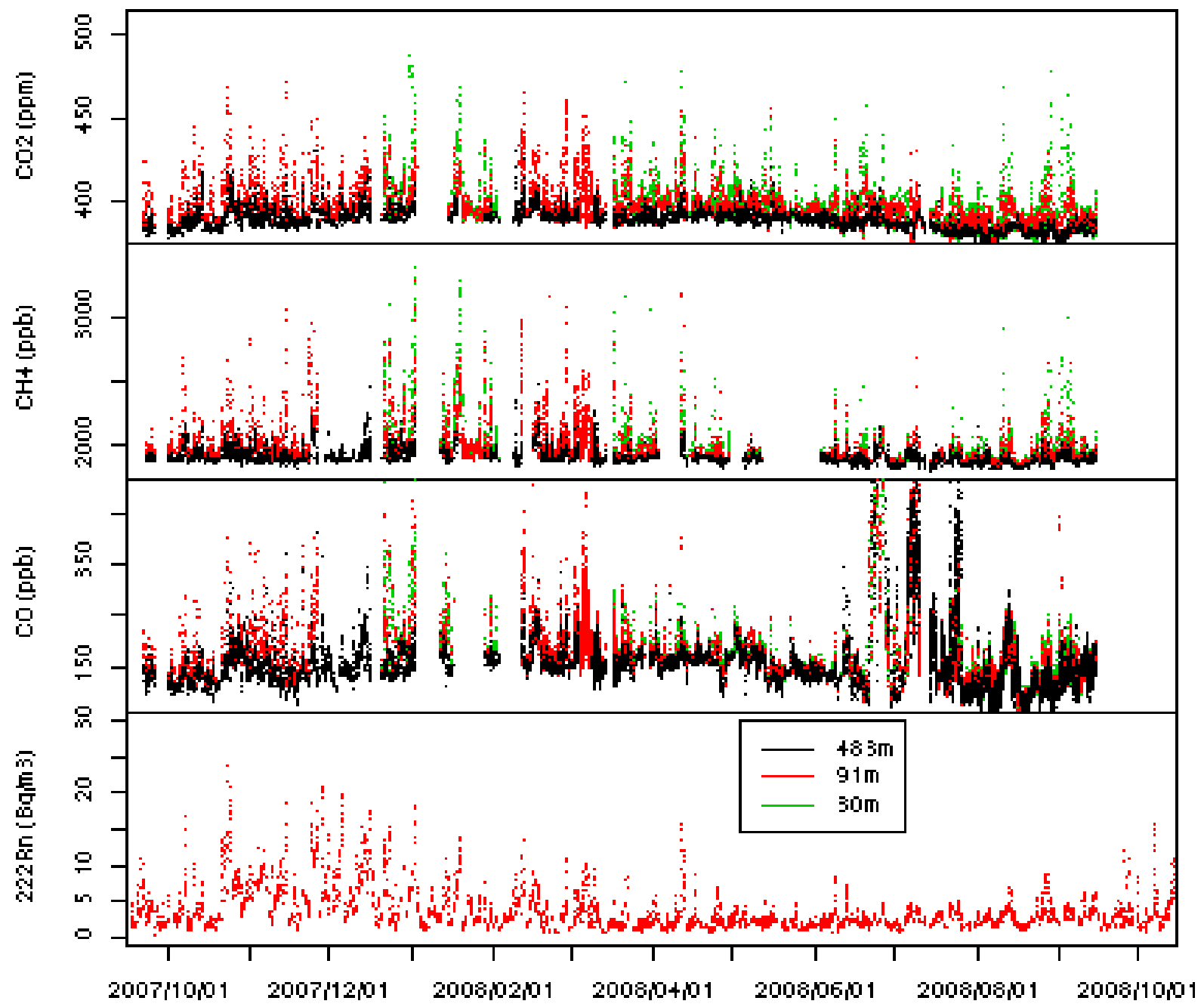

Figure 9. $\mathrm{CO}_{2}, \mathrm{CH}_{4}$, $\mathrm{CO}$ mixing ratios, and ${ }^{222} \mathrm{Rn}$ mixing ratios measured at the Walnut Grove tower.

To evaluate local to regional emissions, the authors focused on the continuous $\mathrm{CH}_{4}$ mixing ratio data measured at $91 \mathrm{~m}$ on the WGC tower in the October to December, 2007 period. Fig. 10 shows 3-hour average of measured $\mathrm{CH}_{4}$ mixing ratios at $91 \mathrm{~m}$ and $483 \mathrm{~m}$ in October 2007. 
Diurnal cycles due to changing boundary layer height are apparent in the data. The daily maximum $\mathrm{CH}_{4}$ mixing ratio measured at $91 \mathrm{~m}$ often occurs when the minimum is obtained at $483 \mathrm{~m}$. This would be expected to occur in cases when the boundary layer lies between 91 and $483 \mathrm{~m}$, trapping surface emissions within a shallow layer that is measured by $91 \mathrm{~m}$ sample height, while the $483 \mathrm{~m}$ sample height observes comparatively decoupled background air. The authors use the daily minimum $\mathrm{CH} 4$ measurements at $483 \mathrm{~m}$ to provide a check on the $\mathrm{CH}_{4}$ background analysis. Moreover, the authors limited the inverse model study to only include measurements collected during well-mixed periods. Henceforth, the authors define the wellmixed periods by using the criteria that the difference of measurements at $91 \mathrm{~m}$ and $483 \mathrm{~m}$ are less than $100 \mathrm{ppb}$, as shown by the black points in Figure 10. This criteria will also be evaluated with a more constricted value of $50 \mathrm{ppb}$ in the authors' study.

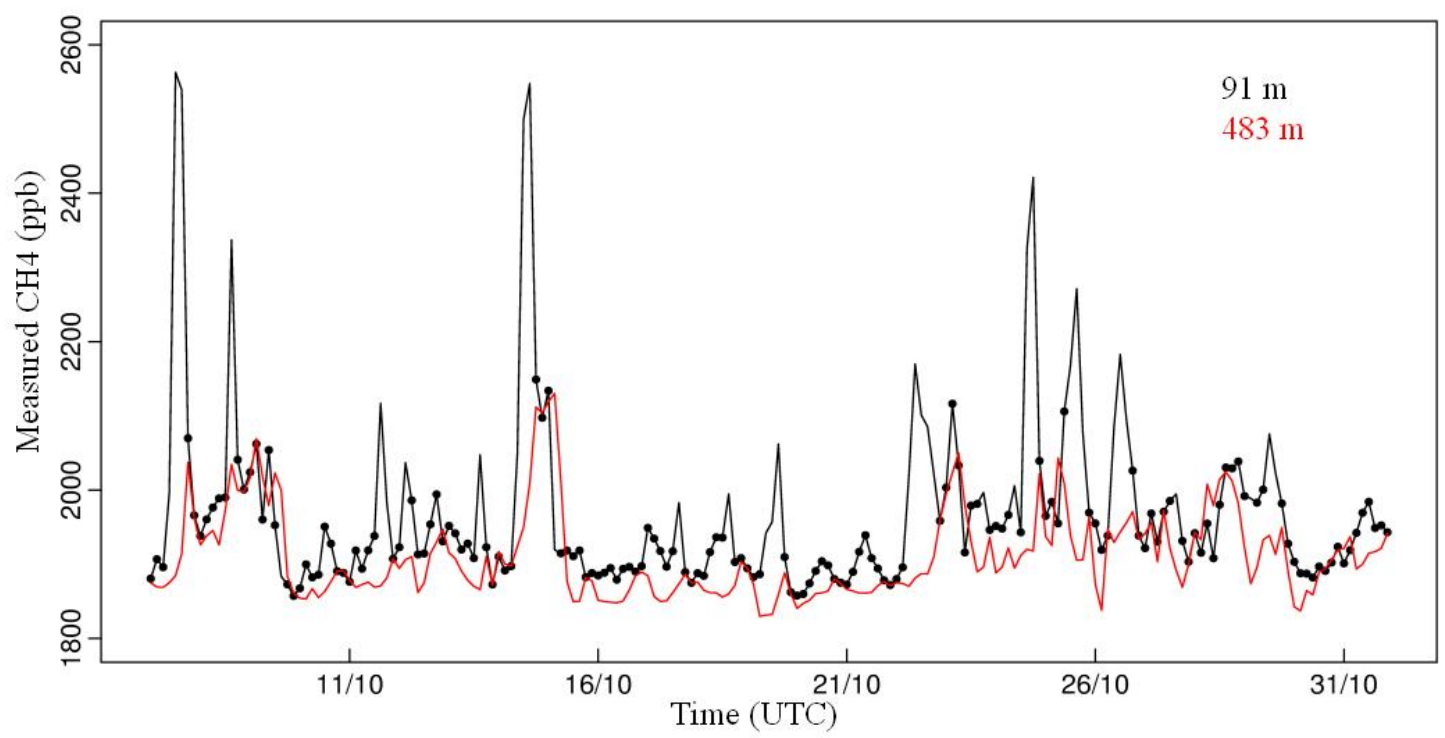

Figure 10. $\mathrm{CH}_{4}$ mixing ratios measured at $91 \mathrm{~m}$ (black) and $483 \mathrm{~m}$ (red) at the WGC tower. Only data (black points) obtained during well-mixed periods (defined as when the difference between measurements at $91 \mathrm{~m}$ and $\mathbf{4 8 3} \mathrm{m}$ are less than 100 $\mathrm{ppb}$ ) are used in this study.

\subsubsection{Background GHG mixing ratio time series}

Figure 11 shows the calculated values of background $\mathrm{CH}_{4}$ mixing ratios from the NOAA MBL average and WGC 483m minimum estimate as a function of time at WGC site during wellmixed periods from October through December in 2007. The background $\mathrm{CH}_{4}$ mixing ratios obtained from NOAA latitudinal average over marine boundary layer mainly lie between 1850 and $1880 \mathrm{ppb}$ with a mean value of $1860 \mathrm{ppb}$, which have a much smaller variation than those from daily minimum at WGC $483 \mathrm{~m}$. Figure $11(\mathrm{~b})$ shows that there is no systematic bias, although the minimum $\mathrm{CH}_{4}$ mixing ratio at $483 \mathrm{~m}$ is occasionally enhanced relative to the NOAA MBL average, likely due to local $\mathrm{CH}_{4}$ contributions. The authors estimate the error in $\mathrm{CH}_{4}$ background calculation as the RMS difference in Figure $11(\mathrm{~b})$, which is $15 \%$ of the mean background-subtracted measurements at $91 \mathrm{~m}$. 

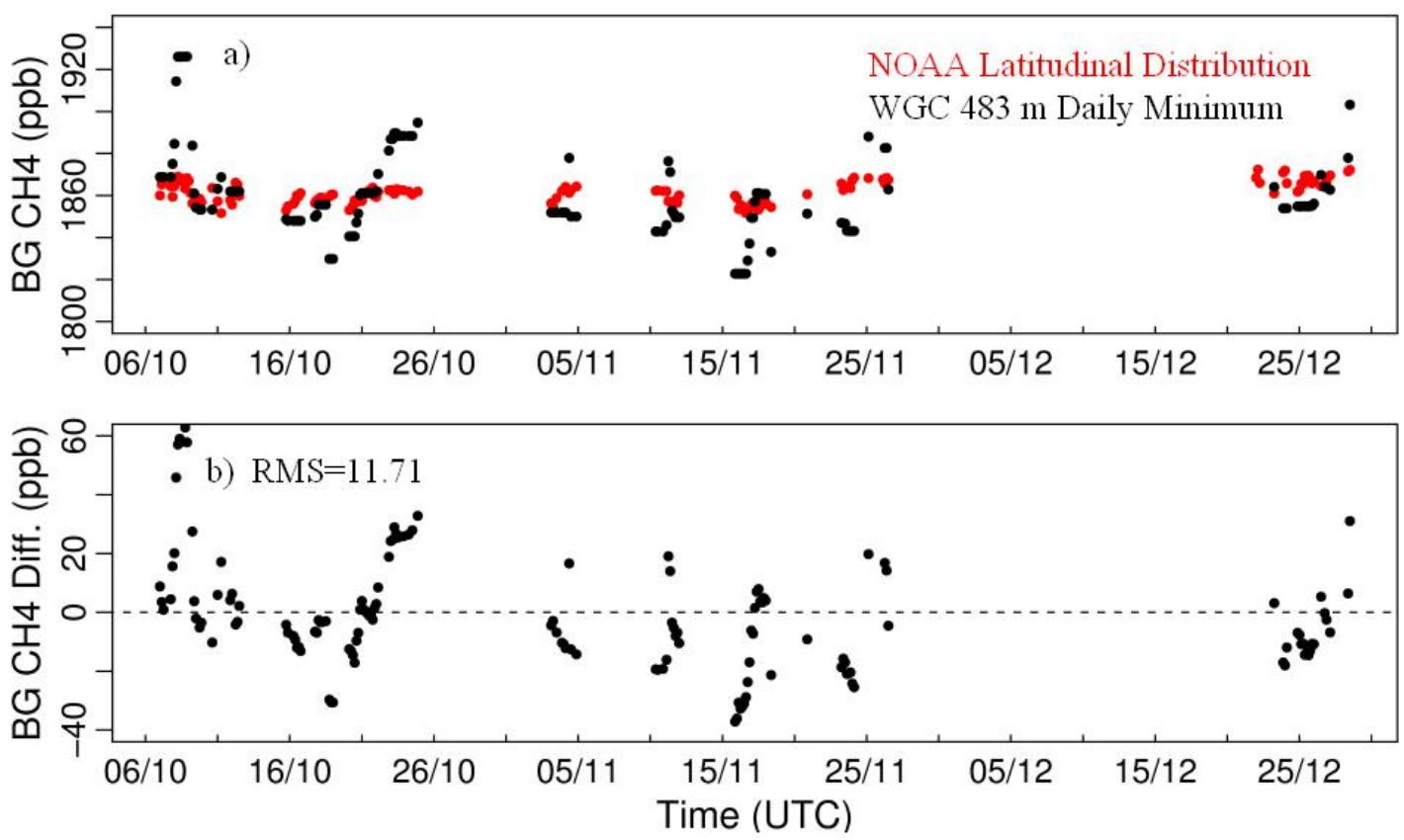

Figure 11. Time series of background $\mathrm{CH}_{4}$ mixing ratios, calculated from the NOAA global latitudinal average marine boundary layer (red) and the daily minimum measured at $483 \mathrm{~m}$ (black) a), and the difference of these signals b).

\subsubsection{Preliminary Measurement of Soil Radon Fluxes}

Preliminary measurements of soil radon flux to the atmosphere were conducted for approximately 10 day periods in November at the Lawrence Berkeley National Laboratory, and in December, 2008 at the WGC tower. The measured soil radon fluxes were $1.2 \pm 0.15$ and $1.1 \pm$ 0.1 atoms $\mathrm{cm}^{-1} \mathrm{~s}^{-1}$ at LBNL and WGC respectively. The authors note these values for soil radon flux are consistent with commonly held assumptions (e.g., Biraud et al., 2000). However, the ${ }^{222} \mathrm{Rn}$ flux measurements do not sample the surface fluxes over the region contributing to the tower measurements. Hence the uncertainty in average ${ }^{222} \mathrm{Rn}$ flux is potentially significantly larger than the roughly $10 \%$ fractional uncertainty obtained from the chamber measurements.

\subsection{Preliminary Estimation of Regional $\mathrm{CH}_{4}$ and $\mathrm{N}_{2} \mathrm{O}$ Emissions}

\subsubsection{Radon Mixing Model Emission Estimates}

The authors estimated $\mathrm{CH}_{4}$ and $\mathrm{N}_{2} \mathrm{O}$ emissions in the footprint of the WGC tower for the October-December, 2007 period using the ${ }^{222} \mathrm{Rn}$ mixing model. As shown in Figure 12, the slopes of $\mathrm{CH}_{4}$ and $\mathrm{N}_{2} \mathrm{O}$ to ${ }^{222} \mathrm{Rn}$ determined from a geometric linear regression are $39 \pm 3\left(\mathrm{R}^{2}=0.67\right)$ and $0.36 \pm 0.04\left(\mathrm{R}^{2}=0.48\right) \mathrm{ppb} /\left(\mathrm{Bq} \mathrm{m}{ }^{-3}\right)$ respectively. Assuming a mean $\mathrm{Rn}$ flux of 1 atom $\mathrm{cm}^{-2} \mathrm{~s}^{-1}$, the footprint averaged flux of $\mathrm{CH}_{4}$ and $\mathrm{N}_{2} \mathrm{O}$ using the mixing model method are 33 and $0.3 \mathrm{nmol} \mathrm{m}^{-2}$ $\mathrm{S}^{-1}$ respectively. The estimated $\mathrm{CH}_{4}$ and $\mathrm{N}_{2} \mathrm{O}$ emissions are approximately consistent with the average inventory emissions for Central California. However, the uncertainty in ${ }^{222} \mathrm{Rn}$ emissions is large (likely significantly greater than the $10 \%$ obtained from soil chamber the measurements), creating a proportional error in $\mathrm{CH}_{4}$ and $\mathrm{N}_{2} \mathrm{O}$ emissions. The authors note that 
these comparisons are preliminary because uncertainty in the mixing model results are subject to uncertainty in the actual radon flux and errors inherent in the assumption that the ${ }^{222} \mathrm{Rn}$ and GHG emissions are spatially correlated. The later assumption can, in principle, be tested if the spatial distributions are assumed to follow those represented by the a priori emission estimates using the method described in Hirsch (2006).
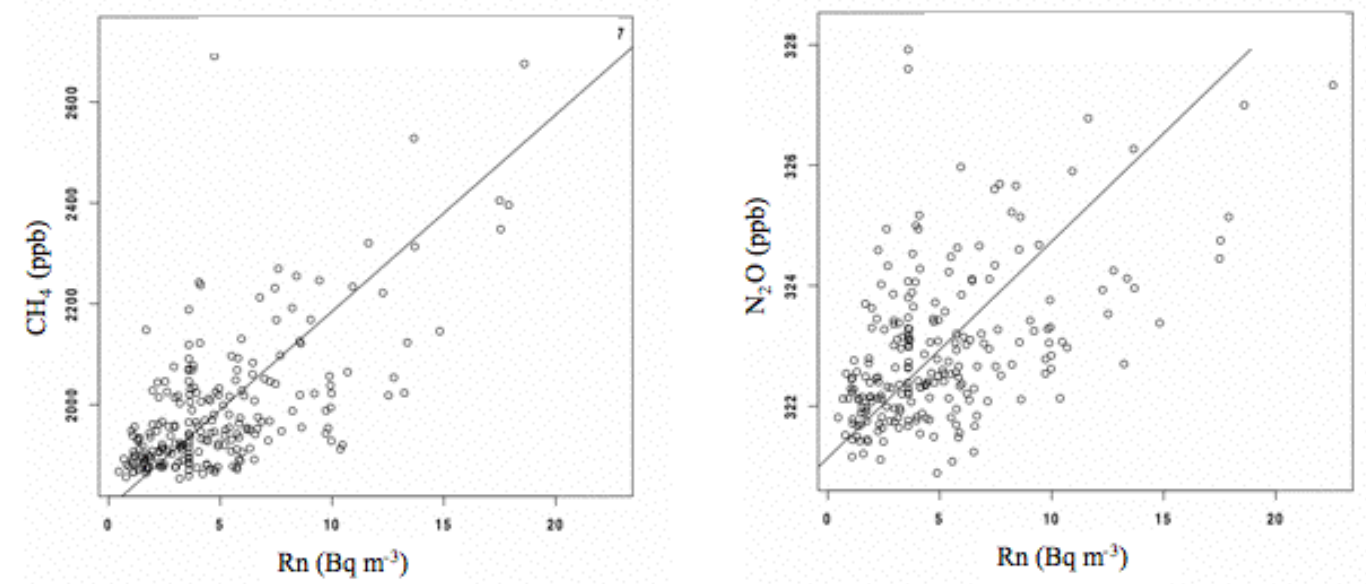

Figure 12. Correlation plots of $\mathrm{CH}_{4}$ and $\mathrm{N}_{2} \mathrm{O}$ versus ${ }^{222} \mathrm{Rn}$ measured at $91 \mathrm{~m}$ on the
Walnut Grove tower over the period. Lines indicate best-fit geometric linear
regressions.

\subsubsection{Lagrangian Model of GHG Mixing Ratios}

As described above, the authors use an inverse model to estimate the regional distributions of GHG fluxes which rely on numerical prediction of regional meteorology. In this section the authors examine the errors in predicted meteorology and how those errors affect predicted GHG signals, and then provide initial estimates of $\mathrm{CH}_{4}$ emissions for Central California.

\section{Atmospheric Transport Model Errors}

The authors evaluated the errors in winds WRF-STILT winds using measurement from October 2007. As shown in Figure 13, WRF-STILT winds highly agree well with the tower measured winds with good correlations in both $\mathrm{u}\left(\mathrm{r}^{2}=0.80\right)$ and $\mathrm{v}\left(\mathrm{r}^{2}=0.69\right)$. The RMS errors in horizontal winds at $137 \mathrm{~m}$ are $\sigma_{u}=2.21$ and $\sigma_{v}=2.86 \mathrm{~m} \mathrm{~s}^{-1}$. Some of this difference can be attributed to the fact that profiler winds are measured at a single site while the WRF winds are the averages over a grid of $1.6 \mathrm{~km} \times 1.6 \mathrm{~km}$. The authors note that the wind RMS error decreased by approximately a factor of 2 between $137 \mathrm{~m}$ and $1000 \mathrm{~m}$, though the decrease was non-linear with most of the decrease occurring between 137 and about $500 \mathrm{~m}$. Henceforth, the authors assume errors in $u$ and $v$ are constant with height and randomly distributed with an RMS 
magnitude of $\sigma_{V}=\sqrt{\sigma_{u}^{2}+\sigma_{v}^{2}}=3.6 \mathrm{~m} \mathrm{~s}^{-1}$. Following Lin and Gerbig (2005), the transport error due to winds $\underline{\underline{S}}_{\text {Trans } W N D}$ is calculated as the RMS difference between signals predicted from simulations with and without input of an additional stochastic component of wind error $\sigma_{V}$ $(3.6 \mathrm{~m} / \mathrm{s})$ in STILT. The resulting RMS signal is equivalent to $8 \%$ of the average predicted $\mathrm{CH}_{4}$ signal..

WGCwindcompare.tower.WRFd3.oct2007.122m.20080131
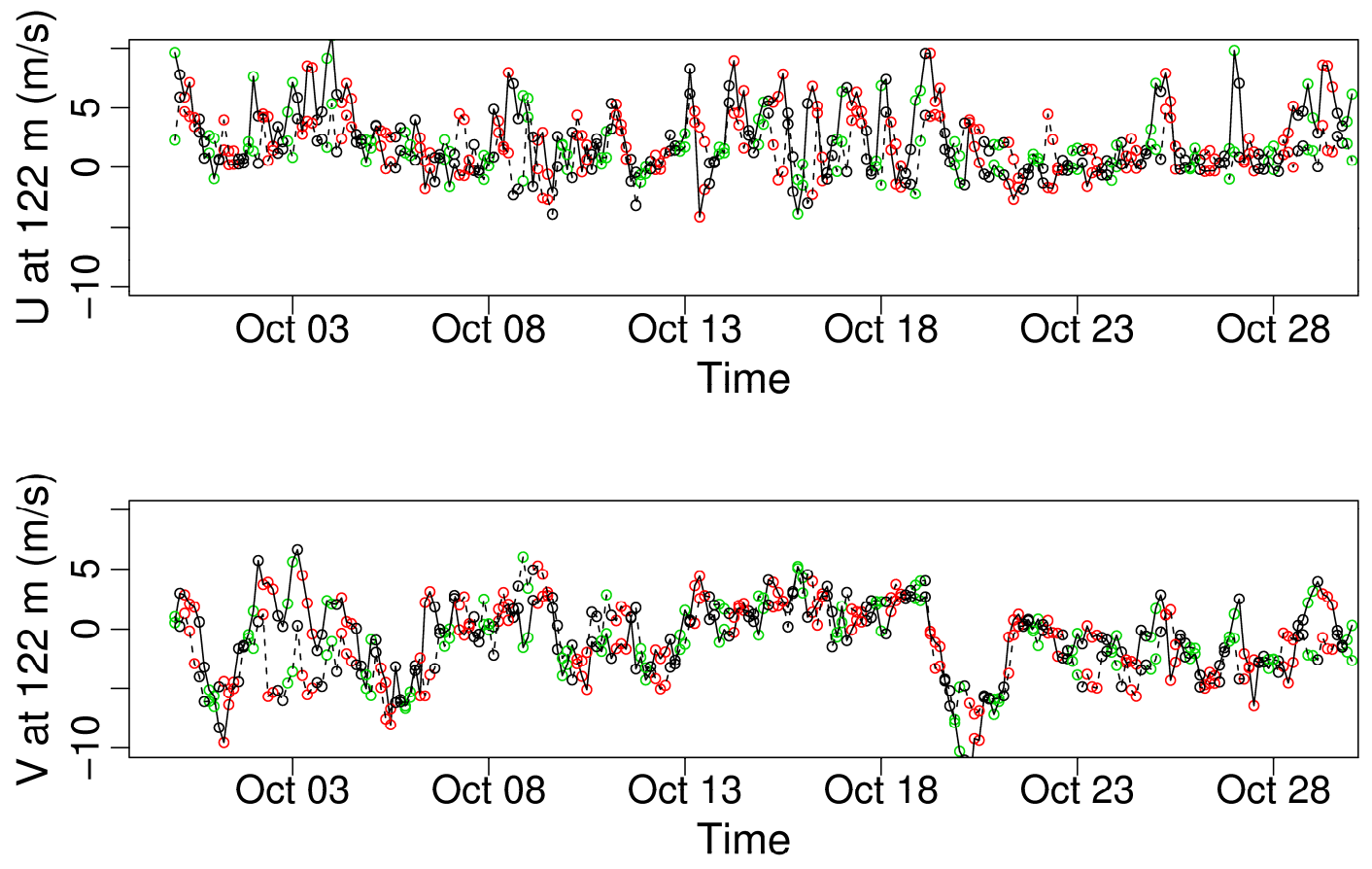

Figure 13. The comparison of winds $U$ and $V$ components between WRF-STILT simulations and tower measurements at WGC site. Solid line is for tower measurements and dashed line is for WRF-STILT simulations; and red, green and black dots represent night period (UTC hour time between 6 and 18), day period (UTC hour time between 18 and 6) and transition period (UTC hour time of 6 and 18), respectively.

For the transport error due to PBL heights, data in October through December 2007 were obtained and used in this analysis. Figure 14 shows the comparisons of daytime PBL heights between radar profiler measurements and WRF-STILT simulations. Profiler data were selected to match the time of the WRF-predictions to within 1 hour. In addition, the WRF-STILT simulations impose a lower limit value of $215 \mathrm{~m}$ on $\mathrm{Zi}$, while the radar profiler has a minimum detection height of $120 \mathrm{~m}$. To avoid biasing the comparison and make sure $\mathrm{CH}_{4}$ well mixed from surface till heights above $483 \mathrm{~m}$, the authors included WRF-STILT predictions of Zi greater than $215 \mathrm{~m}$ in the analysis. The resulting best fit geometric linear regression of WRF-STILT on radar profiler PBL heights yields a slope of $1.25 \pm 0.10$ and intercept of $-138 \pm 70 \mathrm{~m}$. Based on this 
result, the authors obtain a scale factor of $1 / 1.25$ which is then applied to $Z i$ when calculating footprints using STILT. This result is similar to that found in Lin et al. (2003), where STILT predictions of $Z i$ were about 1.09 higher than $Z i$ measurements at a site in Wisconsin. After scaling STILT $Z i$ by a factor of 1/1.25, the RMS residual error between scaled WRF-STILT and profiler $\mathrm{Zi}$ is reduced by a factor of 1.5 to $\sim 200 \mathrm{~m}$, roughly consistent with the estimated error in the profiler measurements. ()

In the following work, the authors calculate particle trajectories and resulting footprints using the scaled parameterization of PBL height. Using Eqs. (7) and (8), the estimated transport error $\underline{S}_{\text {TransPBL }}$ at day time due to PBL uncertainties of $196 \mathrm{~m}$ is about $17 \mathrm{ppb}$, or about $22 \%$ of the mean signal. Assuming the transport errors due to winds and PBL height are independent, the total transport error $\underline{\underline{S}}_{\text {Trans }}$ is $23 \%$.

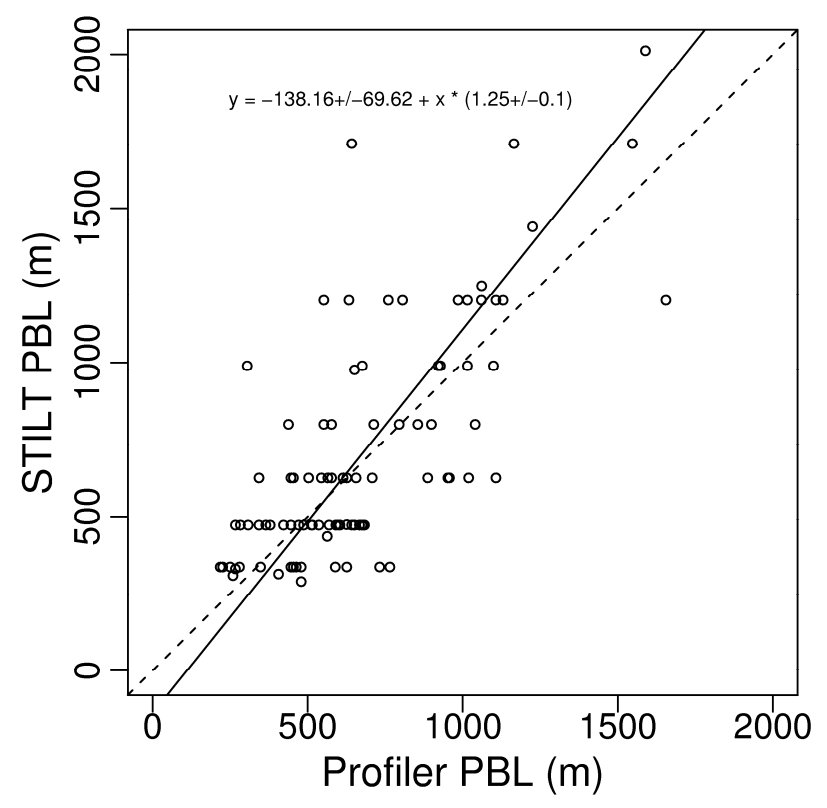

Figure 14. Comparison of daytime PBL heights between radar profiler measurements and WRF-STILT simulations in October through December 2007. Also shown are lines for a 1:1 relationship (grey) and the best-fit (black) from a geometric linear regression.

\section{Footprints for Measurement Sites}

The time-averaged footprint is shown in Figure 15 for the period between October and December in 2007. The high footprint values within approximately the Central California area near the tower site indicate that $\mathrm{CH}_{4}$ signals measured at $91 \mathrm{~m}$ at WGC will be strongly influenced by the $\mathrm{CH}_{4}$ emissions over Central California area. The low values in other areas indicate the low sensitivity of WGC tower measurements to the surface $\mathrm{CH}_{4}$ emissions in those areas. In the following study, the authors show the inversion results based on WGC site measurements, which will have a high reliability for central California area. In order to obtain 
accurate inverse of $\mathrm{CH}_{4}$ emissions over the whole $\mathrm{CA}$, a net of stations is proposed by the authors at the end of this report.

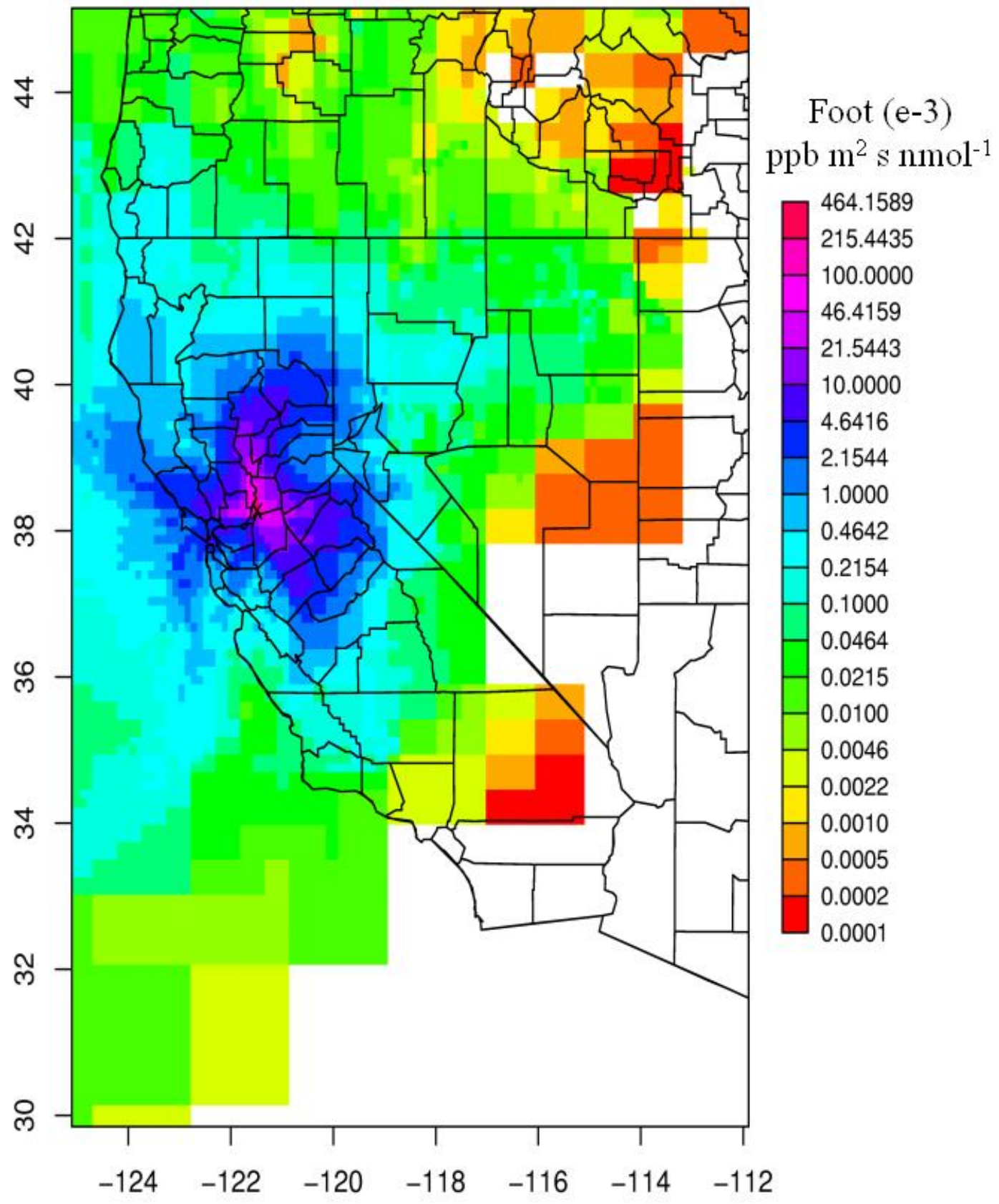

Figure 15. Average footprint for $\mathrm{CH}_{4}$ mixing ratio measurements made at $91 \mathrm{~m}$ on the Walnut Grove tower for the period from October through December 2007.

\section{Linear Regression Analysis of Predicted and Measured $\mathrm{CH}_{4}$ Signals}


The predicted WRF-STILT $\mathrm{CH}_{4}$ mixing ratio signals obtained for the period of October through December 2007, shown in Figure 16, agree qualitatively with the tower measurements. As described in sections 3.2.1 and Figure 10, data are selected to only include times with wellmixed conditions and when background $\mathrm{CH}_{4}$ can be reliably, which are shown as black points in Figure 16. Diurnal cycles due to changing boundary layer height and synoptic variations due to frontal passages are apparent in the data. The measured and predicted $\mathrm{CH}_{4}$ mixing ratios show similar temporal variations, indicating partial success of the model. However, the predicted signals do not always capture the large $\mathrm{CH}_{4}$ measurements, indicating some combination of errors in the a priori emission model (e.g., spatial pattern or limited resolution) and atmospheric transport (e.g, wind fields, boundary layer height). A quantitative comparison of measured and predicted $\mathrm{CH}_{4}$ signals from the $91 \mathrm{~m}$ sampling height at WGC is shown for the October through December 2007 period in Figure 17. Without Zi scaling (Figure 17a), the best-fit slope between predicted and measured $\mathrm{CH}_{4}$ mixing ratios is $0.46 \pm 0.07$. After applying the $\mathrm{Zi}$ scaling to WRF-STILT (Figure 17b), the slope between predicted and measured $\mathrm{CH}_{4}$ is $0.73 \pm$ 0.11. The change in slope between Figure 17a and Figure $17 \mathrm{~b}$ demonstrates that scaling the PBL heights affects the predicted $\mathrm{CH}_{4}$ signals, and any residual uncertainty in PBL height should be considered as a source of uncertainty in the Bayesian analyses that follow. After the $\mathrm{Zi}$ scaling, the slope obtained in Figure 17b suggests that the actual emissions are higher than inventory estimates by a factor of $1.37 \pm 0.21$. The authors note that the normalized Chi-square value for Figure $17 \mathrm{~b}$ is 1.17 , suggesting that the estimated errors do not completely explain the residual variance in the differences between the predictions and measurements. $\mathrm{CH}_{4}$ signals based on Edgar 3.2 emissions are also simulated and compared with the tower measurements in Figure $17 \mathrm{c}$, yielding a slope of $1.09 \pm 0.14$. This slope is roughly consistent ( $\mathrm{p}>0.1$ in a t test) with the slope (0.92 \pm 0.03$)$ obtained by Kort et al. (2008) in their comparison of measured and predicted $\mathrm{CH}_{4}$ signals using Edgar 3.2. However, the slopes obtained with the California specific (Figure $17 \mathrm{~b})$ and Edgar (Figure 17c) emissions are significantly different $(\mathrm{p}<0.01)$, as might be expected given the large difference in the a priori emissions shown in Table 1. For the central California region, the total emission estimated by Edgar 3.2 is about $75 \%$ more than that estimated from California specific sources, which is roughly consistent with the difference $(\sim 50 \%)$ of fitting slopes between Figure 17b and Figure 17c.

To evaluate the effect of the well-mixed data selection criteria, the authors also examined the slopes obtained with a more stringent requirement that the difference between $\mathrm{CH}_{4}$ mixing ratio measured at $91 \mathrm{~m}$ and $483 \mathrm{~m}$ is less than $50 \mathrm{ppb}$. This subset of data are shown as triangles in Figure 17. Using the selection criteria of $50 \mathrm{ppb}$ in Figure 17b, the authors obtain a slope of 0.86 \pm 0.17 , which is quite consistent with that obtained using the selection criteria of $100 \mathrm{ppb}$. The following analyses include data based on the $100 \mathrm{ppb}$ selection criteria. 


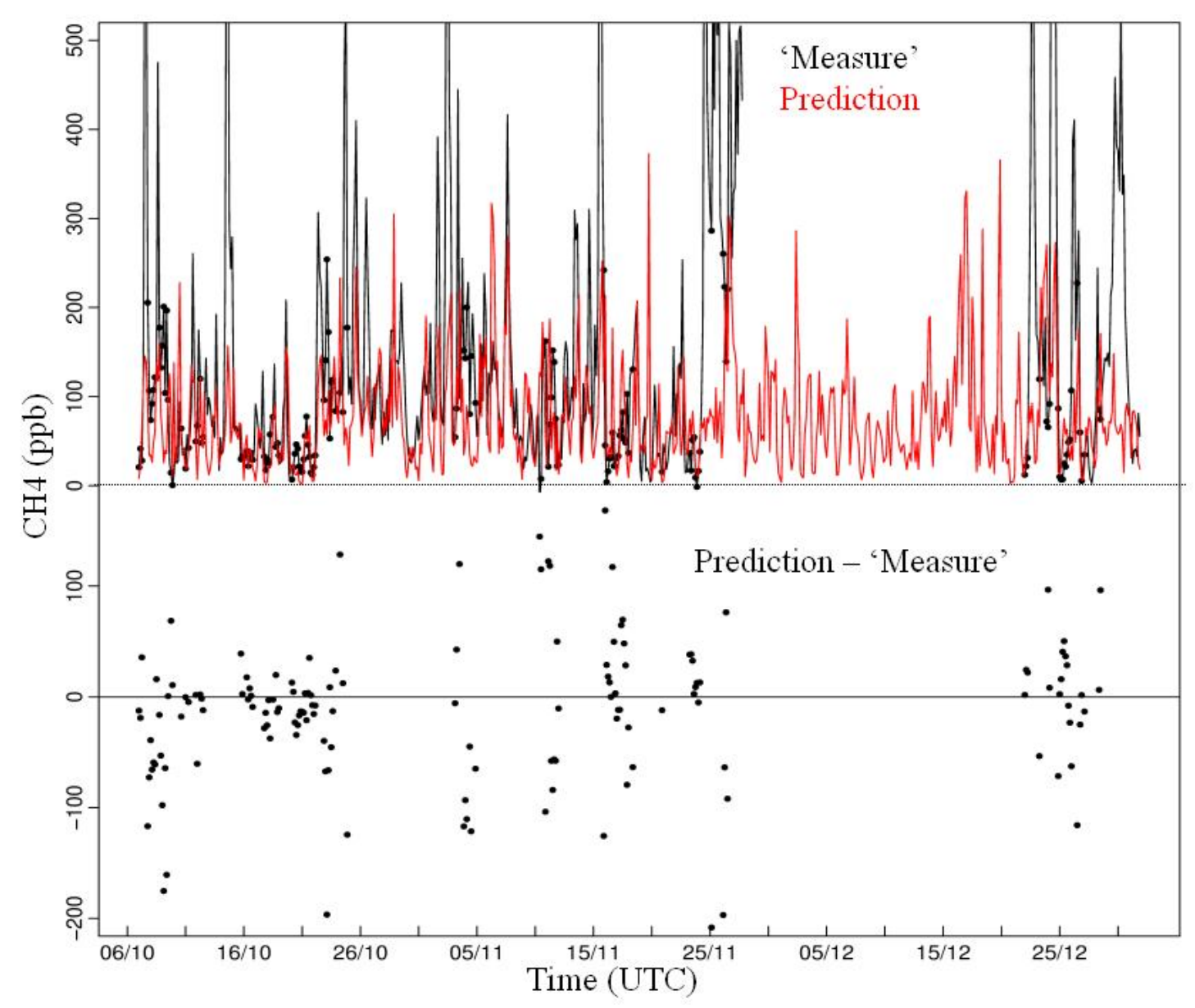

Figure 16. Background subtracted $\mathrm{CH}_{4}$ measurements (black line) and predictions (red line) from $91 \mathrm{~m}$ as a function of time (top), and their difference (bottom) for well mixed conditions (black points). 

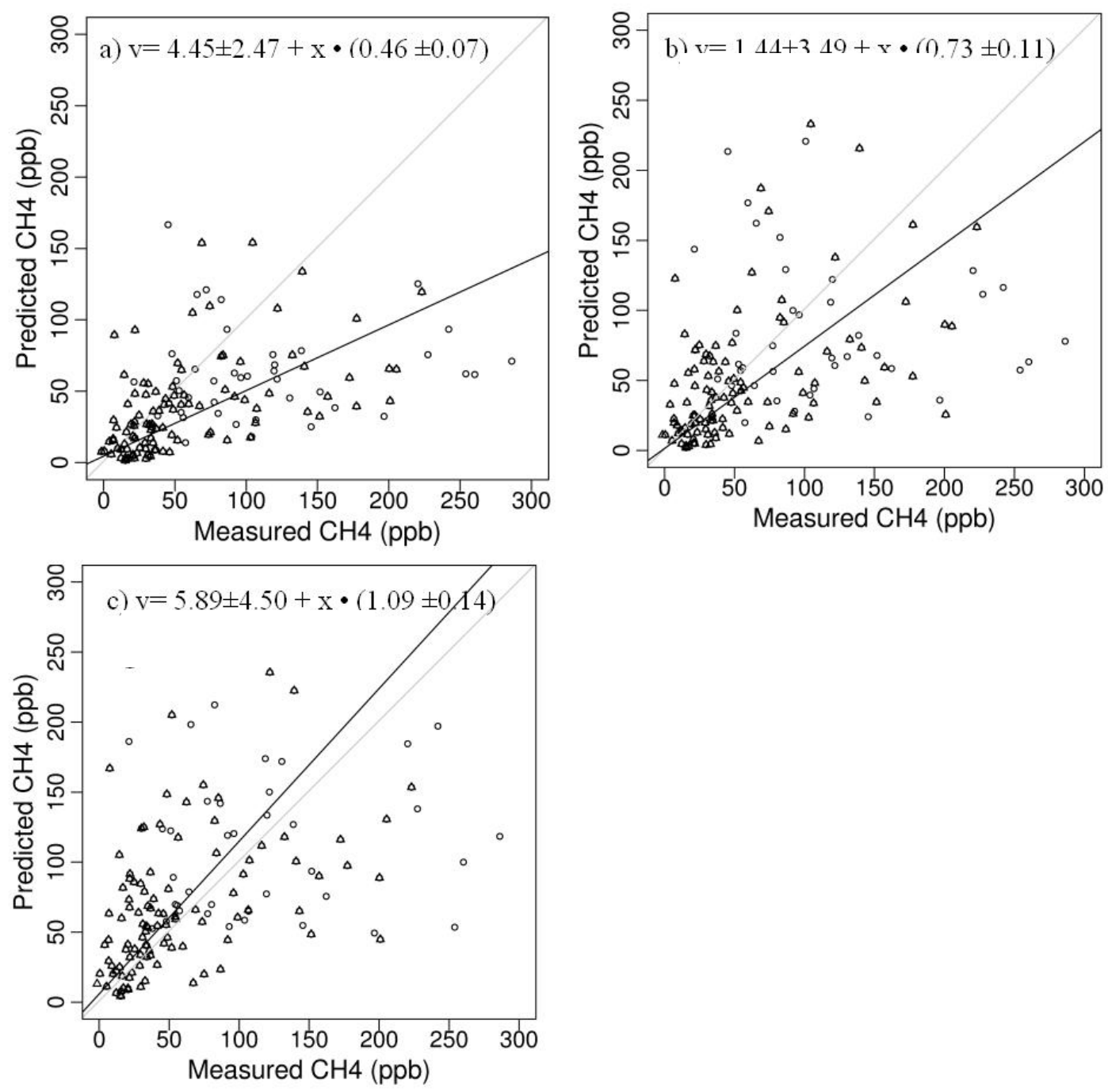

Figure 17. Predicted versus measured $\mathrm{CH}_{4}$ obtained (a) using California specific emissions without Zicorrection, (b) with Zicorrection, and (c) using Edgar 3.2 emissions with $Z$ icorrection. The symbols indicate well-mixed periods when the difference between $\mathrm{CH}_{4}$ mixing ratios measured at 91 and $483 \mathrm{~m}$ are less than 100 ppb (open circles) and less than 50 ppb (triangles), respectively.

\subsubsection{Baysian Inverse Estimates of $\mathrm{CH}_{4}$ Emissions}

\section{Error Covariance Matrix}

Using the WRF simulated meteorology in October 2007 and the total a priori emission map, the $\mathrm{CH}_{4}$ mixing ratios at WGC site are simulated for a release of 1000 particles and a release of 100 particles. The authors found that the standard error between these two simulations is about 3 $\mathrm{ppb}$, indicating 5\% particle number error $S_{\text {part }}$. This value is less than $\sim 13 \%$ particle number error for CO2 indicated by Gerbig et al. (2003a). Considering the 5\% error determined by us 
here and $\sim 13 \%$ error determined by Gerbig et al., for signals in the mixed-layer, $S_{\text {part }}$ for 100 particles is assumed as $10 \%$ in this study. For all of the following error analyses, the authors used 1000 particles in order to minimize the effect of particle number error. As the authors have indicated, $S_{\text {aggr }}$ is estimated by comparing the un-aggregated landfill signal from to the landfill signal estimated after averaging emissions over each county, which is about $11 \%$. Transport error $\underline{S}_{\text {Trans }}=\underline{\underline{S}}_{\text {TransWND }}+\underline{\underline{S}}_{\text {Trans } P B L}$ has been determined as $23 \%$ and the CH4 background error $\left(\underline{S}_{b k g d}\right)$ has been determined as $15 \%$ in section 3.3.2. As the authors have indicated, $S_{e d d y}$ is assumed as $1 \%$, and $S_{\text {emis }}$ and $\underline{\underline{S}}_{\text {ocean }}$ are assumed to be negligible.

With the assumption of independence for different error sources, the total equivalent "measurement" error is assumed to be $32 \%$ of each individual background-subtracted measurement.

\section{Source Sector Analysis}

The Bayesian "source" inverse analysis was carried out for the six source sectors for October through December 2007. As shown in Figure 18 (a), the a posteriori scaling factors for the crop agriculture (CP), landfill (LF), wetland (WL), petroleum (PL), and natural gas (NG) are not significantly different from unity (at $95 \%$ confidence). The scaling factor for livestock is $1.63 \pm$ 0.22 , suggesting the emissions from livestock are significantly ( $95 \%$ confidence) larger than the $a$ priori inventory estimates. Considering that the linear regression (Figure 17b) estimates suggest that $\mathrm{CH}_{4}$ emissions from Central California are estimated to be $37 \pm 21 \%$ higher than the annually averaged California specific $a$ priori inventories, the increase in overall emissions is largely due to the $63 \pm 22(1 \sigma) \%$ increase in estimated emissions from livestock. State-wide $a$ priori livestock emission are 9.7 $\mathrm{MMT} \mathrm{CO}_{2 \mathrm{eq}}$ (see Table 1), which includes 5.6 MMT $\mathrm{CO}_{2 \text { eq }}$ from

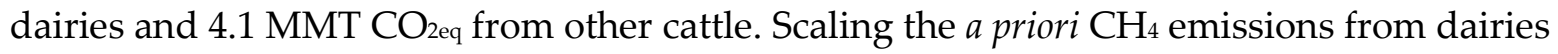
suggests that actual dairy emissions are $9.1 \pm 1.3 \mathrm{MMT} \mathrm{CO}_{2 \mathrm{eq}}$. This result is nominally consistent with or slightly less than the results of a recent study by Salas et al. (2008), which estimated total $\mathrm{CH}_{4}$ emissions from dairies in CA to be approximately 9.8 $\mathrm{MMT} \mathrm{CO}_{2 \text { eq. }}$ Except for the livestock emission source, some other sources also showed smaller differences from inventory estimates. For example, inferred $\mathrm{CH}_{4}$ emissions from crop agriculture are smaller than the annually averaged inventory, consistent to the expectation of higher $\mathrm{CH}_{4}$ emissions from the northcentral Valley during the summer due to flooded rice agriculture (Salas et al., 2006). 

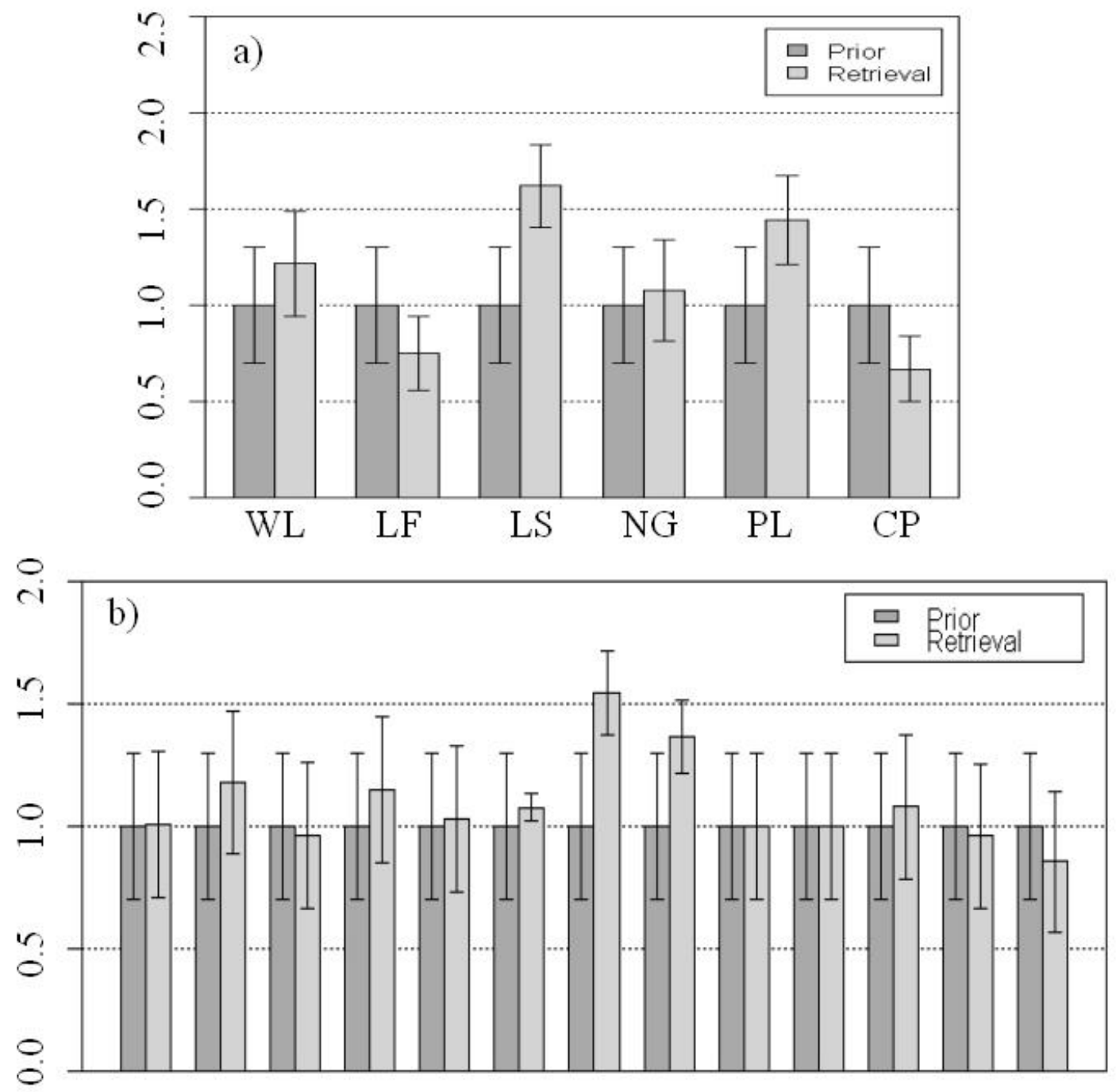

R01 R02 R03 R04 R05 R06 R07 R08 R09 R10 R11 R12 R13

Figure 18. Inversion estimates for the "source" sector analysis (a) and "region" analysis (b). A prioriand posteriorscaling factors for the six source sectors and 13 source regions are shown with corresponding $68 \%$ confidence level uncertainties.

\section{Region Specific Analysis}

The Bayesian "region" inverse analysis of emissions from the 13 California regions is shown in Figure 18(b). The a posteriori uncertainties are noticeably reduced relative to the a priori uncertainties only for regions 6,7 , and 8 , which have a strong influence on the $\mathrm{CH}_{4}$ measurements either because the land surrounds the tower site (regions 6 and 8) or has a teleconnection through the prevailing wind (region 7). The a posteriori scaling factor for region 6 is $1.08 \pm 0.06$, indicating that the posterior emissions agree well with the $a$ priori inventory estimates. Posterior scaling factors for region 7 and 8 are $1.55 \pm 0.17$ and $1.37 \pm 0.15$ respectively, 
indicating that the a posteriori emissions are greater than the a priori estimates for these two regions. The authors also note that the region analysis is consistent with the source sector analysis in that increased emissions from region 8 are consistent increased emissions from livestock.

Finally, the authors report the results of a sensitivity test in Section 6 . The a priori uncertainties were varied from $30 \%$ to $50 \%$ to investigate the effect that loosening the a priori constraint on emissions had on the inverse model results. The results of this test show that increasing the $a$ priori uncertainties will allow posterior results to be more strongly driven by measurements that have a high overlap of footprint function with the spatial distribution of the emission source. In this study, the sensitivity is about $5-15 \%$ for different sources and $1-3 \%$ for regions near WGC site.

\section{Performance of Scaling Factors from Bayesian Inverse}

After applying the scaling factors obtained from Bayesian analyses, the posterior predicted $\mathrm{CH}_{4}$ mixing ratios are compared with measurements in Figure 19. Figure 19a shows the comparison for results from the 'source analysis' with measurements. Compared to Figure $17 \mathrm{~b}$ (before inverse optimization), the fitting slope is closer to unity, and the normalized Chi-square value is slightly reduced from 1.17 to 1.11 . This suggests that the inverse optimization has slightly improved the agreement between the measured and predicted $\mathrm{CH}_{4}$ signals but that on order $10 \%$ of the variance remains unexplained. It is possible that the apparent underestimation of the errors may be due to positive correlation between the error sources that the authors assumed independent. Similar results are obtained for the region analysis, as shown in Figure 19b. In both cases, the slopes after optimization are still slightly less than unity, likely because of the weight on the a priori scaling factors. The authors note that relaxing the $a$ priori uncertainties on the scaling factors from $30 \%$ to $50 \%$, allows the optimization to adjust the posterior scaling factors further from their a priori values (Section 6).
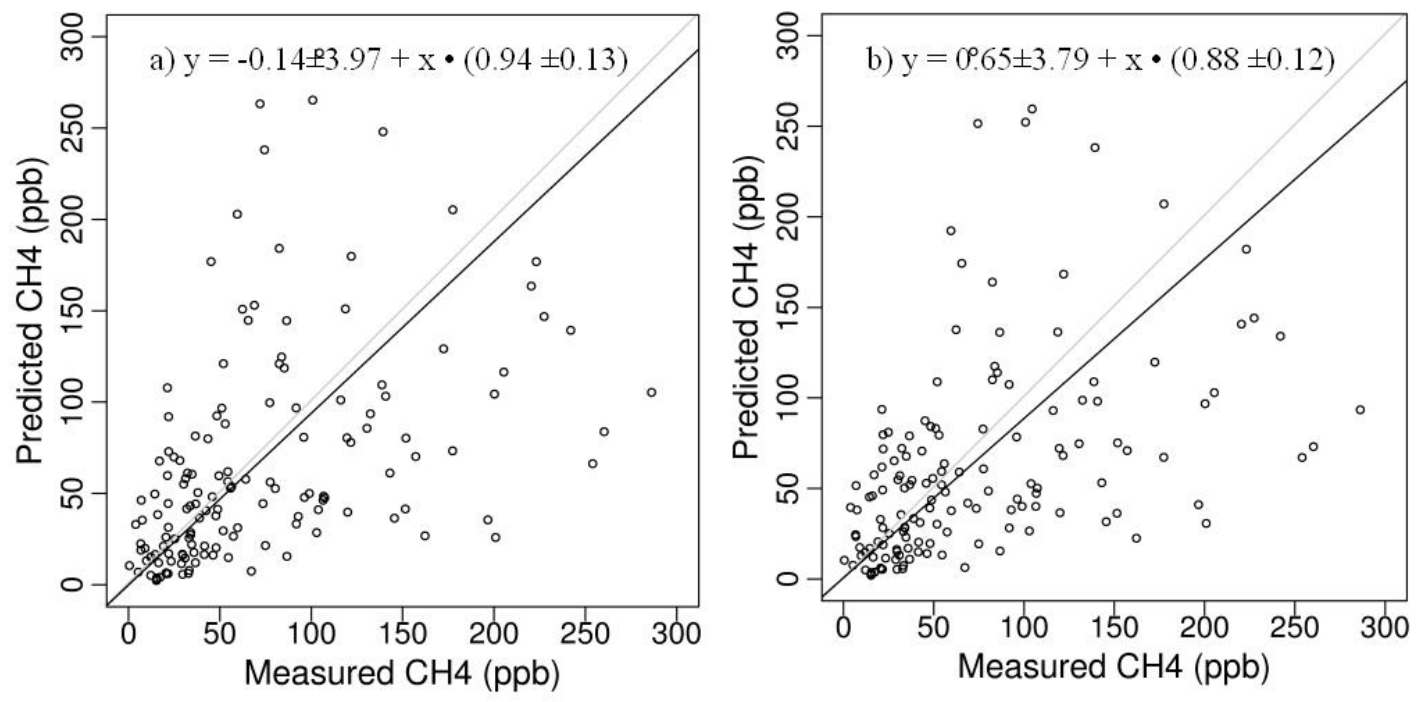
Figure 19. Comparison of $\mathrm{CH}_{4}$ mixing ratios between measurements and predictions modified using posterior scaling factors obtained from the "source" analysis (a) and "region" analysis (b).

\subsection{Design of a Future Observation Network}

The above region analysis shows that emissions from regions 6, 7 and 8 are constrained by the $91 \mathrm{~m}$ measurements at WGC. This is because they either surround the tower (i.e., regions 6 and 8) or have a strong influence on air reaching the tower through prevailing winds from the Bay Area to the Sacramento Valley (i.e., region 7). This observation provides an insight into the spatial domain that can be effectively investigated with the tower measurements and suggests that a network of towers would be required to accurately constrain the multiple regions and air basins in California. In principle, measurements from multiple towers would also be combined in a larger inverse analysis to provide more stringent constraints on emissions from regions that influence several towers.

\subsubsection{Use of multiple measurement stations}

As shown in Fig. 20, the mean monthly footprint maps for 7 stations exhibit reasonably complete spatial coverage of the main regions of California. The exceptions are parts of regions 1 and 10, where the $\mathrm{CH}_{4}$ inventory emissions are very small (see Fig. 2).
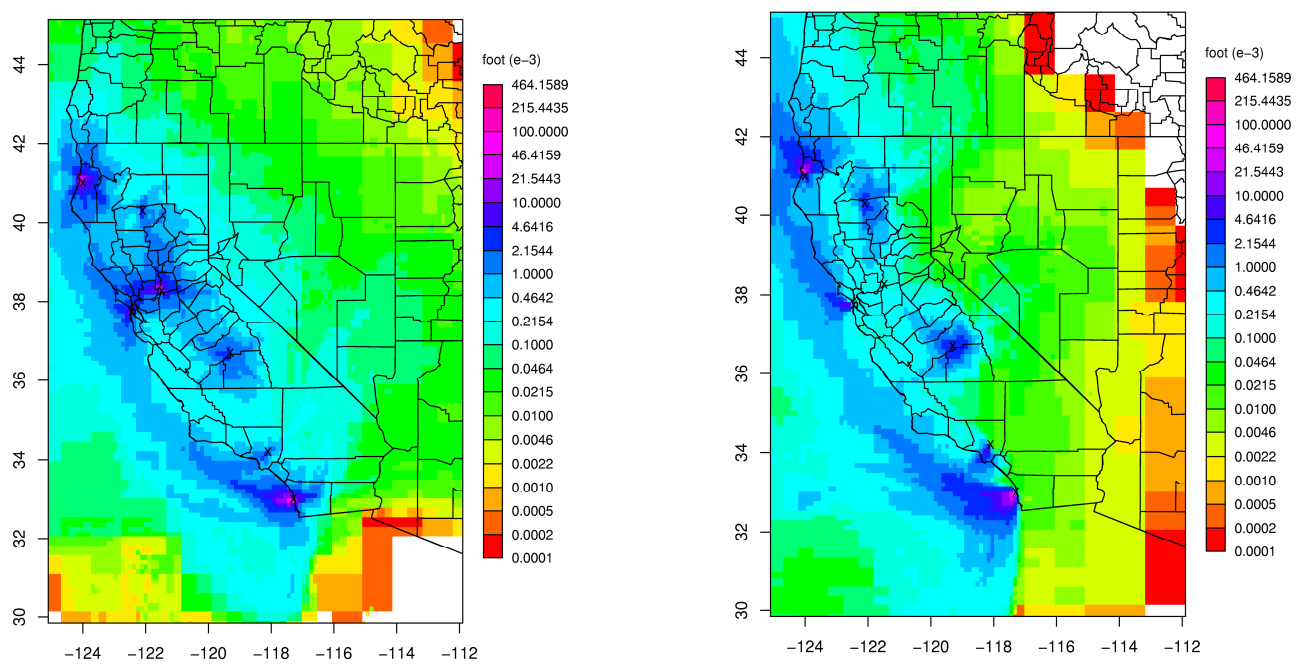

Figure 20. The monthly mean footprint maps for 7 observation stations simulated for Oct 2007 (left) and Jul 2008 (right).

To evaluate the constraint of measurements from current stations and proposed stations to the inverse of California's $\mathrm{CH}_{4}$ emissions, the authors first examined four ideal inverse tests using varied amounts of pseudo-data to retrieve emissions for the "source analysis" and "region analysis" described above. In both cases, the inverse results were calculated using pseudo-data computed for four cases in October 2007, and July 2008; which are cases with 3 hour resolution 
WGC data, 3 hour resolution WGC and 12 hour resolution STR data, 12 hour resolution data from all 7 stations, and 3 hour resolution data from all 7 stations. The results of all analyses are provided in Appendix 6.2. Here, the authors summarize the results from modeling with all 3 hour resolution data from 7 stations in Fig. 21 and Fig. 22. Because the different sources and regions have very different emissions levels, the results are re-plotted to show the $\mathrm{CO}_{2}$ equivalent emissions of $\mathrm{CH}_{4}$ (rather than scaling factors). Generally, all source regions and source sectors are estimated with significant reduction in uncertainty, with the exception of regions $1,2,3$, and 13 .
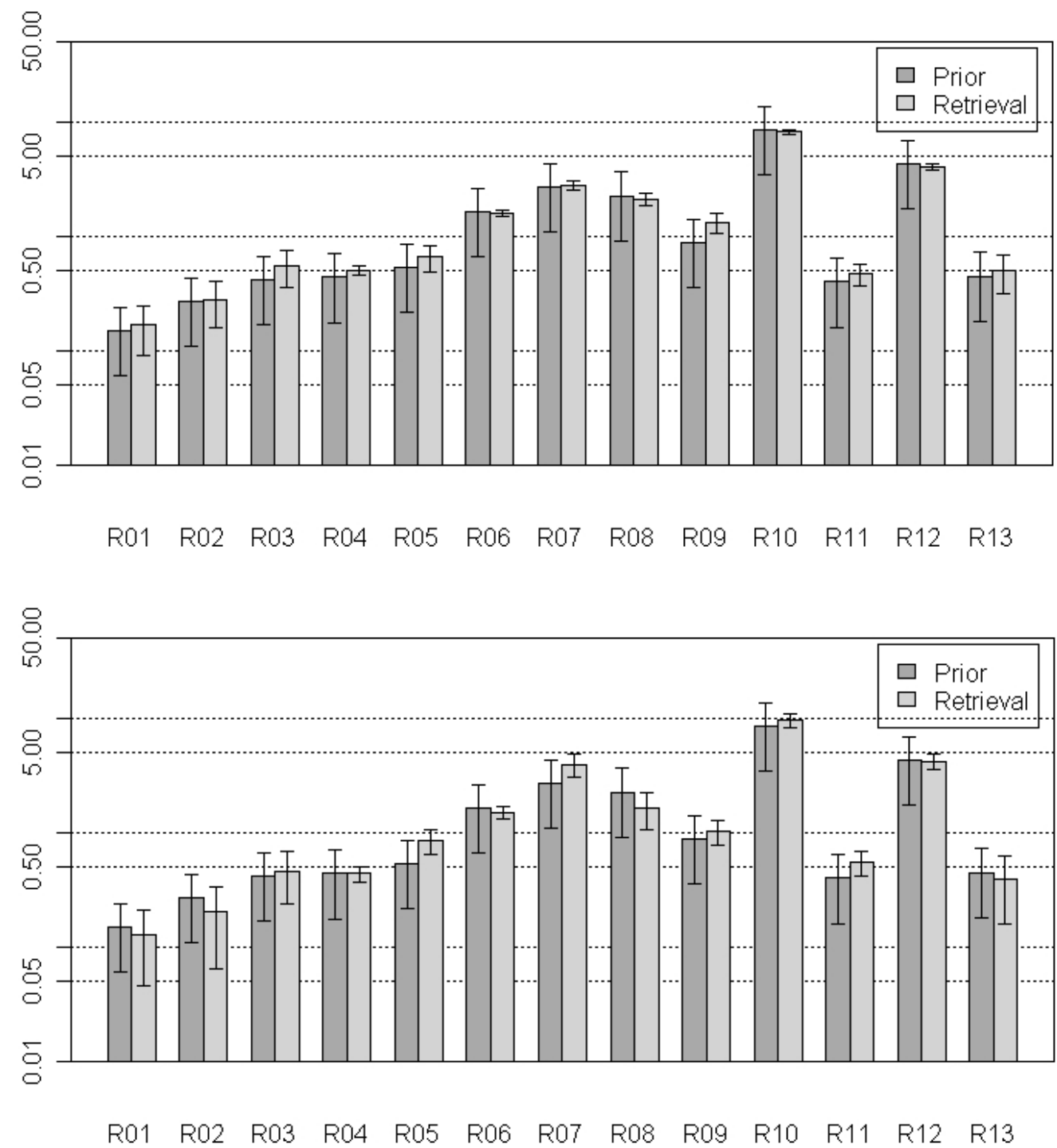

Figure 21. Inverse model estimates of total $\mathrm{CH}_{4}$ emissions for 13 regions in California obtained for October 2007 (top) and July 2008 (bottom), based on the analysis of 3 hour resolution pseudo-data from 7 stations. Units are $\mathrm{MMTCO}_{2}$ equivalent. 

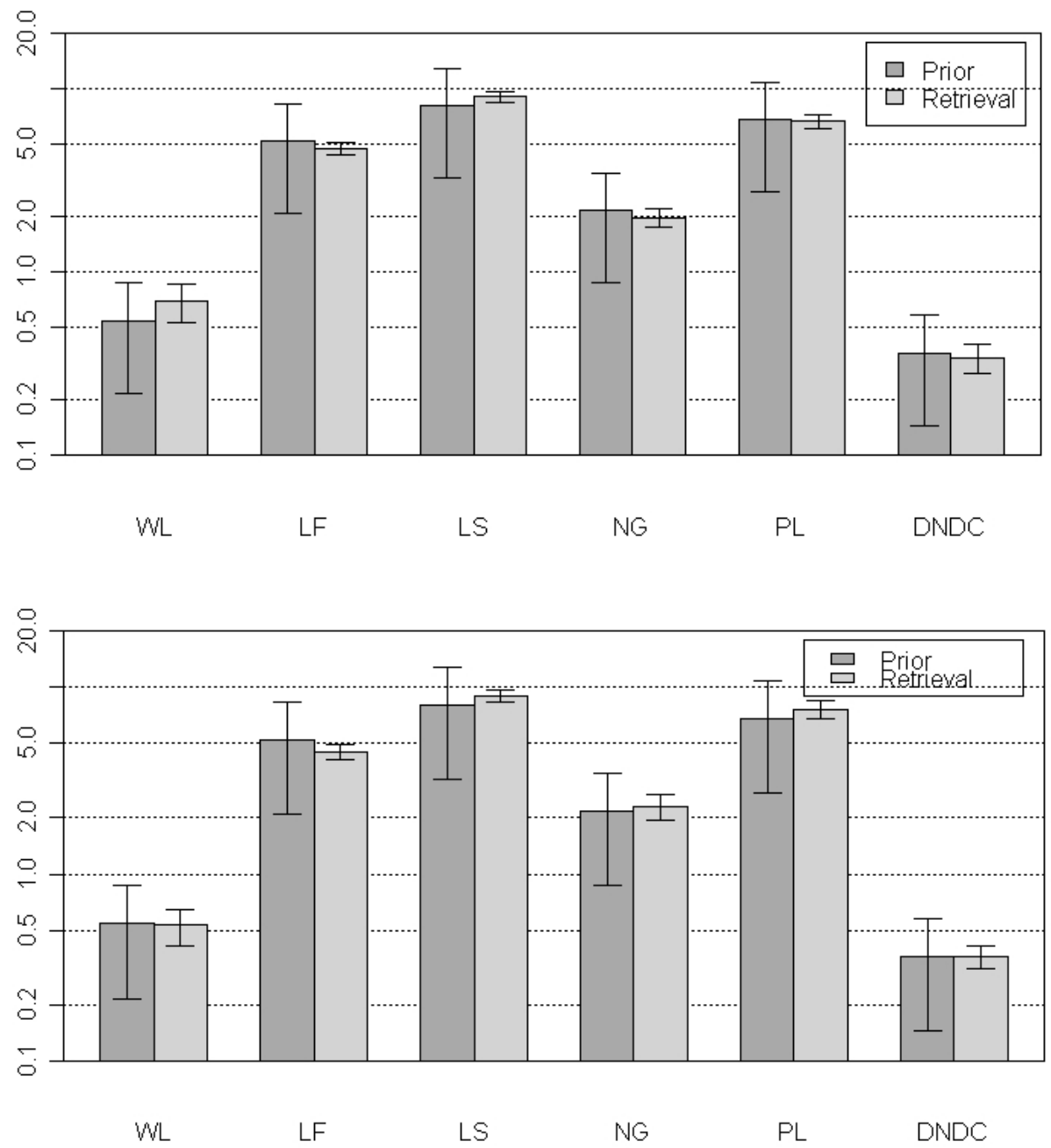

Figure 22. The inverse results of source analysis for $\mathrm{CH}_{4}$ emissions from different sources in October 2007 (top) and July 2008 (bottom), based on the analysis of 3 hour pseudo-data from 7 stations. Units are $\mathrm{MMTCO}_{2}$ equivalent.

\subsubsection{Use of Radiocarbon Methane $\left({ }^{14} \mathrm{CH}_{4}\right)$ to Identify Fossil $\mathrm{CH}_{4}$ Emissions}

The predicted radiocarbon content of atmospheric $\mathrm{CH}_{4}$ vary diurnally, synoptically, and monthly, but produce time averaged signals that are measurable, provided that large ( 100 liter) air samples can be collected and purified. As shown in Fig. 23, the monthly-mean midday ${ }^{14} \mathrm{CH}_{4}$ at $91 \mathrm{~m}$ across the state indicates that the largest depletions (corresponding to the largest fossil fuel inputs) occurred near San Francisco, Sacramento, and Los Angeles. The extent to which the $\mathrm{CH} 4$ sources in these regions affected the larger-scale $\mathrm{CH}_{4}$ radiocarbon content varied over the year as atmospheric mixing and source strength varied. For example, the radiocarbon content in the Los Angeles air basin in January was elevated 15-20\%o compared to the other three months simulated. There was also a large depleted plume moving out over the Pacific towards the south from the SF Bay region in January that was not present in the other months 
simulated. This plume was likely caused by strong offshore winds in the region, which can be strong during the winter.
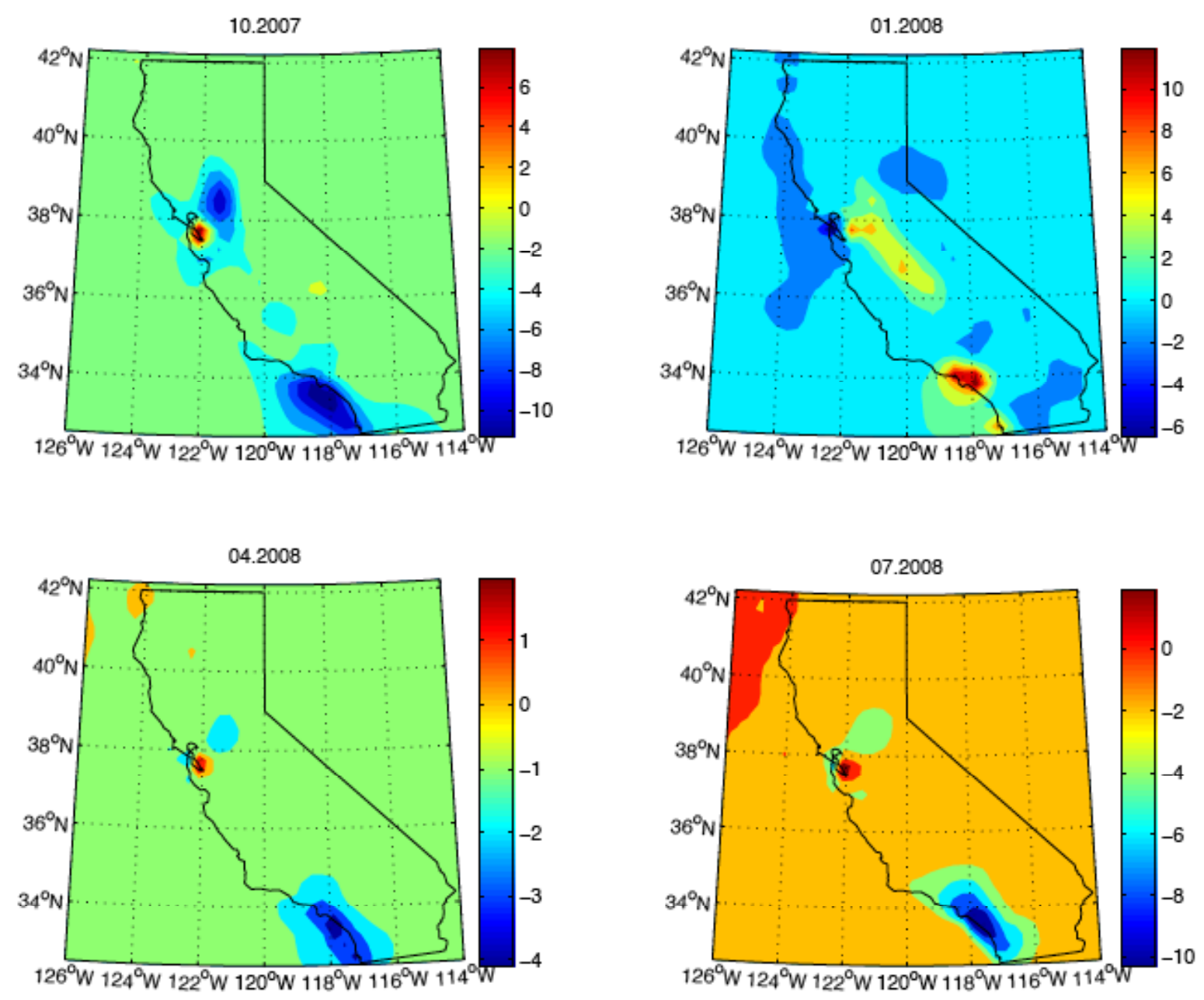

Figure 23. Predicted monthly mean daytime ${ }^{14} \mathrm{CH}_{4}$ signals (per mil) from fossil and biogenic $\mathrm{CH}_{4}$ emissions in California.

\subsection{Recommendations}

\subsection{Refinement of Atmospheric Transport Model}

The results of this work highlight the need for careful estimation and minimization of errors in the transport model. The comparison between the radar profiler measurements and WRF-STILT predictions of PBL height show a systematic overestimation in the WRF-STILT predictions, while the sensitivity test shows that predicted $\mathrm{CH}_{4}$ emission estimates are sensitive to PBL height. The error in WRF-STILT predictions of PBL height may be a result of imperfect land surface parameterization in WRF that does not account for a suppression of PBL height in the Central Valley. Possible causes for overestimation of PBL height include the Pacific low over 
California's interior and low ratios of sensible to latent heat (Bowen ratios) driven by agricultural irrigation as shown in recent model studies of California (Kueppers et al., 2008; Lobel and Bonfils, 2008). Because of the limited amount of PBL height data, the present work should be considered a first step toward a more comprehensive analysis employing profiler data from additional profiler sites and over longer periods. Other trace gases are also likely to provide important constraints on boundary layer mixing and their use should be explored. For example, sufficiently detailed inventories for reasonably long-lived criteria pollutants (e.g., CO) may allow effective testing of the transport model. Similarly, although the absolute fluxes may of ${ }^{222} \mathrm{Rn}$ fluxes are poorly known, as long as the diurnal variations in average flux are reasonably small, radon may provide a constraint in errors in modeling nighttime boundary layer heights. The authors expect that some combination of these efforts will substantially improve the fidelity of the WRF-STILT PBL predictions and hence accuracy of GHG emission inversions.

\subsection{Long-term Measurements for Trend Detection}

The first year of data from the observations at Walnut Grove and Sutro towers and the inverse modeling described above, provide a starting point for analyzing the magnitude of Central California's GHG emissions. Because emissions of GHGs from both natural and biogeochemical and anthropogenic processes depend on other time-varying drivers (e.g., climate, the economy, and human management), it is reasonable to expect that emissions will change from over multiple time scales from seasons to years to decades. Hence, efforts to control annual GHG emissions to within a target based on some reference point in time need to include a quantitative measure of both the trends and inter-annual variations in emissions. This will require that GHG emissions need to be measured over multiple years.

\section{3. $\mathrm{N}_{2} \mathrm{O}$ and Halocarbon Measurements}

Recent revisions to California's GHG emission inventory, suggest that $\mathrm{N}_{2} \mathrm{O}$ emissions constitute the second largest contribution to global warming after $\mathrm{CO}_{2}$ (Bemis, 2006), slightly greater than that from $\mathrm{CH}_{4}$. However, like $\mathrm{CH}_{4}$, the inventory estimates of $\mathrm{N}_{2} \mathrm{O}$ emissions are highly uncertain (Farrell et al., 2004). To address the gap in verified regional $\mathrm{N}_{2} \mathrm{O}$ emissions estimates, the authors expect estimates of $\mathrm{N}_{2} \mathrm{O}$ emissions from Central California (and other regions) could be achieved by applying a combination of continued flask measurements using a combination of the radon mixing model and the inverse model approaches applied to $\mathrm{CH}_{4}$ above in this report. However, further analysis of the $\mathrm{N}_{2} \mathrm{O}$ flask measurements is needed to determine whether the relatively infrequent (12 hour) measurements are sufficient for the inverse model analysis or whether continuous $\mathrm{N}_{2} \mathrm{O}$ measurements (as performed for $\mathrm{CH}_{4}$ at WGC) are necessary. In addition to the measurements, the authors also note that bottom up modeling studies of $\mathrm{N}_{2} \mathrm{O}$ emissions from all source sectors (e.g., agriculture, waste water, and biomass and fossil fuel combustion) should be improved to provide a priori information for the inverse modeling.

Although likely currently smaller than $\mathrm{CH}_{4}$ and $\mathrm{N}_{2} \mathrm{O}$ emissions on $\mathrm{CO}_{2}$ equivalent scale, halocarbon emissions are expected to increase over time, becoming a large fraction of California's non- $\mathrm{CO}_{2}$ GHG budget. Given the initial results from this study, measurement of 
halocarbon mixing ratios at tower sites in California may offer the same potential for inverse model analysis as $\mathrm{CH}_{4}, \mathrm{~N}_{2} \mathrm{O}$. As above, there is a question of how frequently measurements need to be taken in order to provide a sufficiently precise estimate of emissions. However, given the very limited information currently available for most halocarbon species, even 12 hourly flask sampling may provide sufficient data. As with $\mathrm{N}_{2} \mathrm{O}$, bottom up estimates of spatially resolved halocarbon emissions will be valuable for any inverse modeling efforts.

\subsection{Stable Isotopic $\mathrm{CH}_{4}$ Measurements}

Identifying which source sectors are actually responsible for the emissions in a given region (and which sectors are responsible for future reductions or increases) will be critical for determining the success of GHG emission control strategies being contemplated by California. Generally, multiple source sectors contribute to the emissions of nearly all GHGs at the regional scale in California. As shown above, inventory estimates of $\mathrm{CH}_{4}$ emissions suggest significant emissions from landfills, livestock, natural gas transmission and use, and petroleum facilities and use. Hence, research is needed to investigate techniques that can separate the relative contributions of GHG emissions from different source sectors. One promising avenue is the measurement and analysis of additional atmospheric trace gas species. In particular, stable (and radiocarbon) isotopes ${ }^{13} \mathrm{CO}_{2}$ (Pataki et al., 2007) and ${ }^{14} \mathrm{CO}_{2}$ (Turnbull et al., 2007) have been used effectively for this purpose in contemporary studies, while ${ }^{13} \mathrm{CH}_{4}$ and $\mathrm{CHD}$ have been used in studies of global paleoclimate (Whiticar and Schaefer, 2007). Efforts to measure the stable isotopic signatures near individual sources as well in atmospheric samples collected at towers is hence likely to provide additional constraints on GHG emission sources in California.

\subsection{Radiocarbon $\mathrm{CH}_{4}$ Measurements}

Although preliminary, the results ${ }^{14} \mathrm{CH}_{4}$ content in the atmosphere indicate that radiocarbon measurements are sensitive markers of fossil fuel sources of $\mathrm{CH}_{4}$ emission. Further work must be done to better constrain the ${ }^{14} \mathrm{C}$ content of non-fossil sources (e.g., wetlands, agriculture) to improve the simple values applied here. With this information, atmospheric ${ }^{14} \mathrm{CH}_{4}$ mixing ratio predictions could be applied in an inverse approach, similar to that described above for $\mathrm{CH}_{4}$, to estimate the sensitivity of estimated emission fields to changes in diurnal, synoptic, monthly, and seasonal time frames. This sensitivity analysis will allow the design of a rational sampling strategy to best take advantage of the unique value of radiocarbon as a tracer of fossil $\mathrm{CH}_{4}$ emissions.

\subsection{Statewide Measurement Network and Other Platforms}

Data from additional measurements locations will be necessary to broaden the spatial scale over which the inverse models can be applied to constrain the total GHG emissions from California. These should include tower measurements as explored in Section 3.4 above. However, given the difficulty of obtaining access to towers in desirable locations, the authors emphasize that site selection will likely require considerable effort to find candidate towers, model the footprints 
In addition to the towers, intensives with aircraft, and remote sensing from space provide additional important data. For example, the California Air Resources Board and NASA conducted joint observations (ARCTAS-CA) of air quality and GHG species over California in June, 2008. In winter 2009, the NASA Orbiting Carbon Observatory (OCO) and the Japanese Space Agency Greenhouse Gas Observing Satellite (GOSAT) are expected for launch. Both satellites will provide column integrated $\mathrm{CO}_{2}$ measurements, but GOSAT, in particular, will provide column integrated $\mathrm{CH}_{4}$ which might be used in combination with other measurements to improve estimates of California's $\mathrm{CH}_{4}$ budget. Finally, future campaigns to study air quality and climate such as the joint CEC-CARB-NOAA CALNEX 2010 campaign will provide intensive measurements over approximately month-long time scales that will likely be useful for process-based studies. 


\subsection{References}

Bergamaschi, P., M. Krol, F. Dentener, A. Vermeulen, F. Meinhardt, F. Graul, M. Ramonet, W. Peters, and E. J. Dlugokencky (2005), Inverse modelling of national and European CH4 emissions using the atmospheric zoom model TM5. Atmos. Chem. Phys., 5, 2431-2460.

Bergamaschi, P., M. Braunlich, T. Marik, and C. A. M. Brenninkmeijer (2000), Measurements of the carbon and hydrogen isotopes of atmospheric methane at Izana, Tenerife: Seasonal cycles and synoptic-scale variations, J. Geophys. Res., 105(D11), 14531-14546.

Bergamaschi, P., et al. (2007), Satellite chartography of atmospheric methane from SCIAMACHY on board ENVISAT: 2. Evaluation based on inverse model simulations, J. Geophys. Res., 112, D02304, doi:10.1029/2006JD007268.

Bemis, G. (2006), Inventory of California Greenhouse Gas Emissions and Sinks 1990 to 2004. California Energy Commission (Report \# CEC-600-2006-013-SF).

Bianco, L., and J. M. Wilczak (2002), Convective boundary layer depth: improved measurement by Doppler radar wind profiler using fuzzy logic methods. J. Atmos. Ocean. Technol., 19(11), 1745-1758.

Bianco, L., J. M. Wilczak, and A. B. White (2008), Convective boundary layer depth estimation from wind profilers: Statistical comparison between an automated algorithm and expert estimations, J. Atmos. Ocean. Technol., 25(8), 1397-1413.

Biraud, S., P. Ciais, M. Ramonet, et al. (2000), European greenhouse gas emissions estimated from continuous atmospheric measurements and radon 222 at Mace Head, Ireland, J. Geophys. Res., 105(D1), 1351-1366.

Bubier, J., T. Moore, K. Savage, and P. Crill (2005), A comparison of methane flux in a boreal landscape between a dry and a wet year, Global Biogeochem. Cycles, 19, GB1023, doi:10.1029/2004GB002351.

Butler, T. M., P. J. Rayner, I. Simmonds, and M. G. Lawrence (2005), Simultaneous mass balance inverse modeling of methane and carbon monoxide, J. Geophys. Res., 110, D21310, doi:10.1029/2005JD006071.

CARB (2007), California 1990 Greenhouse Gas Emissions Level and 2020 Emissions Limit. California Air Resources Board Staff Report.

Carr, N.(2004), Overall Waste Stream Composition Data. California Integrated Waste Management Board: 1999 California Statewide Waste Disposal Characterization Study. (http://www.ciwmb.ca.gov/WasteChar/Study1999/OverTabl.htm).

Census of Agriculture 2002 - Volume 1 California County Level Data. National Agricultural Statistical Services for U.S. Agriculture Statistical Information and Graphs. United States Department of Agriculture. (http://www.nass.usda.gov/census/census02/volume1/ca/index2.htm). 
Chanton, J. P., C. M. Rutkowski, and B. Mosher (1999), Quantifying Methane oxidation from landfills using stable isotope analysis of downwind plumes, Environ. Sci. Technol., 33(21), 3755-3760, 1999.10.1021/es9904033.

Chen, Y.-H., and R. G. Prinn (2006), Estimation of atmospheric methane emissions between 1996 and 2001 using a three-dimensional global chemical transport model, J. Geophys. Res., 111, D10307, doi:10.1029/2005JD006058.

Chen S.-H., and W.-Y. Sun (2002), A one-dimensional time dependent cloud model. J. Meteor. Soc. Japan, 80, 99-118.

Cooley, H. S., W. J. Riley, M. S. Torn, and Y. He (2005), Impact of agricultural practice on regional climate in a coupled land surface mesoscale model, J. Geophys. Res., 110, ISI:000227065800002.

Chou, M.-D., and M. J. Suarez (1994), An efficient thermal infrared radiation parameterization for use in general circulation models. NASA/TM-104606, 10, 84pp.

Czepiel, P. M., J. H. Shorter, B. Mosher, E. Allwine, J. B. McManus, R. C. Harriss, C. E. Kolb, and B. K. Lamb (2003), The influence of atmospheric pressure on landfill methane emissions, Waste Management, 23 (7), 593-598, doi:10.1016/S0956-053X(03)00103-X.

Dentener, F., W. Peters, M. Krol, M. van Weele, P. Bergamaschi, and J. Lelieveld (2003), Interannual-variability and trend of $\mathrm{CH} 4$ lifetime as a measure for $\mathrm{OH}$ changes in the 1979-1993 time period, J. Geophy. Res., 108(D15), 442, doi: 10.1029/2002JD002916.

Dye, T.S., C. G. Lindsey, and J. A. Anderson (1995), Estimates of mixing depth from “boundary layer" radar profilers. Preprints from the 9th Symposium on Meteorological Observations and Instrumentation, Charlotte, NC, March 27-31, 156-160 (STI-94212-1451).

Duval, J.S., Jones, W.J., Riggle, F.R., and Pitkin, J.A. (1989). Equivalent uranium map of conterminous United States, USGS Open-File Report 89-478.

USEPA, (2004), Inventory of U.S. Greenhouse Gas Emissions and Sinks: 1990-2002. Washington D.C., U.S. Environmental Protection Agency, April 15, 2004. EPA 430-R-04-003.

Farrell, A., Kerr, A.C., Brandt, A.R., Torn, M.S., and G. Franco (2005). Research Roadmap for Greenhouse Gas Inventory Methods. California Energy Commission: Public Interest Energy Research. (CEC-500-2005-097)

Franco, G. (2002). Inventory of California Greenhouse Gas Emissions and Sinks: 1990-1999. California Energy Commission: Public Interest Energy Research. (CEC-600-02-001F).

Fischer, M.L., W.J. Riley, and S.Tonse. 2005. Development of an Implementation Plan for Atmospheric Carbon Monitoring in California. California Energy Commission, PIER Energy-Related Environmental Research. CEC-500-2005-123 (LBNL-57485).

Gerbig C., J. C. Lin, S. C. Wofsy, B. C. Daube, A. E. Andrews, B. B. Stephens, P. S. Bakwin, and C. A. Grainger (2003a), Toward constraining regional-scale fluxes of $\mathrm{CO}_{2}$ with atmospheric 
observations over a continent: 1 . Observed spatial variability from airborne platforms, J. Geophys. Res., 108(D24), 4756, doi:10.1029/2002JD003018.

Gerbig, C., J. C. Lin, S. C. Wofsy, B. C. Daube, A. E. Andrews, B. B. Stephens, P. S. Bakwin, and C. A. Grainger (2003b), Toward constraining regional-scale fluxes of $\mathrm{CO}_{2}$ with atmospheric observations over a continent: 2. Analysis of COBRA data using a receptor-oriented framework, J. Geophys. Res., 108(D24), 4757, doi:10.1029/2003JD003770.

Gimson, N. R. and Uliasz, M., 2003: The determination of agricultural methane emissions in New Zealand using receptor-oriented modelling techniques. Atmos. Environ., 37, 3903-3912.

Gloor, M., et al. (1999), A model-based evaluation of inversions of atmospheric transport, using annual mean mixing ratios, as a tool to monitor fluxes of nonreactive trace substances like $\mathrm{CO}_{2}$ on a continental scale, J. Geophys. Res., 104(D12), 14,245-14,260.

Grell, G.A. and D. Devenyi (2002), A generalized approach to parameterizing convection combining ensemble and data assimilation techniques, Geoph. Res. Let., 29(14), 10.1029/2002GL015311.

Hansen, J., Mki. Sato, J. Glascoe, and R. Ruedy, 1998: A common sense climate index: Is climate changing noticeably? Proc. Natl. Acad. Sci., 95, 4113-4120.

Hansen, J., 2004: Defusing the global warming time bomb. Sci. Amer., 290, no. 3, 68-77.

Harriss, R.C. (1994), Reducing urban sources of methane: an experiment in industrial ecology. Industrial Ecology and Global Change, Cambridge Univ. Press, pp. 223-238.

Hein, R., P. J. Crutzen, and M. Heimann (1997), An inverse modeling approach to investigate the global atmospheric methane cycle. Global Biogeochemical Cycles, 11(1), 43-76.

Hirsch, A. I. (2006), On using radon-222 and $\mathrm{CO}_{2}$ to calculate regional scale CO2 fluxes, Atmos. Chem. Phys. Discuss, 6, 10929-10958.

Hofmann, D. J., J. H. Butler, E. J. Dlugokencky, J. W. Elkins, K. Masarie, S. A. Montzka, and P. Tans, (2006): The role of carbon dioxide in climate forcing from 1979 - 2004: Introduction of the Annual Greenhouse Gas Index, Tellus B, 58B, 614-619.

Houweling, S., T. Kaminski, F. Dentener, J. Lelieveld, and M. Heimann (1999), Inverse modeling of methane sources and sinks using the adjoint of a global transport model. J. Geophys. Res., 104(D21), 26137-26160.

Houweling et al., 2006, Atmospheric constraints on global emissions of methane from plants, Geophys. Res. Lett., 33, L15821, doi:10.1029/2006GL026162.

IPCC (2006) Guidelines for National Greenhouse Gas Inventories(http://www.ipccnggip.iges.or.jp/public/2006gl/index.htm)

IPCC (2007), IPCC Fourth Assessment Report (AR4), “Climate Change 2007”. 
Kaminski, T., P. J. Rayner, M. Heimann, and I. G. Enting (2001), On aggregation errors in atmospheric transport inversions, J. Geophys. Res., 106(D5), 4703-4715.

Kueppers, L. M., M. A. Snyder, and L. C. Sloan, (2007), Irrigation cooling effect: Regional climate forcing by land-use change. Geophys. Res. Lett., 34, L03703.

Kort, E. A., J. Eluszkiewicz, B. B. Stephens, J. B. Miller, C. Gerbig, T. Nehrkorn, B. C. Daube, J. O. Kaplan, S. Houweling, and S. C. Wofsy (2008), Emissions of CH4 and N2O over the United States and Canada based on a receptor-oriented modeling framework and COBRA-NA atmospheric observations, Geophy. Res. Lett., 35, L18808, doi:10.1029/2008GL034031.

Levin, I., H. Glatzel-Mattheier, T. Marik, et al. (1999), Verification of German methane emission inventories and their recent changes based on atmospheric observations, J. Geophys. Res. 104(D3), 3447-3456.

Lelieveld, J., P. J. Crutzen, and F. J. Dentener (1998), Changing concentration, lifetime, and climate forcing of atmospheric methane, Tellus B, 50, 128-150.

Lin Y.-L., R. D. Farley, and H. D. Orville (1983), Bulk parameterization of the snow field in a cloud model. J. Appl. Meteor., 22, 1065-1092.

Lin, J. C., and C. Gerbig (2005), Accounting for the effect of transport errors on tracer inversions, Geophys. Res. Lett., 32, L01802, doi:10.1029/2004GL021127.

Lin, J. C., C. Gerbig, S. C. Wofsy, A. E. Andrews, B. C. Daube, C. A. Brainger, B. B. Stephens, P. S. Bakwin, and D. Y. Hollinger (2004), Measuring fluxes of trace gases at regional scales by Lagrangian observations: Application to the CO2 Budget and Rectification Airborne (COBRA) study, J. Geophys. Res., 109, D15304, doi:10.1029/2004JD004754.

Lin, J. C., C. Gerbig, S. C. Wofsy, A. E. Andrews, B. C. Daube, K. J. Davis, and C. A. Grainger (2003), A near-field tool for simulating the upstream influence of atmospheric observations: The Stochastic Time-Inverted Lagrangian Transport (STILT) model, J. Geophys. Res., 108(D16), 4493, doi:10.1029/2002JD003161.

Lobel, D.B., C. Bonfils, (2008) The Effect of Irrigation on Regional Temperatures: A Spatial and Temporal Analysis of Trends in California, 1934-2002, J. Climate., 21, 2063-2071.

Mau, S., D. L. Valentine, J. F. Clark, J. Reed, R. Camilli, and L. Washburn (2007), Dissolved methane distributions and air-sea flux in the plume of a massive seep field, Coal Oil Point, California, Geophys. Res. Lett., 34, L22603.

Mesinger, F., G. DiMego, E. Kalnay, K. Mitchell, P. C. Shafran, W. Ebisuzaki, D. Jovic, J. Woollen, E. Rogers, E. H. Berbery, M. B. Ek, Y. Fan, R. Grumbine, W. Higgins, H. Li, Y. Lin, G. Manikin, D. Parrish, and W. Shi (2006), North American Regional Reanalysis, Bull. Amer. Meteor. Soc., 87(3), 343-360.

Mikaloff Fletcher, S. E., P. P. Trans, L. M. Bruhwiler, J. B. Miller, and M. Heimann (2004a), CH4 sources estimated from atmospheric observations of $\mathrm{CH} 4$ and its $13 \mathrm{C} / 12 \mathrm{C}$ isotopic ratios: 1 . 
Inverse modeling of source processes, Global Biogeochem. Cycles, 18, doi: 10.1029/2004GB002223.

Mikaloff Fletcher, S. E., P. P. Trans, L. M. Bruhwiler, J. B. Miller, and M. Heimann (2004b), CH4 sources estimated from atmospheric observations of $\mathrm{CH} 4$ and its $13 \mathrm{C} / 12 \mathrm{C}$ isotopic ratios: 2 . Inverse modeling of $\mathrm{CH} 4$ fluxes from geographical regions, Global Biogeochem. Cycles, 18, doi: 10.1029/2004GB002224

Miller, J. B., and P. P. Tans (2003), Calculating isotopic fractionation from atmospheric measurements at various scales, Tellus B, 55(2), 207-214.

Mlawer, E. J., S. J. Taubman, P. D. Brown, M. J. Iacona, and S. A. Clough (1997), Radiative transfer for inhomogeneous atmospheres: RRTM, a validated correlated-k model for the longwave, J. Geophys. Res., 102, 16663-16682.

Olivier, J. G. J., J. A. Van Aardenne, F. Dentener, L. Ganzeveld, and J. A. H. W. Peters (2005), Recent trends in global greenhouse gas emissions: regional trends and spatial distribution of key sources. In: “Non-CO2 Greenhouse Gases (NGGG-4)”, A. Van Amstel, page 325-330. Millpress, Rotterdam, ISBN 9059660439.

Pataki, D. E., T. Xu, Y. Q. Luo and J. R. Ehleringer (2007). Inferring biogenic and anthropogenic carbon dioxide sources across an urban to rural gradient. Oecologia 152(2): 307-322.

Potter, C., S. Klooster, S. Hiatt, M. Fladeland, V. Genovese and P. Gross (2006). Wetlands in the United States: Satellite-derived estimation based on ecosystem carbon, Earth Interactions, 10, 22.

Press, W.H., S.A. Teukolsky, W.T. Vetterling, and B.P. Flannery (1992), Numerical Recipes in FORTRAN The Art of Scientific Computing, 2nd ed., Cambridge Univ. Press, New York.

Prinn, R., J. Reilly, M. Sarofim, C. Wang and B. Felzer (2005), Effects of Air Pollution Control on Climate, Human-Induced Climate Change: An Interdisciplinary Assessment, Cambridge University Press.

Riley, W. J., C. J. Still, B. R. Helliker, M. Ribas-Carbo, and J. A. Berry (2003), 180 composition of $\mathrm{CO} 2$ and $\mathrm{H} 2 \mathrm{O}$ ecosystem pools and fluxes in a tallgrass prairie: Simulations and comparisons to measurements, Global Change Biology, 9,740DV-0005 740DV: Document Delivery available, 1567-1581.

Riley, W. J., J. T. Randerson, P. N. Foster, and T. J. Lueker (2005), The influence of terrestrial ecosystems and topography on coastal CO2 measurements: A case study at Trinidad Head, California, J. Geophys. Res., 110, G01005.

Riley, W. J., D. Y. Hsueh, J. T. Randerson, M. L. Fischer, J. G. Hatch, D. E. Pataki, W. Wang, and M. L. Goulden (2008), Where do fossil fuel carbon dioxide emissions from California go? An analysis based on radiocarbon observations and an atmospheric transport model, Journal of Geophysical Research-Biogeosciences, 113,ISI:000259989300001. Salas, W., P. Green, S. Frolking, C. Li and S. Boles (2006). Estimating Irrigation Water Use for California 
Agriculture: 1950s to Present. California Energy Commission, PIER Energy-Related Environmental Research. CEC-500-2006-057.

Salas, W., Li, C., Mitloehner, F., and J. Pisano (2008), Developing and Applying Process-based Models for Estimating GHG and Air Emission from California Dairies. California Energy Commission, PIER Energy-Related Environmental Research. CEC-500-2008-XXX (in press).

Szegvary, T., M. C. Leuenberger and F. Conen (2007), Predicting terrestrial Rn-222 flux using gamma dose rate as a proxy. Atmos. Chem. and Phys., 7(11), 2789-2795.

Skamarock, W. C., J. B. Klemp, J. Dudhia, D. O. Gill, and D. M. Barker, and W. Wang, and J. G. Powers (2005), A description of the advanced research WRF version 2. Technical Note 468+STR, MMM Division, NCAR, Boulder, CO, 88 p.

Shindell, D. T., G. Faluvegi, N. Bell, and G. A. Schmidt (2005), An emissions based view of climate forcing bymethane and tropospheric ozone, Geophys. Res. Lett., 32, L04803, doi:10.1029/2004GL021900.

Szegvary, T., M. C. Leuenberger and F. Conen (2007). "Predicting terrestrial Rn-222 flux using gamma dose rate as a proxy." Atmos. Chem. and Phys., 7(11): 2789-2795.

Watanabe, A., H. Yamada, and M. Kimura (2005), Analysis of temperature effects on seasonal and interannual variation in $\mathrm{CH} 4$ emission from rice-planted pots, Agriculture, Ecosystems $\mathcal{E}$ Environment, 105, 439-443, doi:10.1016/j.agee.2004.02.009.

Wyngaard, J.C., and M. A. LeMone (1980), Behavior of the refractive index structure parameter in the entraining convective boundary layer, J. Atmos. Sci., 37,1573-1585.

Zahorowski, W., S.D. Chambers, and A. Henderson-Sellers (2004), Ground based radon-222 observations and their application to atmospheric studies, Journal of Environmental Radioactivity, 76, 3-33. 


\subsection{Appendices}

\subsection{Sensitivity Test for the a priori $\mathrm{CH}_{4}$ Emission Uncertainty}

In this study, the authors assumed the a priori uncertainty in the inventory $\mathrm{CH}_{4}$ emissions of $30 \%$ based on previous work. To evaluate the effect of varying the assumed a priori uncertainty on the posterior emission estimates and uncertainties, the authors conducted a sensitivity test by comparing the inverse model results using a priori uncertainties of $30 \%$ and $50 \%$. Generally speaking, increasing the a priori uncertainties will allow posterior results to be more strongly driven by measurements that have a high overlap of footprint function with the spatial distribution of the emission source. In the case of the source sector analysis shown in Fig. 24, using the WGC measurements, the scaling factors for sources sectors were different from unity were allowed to move even further from unity when a priori uncertainty was relaxed. For example, Table 3 lists the sensitivity of retrieved emissions (scaling factors) to the a priori uncertainties for source or regions with relatively big reductions in uncertainties.

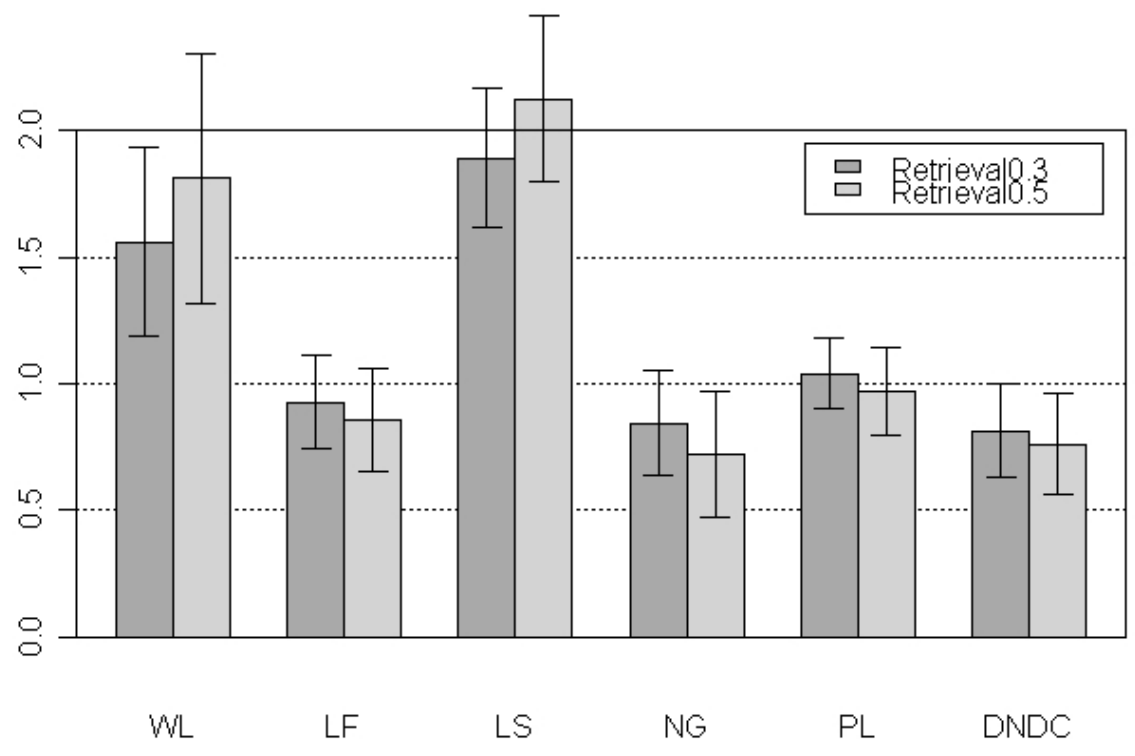

Figure 24. Sensitivity test of the source sector analysis to increasing the a priori emission uncertainties from $30 \%$ to $50 \%$.

\begin{tabular}{|l|l|l|l|l|l|l|l|l|l|}
\hline $\mathrm{CH}_{4}$ & WL & LF & LS & NG & PL & DNDC & R06 & R07 & R08 \\
\hline Sensitivity & $16 \%$ & $8 \%$ & $12 \%$ & $15 \%$ & $7 \%$ & $6 \%$ & $1 \%$ & $1 \%$ & $3 \%$ \\
\hline
\end{tabular}

Table 3. The sensitivity of retrieved emissions (scaling factors) to the a priori uncertainties for 6 sources or 3 regions. 


\subsection{The Effects of Multiple Stations for Source Sector Analysis.}

The appendix shows the varied results for inverse modeling of $\mathrm{CH}_{4}$ emissions by adding measurements from more stations. Four cases were run for both the region and source analysis: 3 hour pseudo-data for WGC, 3 hour pseudo-data for WGC and 12 hour pseudo-data for STR site, and 3 and 12 hour pseudo-data from 7 stations respectively. The results for these cases are shown in Figure 25 through Figure 32. In general uncertainties in a posterior emissions are reduced for all sources as the number of stations and frequency of observations increase.

As expected, uncertainties decrease with the frequency of sampling and very strongly with the addition of stations covering additional regions. For example, the results using the WGC site only or WGC and STR sites obtain increased accuracy in estimating emissions for region 6, 7 and 8. Using all 7 stations, accurate posterior emissions are obtained for almost all regions except regions 1, 2, 3 and 13. The authors note that the inventory $\mathrm{CH}_{4}$ emissions from regions 1 , 2,3 , and 13 are significantly smaller than for most of the other regions.

As observed for the source sector analysis using actual WGC measurements, there are significant reductions in the uncertainties for the LF, LS, NG and PL sources when using data from the WGC site alone, while WL and DNDC were not as effectively constrained. In addition, the WL and DNDC sources are significantly better constrained using 3 hour pseudo-data for 7 sites, where the authors expect the principle leverage will be obtained from the additional sites in the Central Valley. 

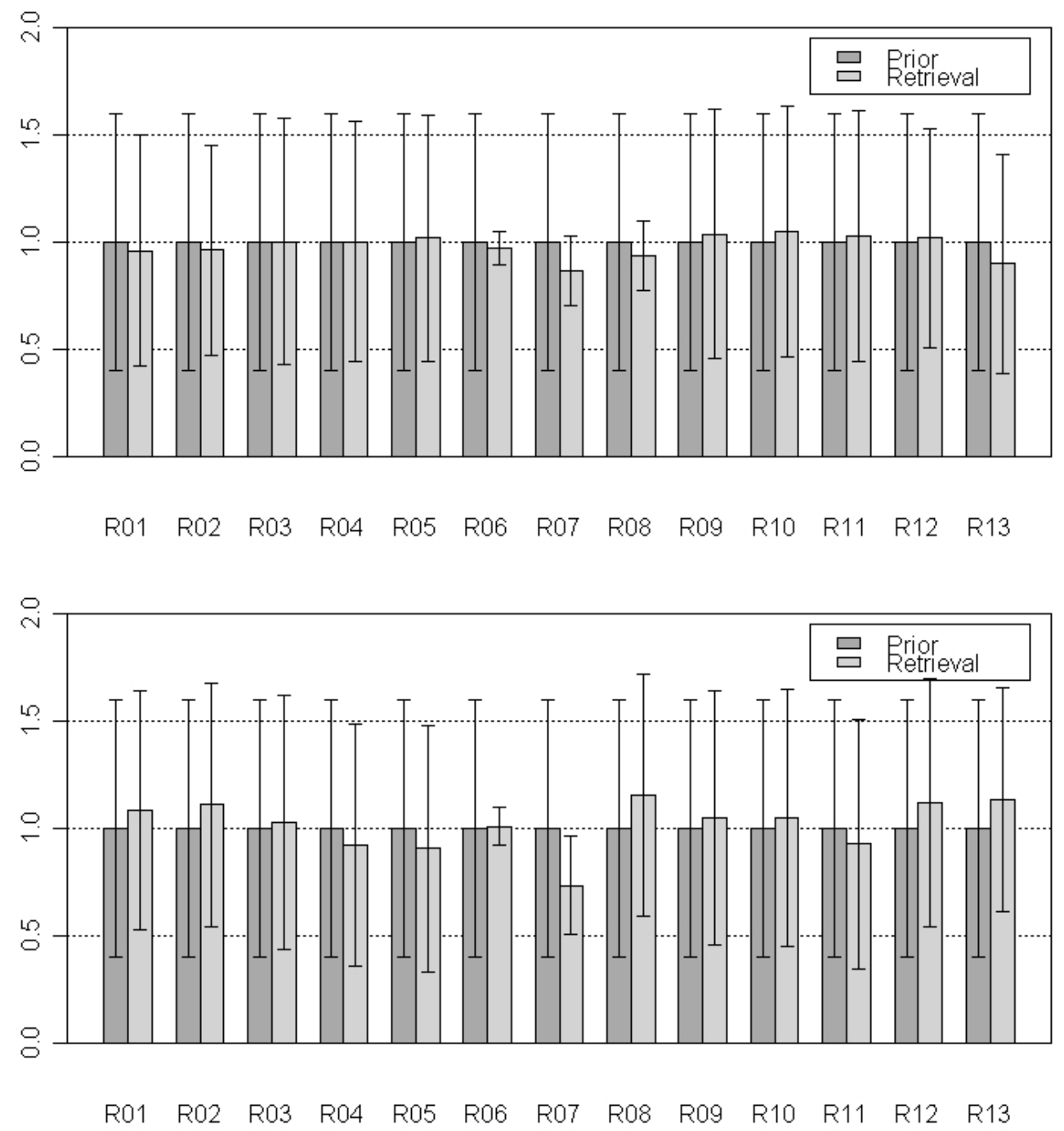

Figure 25. Inverse results of region analysis for (a) October 2007 and (b) July 2008, using 3 hour resolution pseudo-data for the WGC site. 


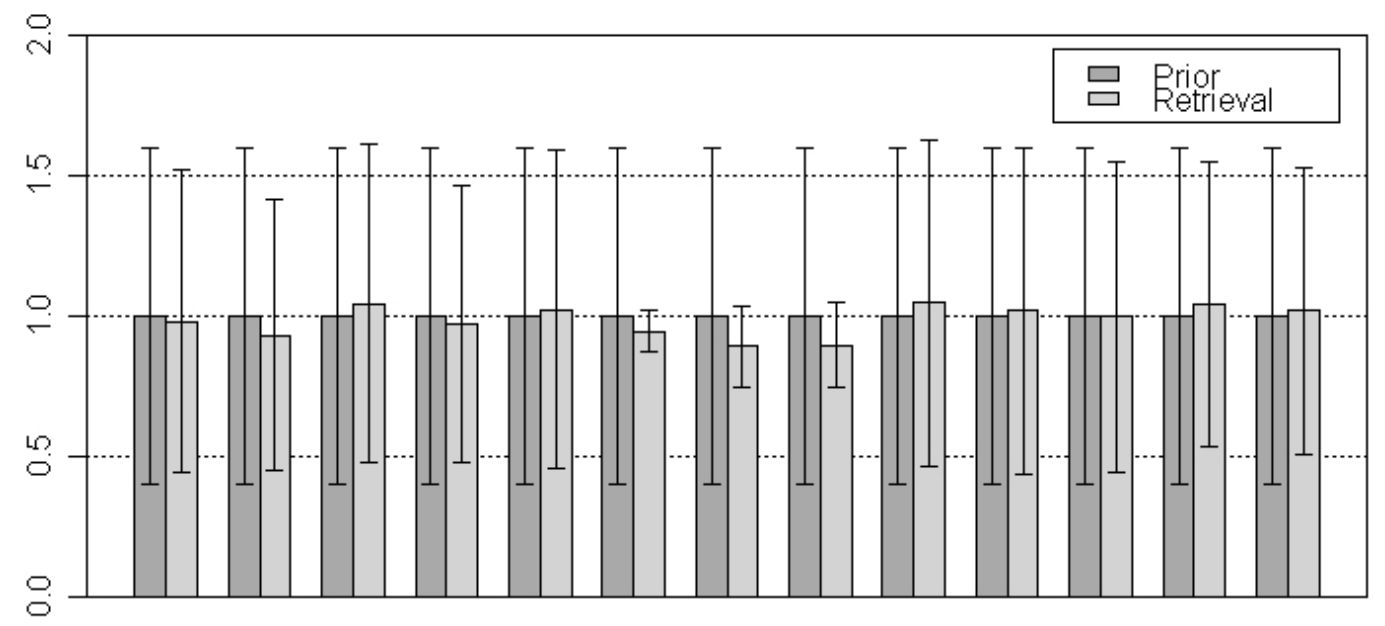

$\begin{array}{lllllllllllll}\mathrm{R} 01 & \mathrm{R} 02 & \mathrm{R} 03 & \mathrm{R} 04 & \mathrm{R} 05 & \mathrm{R} 06 & \mathrm{R} 07 & \mathrm{R} 08 & \mathrm{R} 09 & \mathrm{R} 10 & \mathrm{R} 11 & \mathrm{R} 12 & \mathrm{R} 13\end{array}$

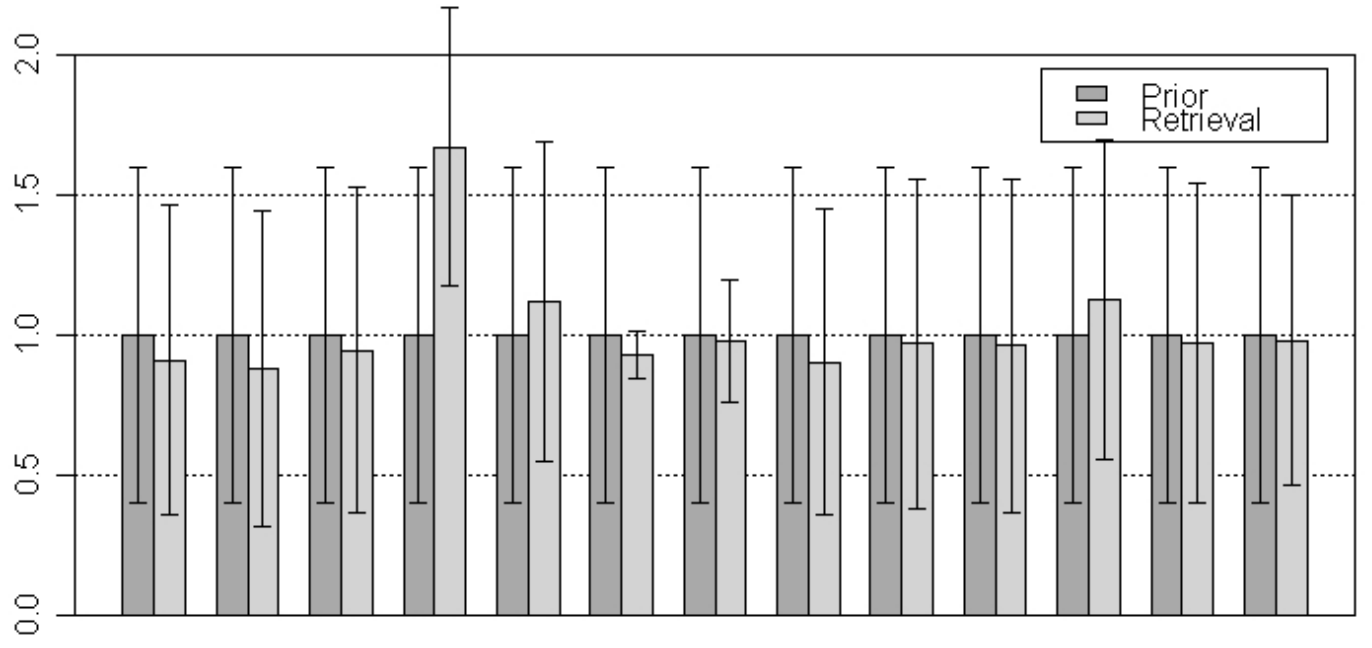

$\begin{array}{lllllllllllll}\mathrm{R} 01 & \mathrm{R} 02 & \mathrm{R} 03 & \mathrm{R} 04 & \mathrm{R} 05 & \mathrm{R} 06 & \mathrm{R} 07 & \mathrm{R} 08 & \mathrm{R} 09 & \mathrm{R} 10 & \mathrm{R} 11 & \mathrm{R} 12 & \mathrm{R} 13\end{array}$

Figure 26. Inverse results of region analysis for (a) October 2007 and (b) July 2008, using 3 hour resolution pseudo-data for the WGC site and 12 hour pseudodata for the STR site. 


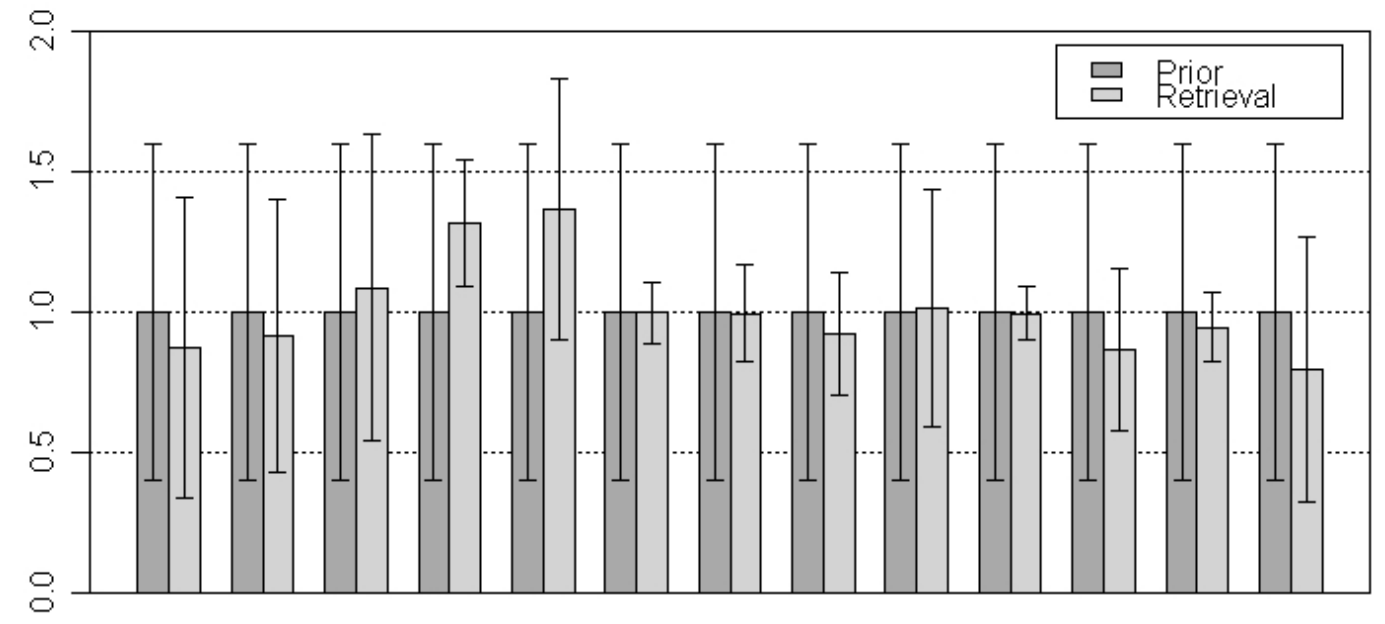

$\begin{array}{lllllllllllll}\mathrm{R} 01 & \mathrm{R} 02 & \mathrm{R} 03 & \mathrm{R} 04 & \mathrm{R} 05 & \mathrm{R} 06 & \mathrm{R} 07 & \mathrm{R} 08 & \mathrm{R} 09 & \mathrm{R} 10 & \mathrm{R} 11 & \mathrm{R} 12 & \mathrm{R} 13\end{array}$

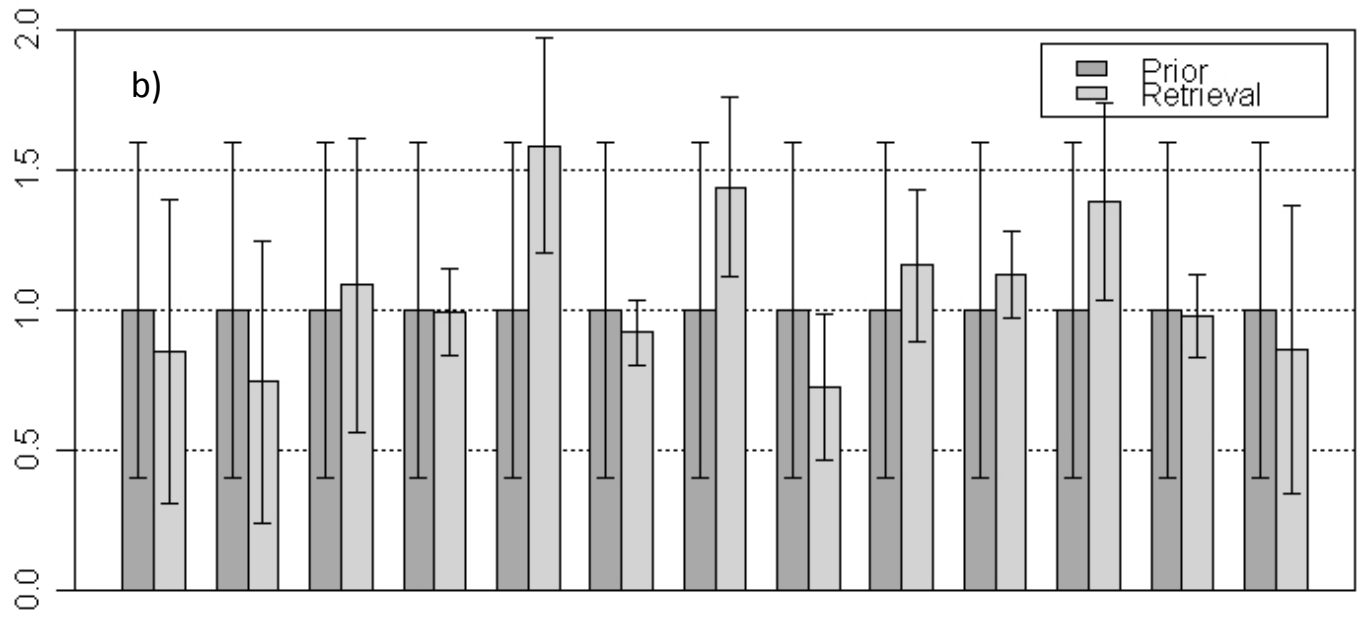

$\begin{array}{lllllllllllll}\mathrm{R} 01 & \mathrm{R} 02 & \mathrm{R} 03 & \mathrm{R} 04 & \mathrm{R} 05 & \mathrm{R} 06 & \mathrm{R} 07 & \mathrm{R} 08 & \mathrm{R} 09 & \mathrm{R} 10 & \mathrm{R} 11 & \mathrm{R} 12 & \mathrm{R} 13\end{array}$

Figure 27. Inverse results of region analysis for (a) October 2007 and (b) July 2008, using 12 hour resolution pseudo-data for all 7 stations. 


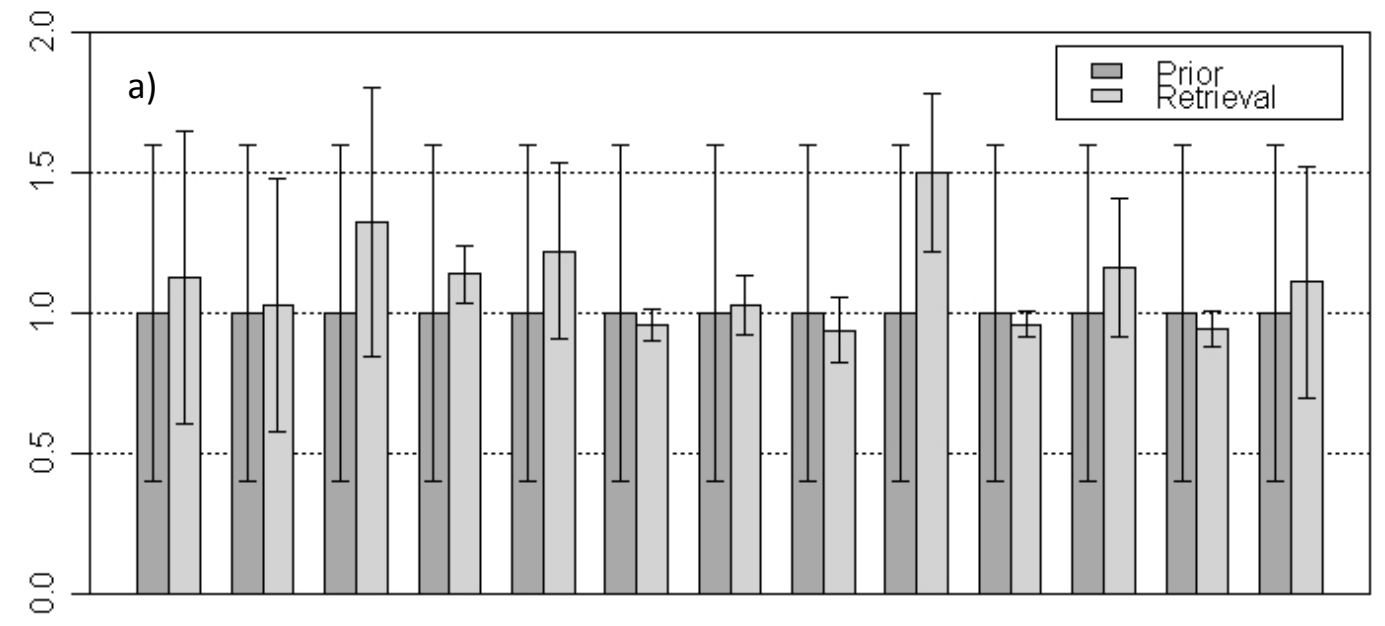

$\begin{array}{lllllllllllll}\mathrm{R} 01 & \mathrm{R} 02 & \mathrm{R} 03 & \mathrm{R} 04 & \mathrm{R} 05 & \mathrm{R} 06 & \mathrm{R} 07 & \mathrm{R} 08 & \mathrm{R} 09 & \mathrm{R} 10 & \mathrm{R} 11 & \mathrm{R} 12 & \mathrm{R} 13\end{array}$

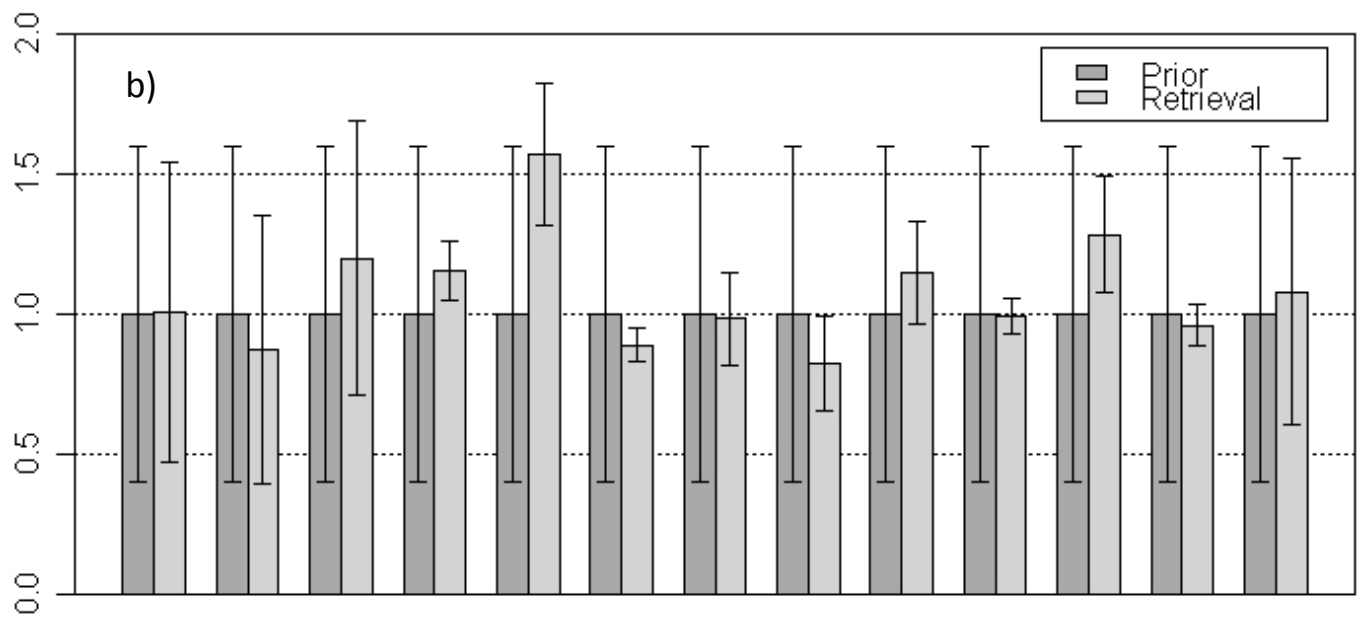

$\begin{array}{lllllllllllll}\mathrm{R} 01 & \mathrm{R} 02 & \mathrm{R} 03 & \mathrm{R} 04 & \mathrm{R} 05 & \mathrm{R} 06 & \mathrm{R} 07 & \mathrm{R} 08 & \mathrm{R} 09 & \mathrm{R} 10 & \mathrm{R} 11 & \mathrm{R} 12 & \mathrm{R} 13\end{array}$

Figure 28. Inverse results of region analysis for (a) October 2007 and (b) July 2008, using 3 hour resolution pseudo-data for all 7 stations. 

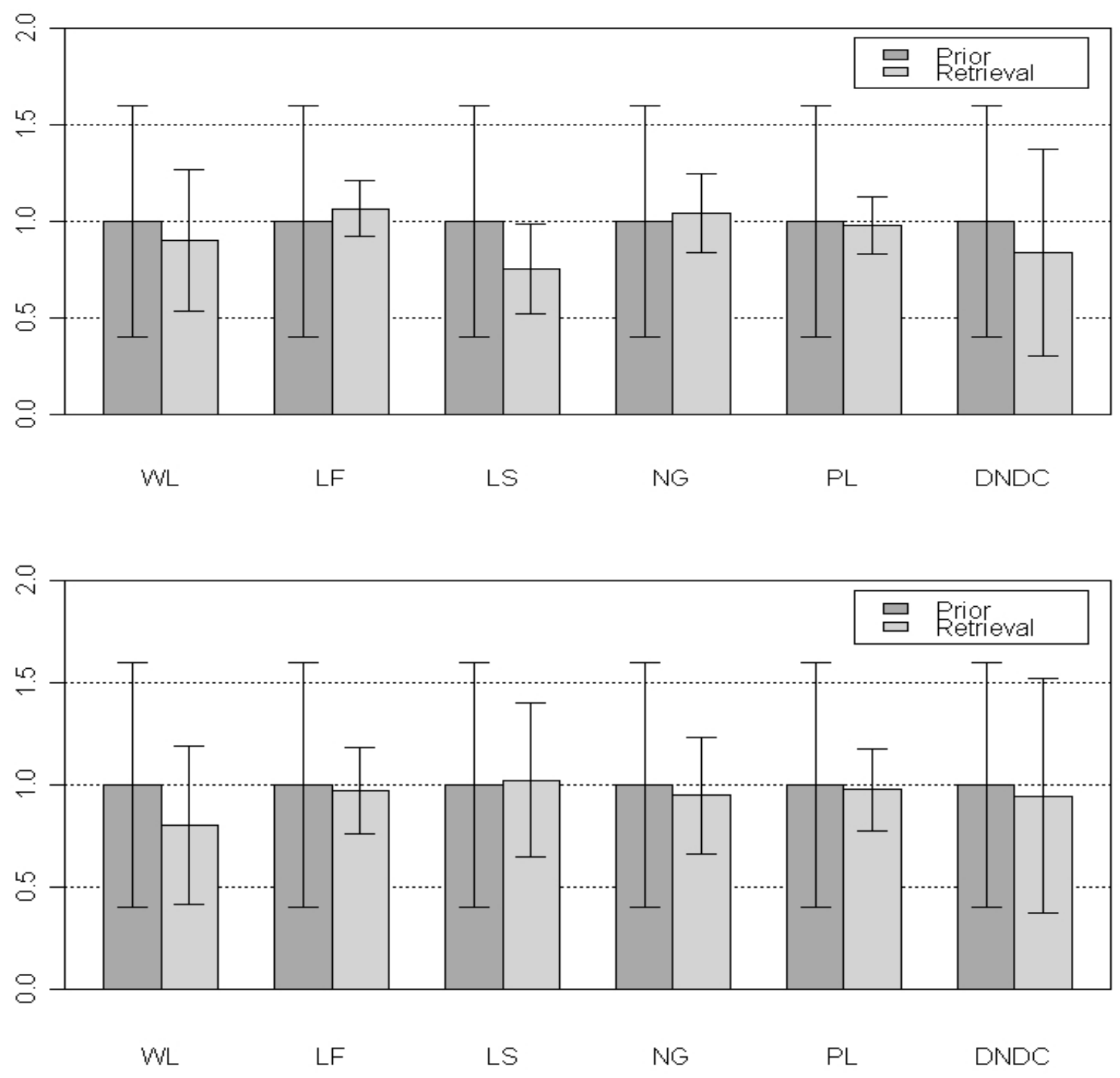

Figure 29. The inverse results of source sector analysis for October 2007 (top) and July 2008 (bottom) using 3 hour pseudo-data from the WGC site. 

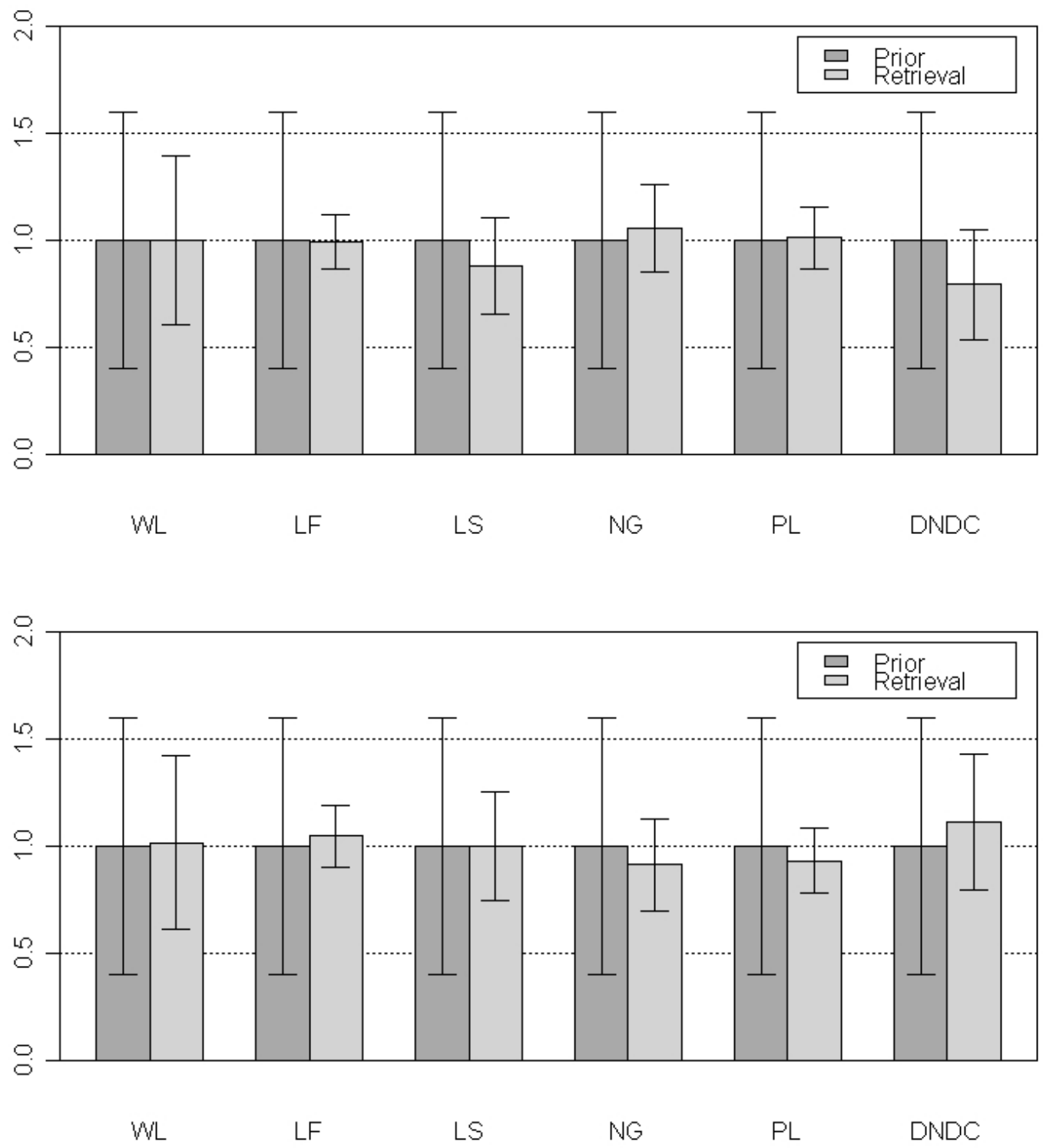

Figure 30. The inverse results of source sector analysis for October 2007 (top) and July 2008 (bottom) using 3 hour resolution pseudo-data for the WGC site and 12 hour pseudo-data for the STR site. 

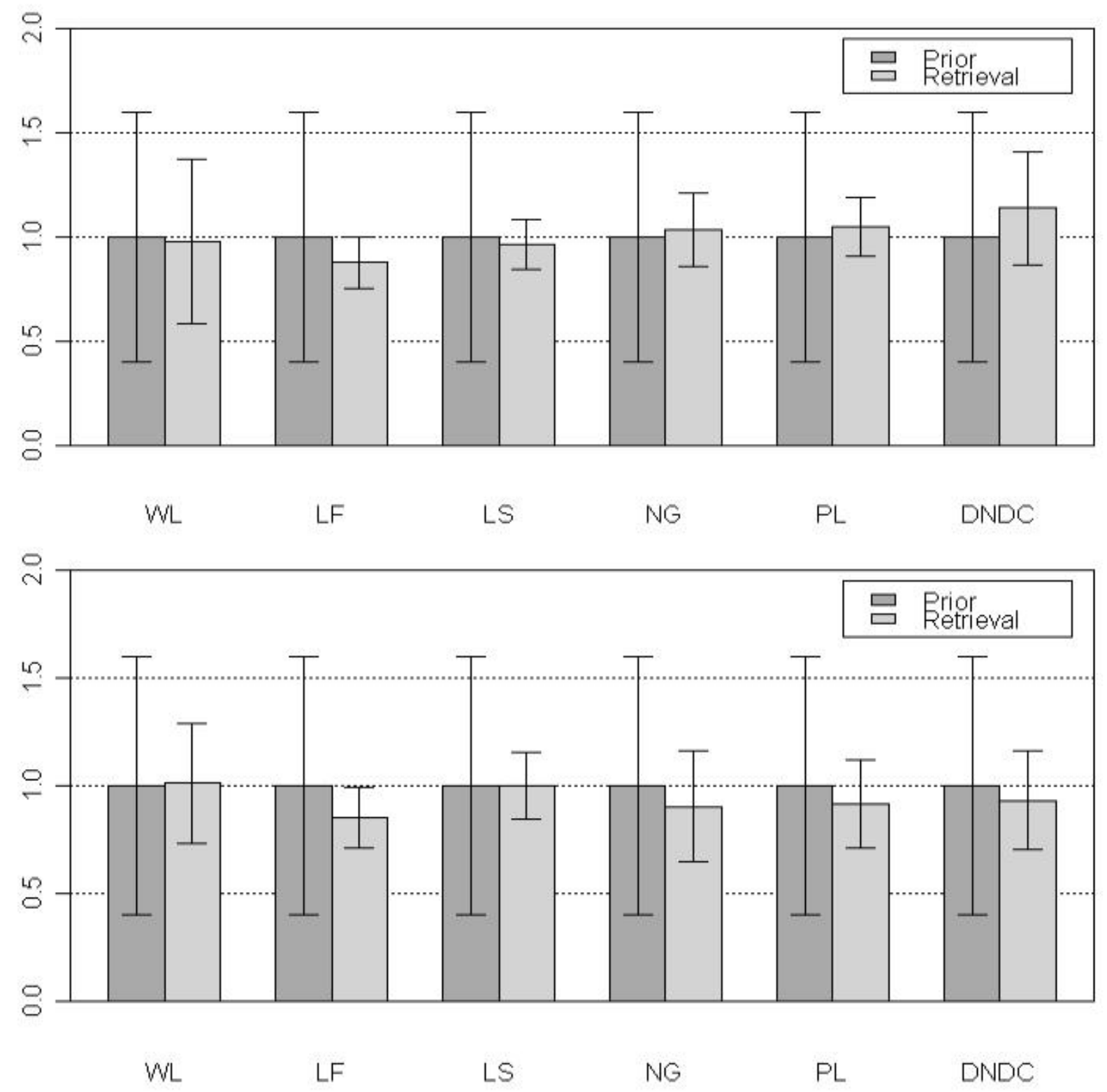

Figure 31. The inverse results of source sector analysis for October 2007 (top) and July 2008 (bottom) using 12 hour resolution pseudo-data for all 7 stations. 

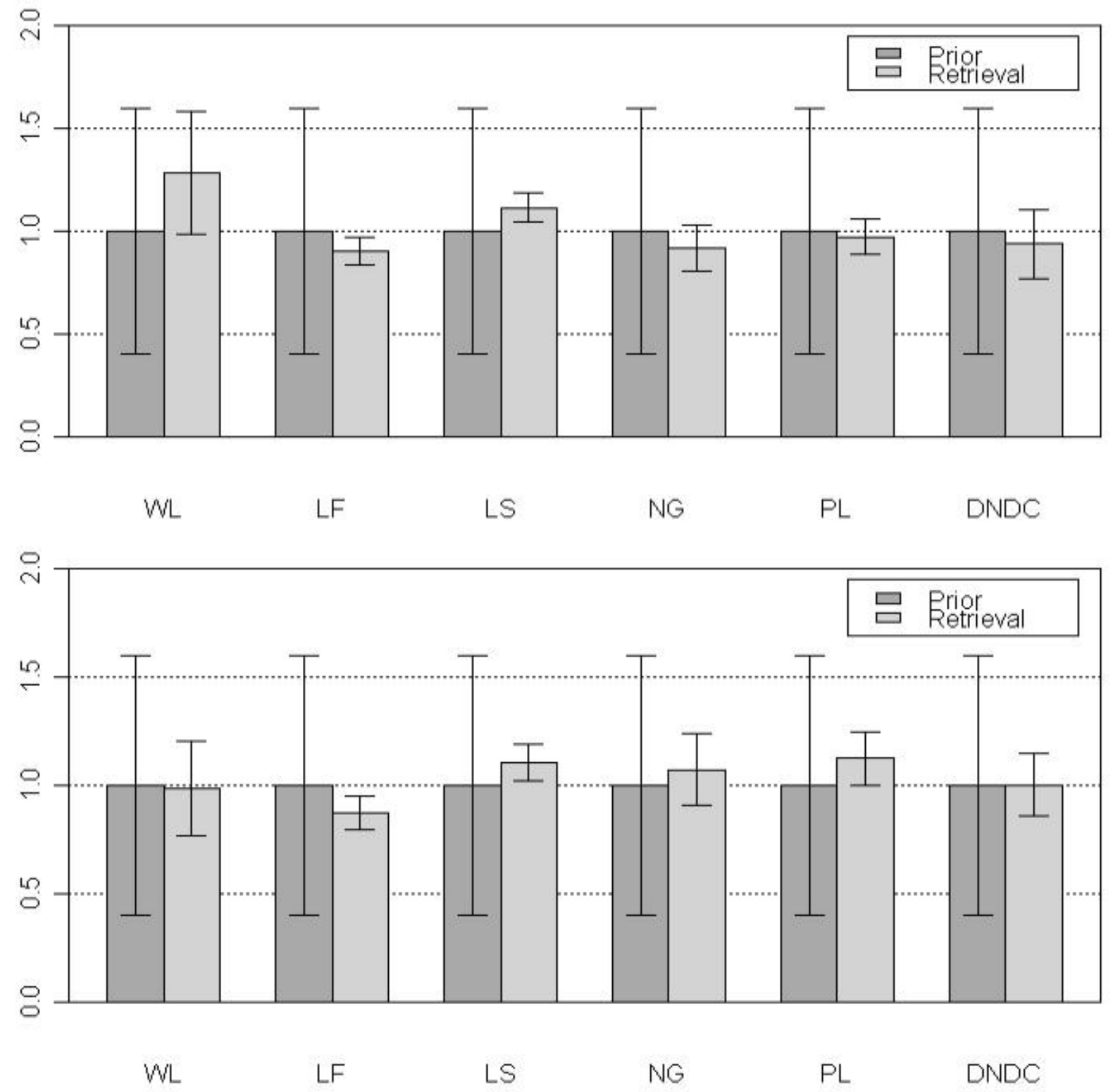

Figure 32. The inverse results of source sector analysis for October 2007 (top) and July 2008 (bottom) using 3 hour resolution pseudo-data for all 7 stations. 